ZENTRUM

FÜR BIODIVERSITÄT UND NACHHALTIGE LANDNUTZUNG SEKTION

Biodiversität, ÖKOLOGIE UND NATURSChUtZ

- Centre of Biodiversity and Sustainable Land Use -

Section: Biodiversity, Ecology and Nature Conservation

\title{
Structure, Productivity and Carbon Storage of Primeval European Beech Forests
}

\author{
Dissertation zur Erlangung des Doktorgrades der \\ Mathematisch-Naturwissenschaftlichen Fakultäten der \\ Georg-August-Universität Göttingen \\ vorgelegt von \\ Jonas Glatthorn \\ aus \\ Tübingen
}

Göttingen, Juni 2018 

Referent: Prof. Dr. Christoph Leuschner Korreferent: Prof. Dr. Markus Hauck 



\section{Summary}

A major part of the potential natural vegetation of central Europe consists of European beech forests (Fagus sylvatica L.). Beech is one of the most important broadleaf tree species for forestry within its distribution range and of outstanding value for biodiversity conservation. Despite their geographic confinedness, the last remnants of primeval beech forests are due to their variability well suited to study relationships between ecosystem functioning and stand structure. Through comparative study, effects of production forestry on forest functioning can be assessed.

The present work focuses on (1) the effect of age-class forestry and (2) influences of the natural development cycle on stand and canopy structure, aboveground biomass stocks, and net primary production $(A N P P)$. Parameters describing the stand structure and biomass budget were inventoried in three primeval beech forests in eastern Slovakia and in three close-by production forests. Canopy density and canopy structural diversity were quantified via the leaf area index (LAI; mean and dispersion of multiple measurements per plot with a LAI-2000 system). Live- and dead biomass stocks were calculated with allometric equations and the ANPP (woody biomass and litter production) was derived from seasonal diameter-increments of trees and with litter trapping. Additionally, a complete inventory of two large plots in primeval beech forests in Albania was used to test the hypothesis that an unsupervised classification algorithm is suitable to detect naturally existing thresholds within multivariate stand structural datasets of primeval forests, which mark transitions between forest development stages.

Linear regression models show that canopy density is greater by $1.6 \mathrm{~m}^{2} \mathrm{~m}^{-2}$ in the Slovakian primeval forests compared to the production forests. Canopy structural diversity is as well considerably greater in the primeval forests. Wood mass stocks (live and dead) are $39 \%$ larger in the primeval forests, while ANPP is approximately equal in both systems. Canopy structural diversity is identified as a key promoting factor of ANPP responsible for an increase of approximately $1 \mathrm{Mg} \mathrm{ha}^{-1} \mathrm{yr}^{-1}$. The multivariate structural data of the Albanian primeval forests is rather homogeneously distributed, no natural thresholds are present. This confirms the practicability of current methods to discriminate between forest development stages.

The presented results may provide insights for the advancement of silvicultural techniques to ensure the maintenance of the full set of ecosystem services provided by beech forests. 



\section{Table of Contents}

Summary

Table of Contents

vii

1 General Introduction 1

1.1 Primeval European beech forests - history, importance, and distribution . . . . 1

1.2 Biomass stocks and productivity of forest ecosystems . . . . . . . . . 2

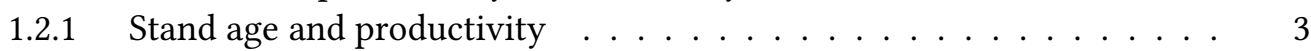

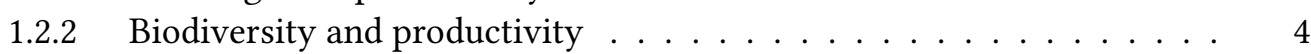

1.2.3 Structural diversity and its relevance for productivity . . . . . . . . . 4

1.3 The natural development cycle of primeval forests . . . . . . . . . . . 6

1.4 Scale-dependency of the stand structure in primeval forests . . . . . . . . . 8

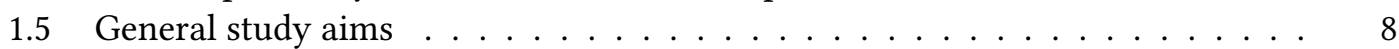

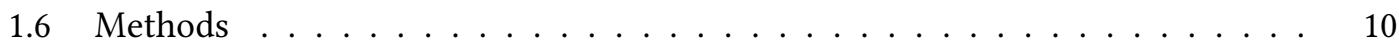

1.6.1 Description of the Study areas . . . . . . . . . . . . . . . 10

1.6.2 Study region and investigated stands . . . . . . . . . . . . . 10

1.6 .3 Study designs . . . . . . . . . . . . . . . . . . . . . . . . . 11

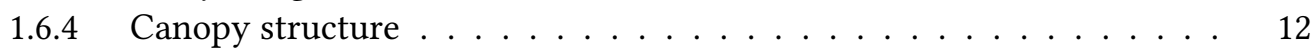

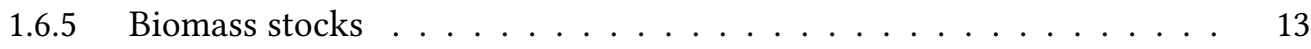

1.6 .6 Productivity . . . . . . . . . . . . . . . . . . . 14

References ........................ 16

2 Effects of forest management on stand leaf area: Comparing beech production $\begin{array}{ll}\text { and primeval forests in Slovakia } & 21\end{array}$

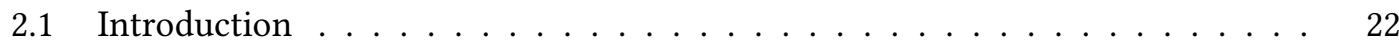

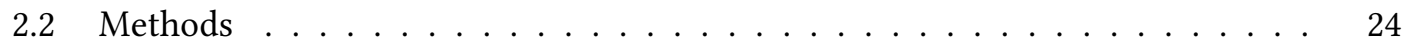

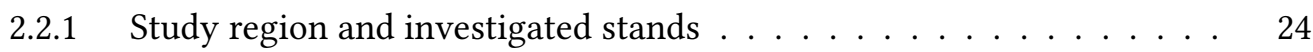

2.2 .2 Study design . . . . . . . . . . . . . . . . . . . 27

2.2.3 Canopy structural analysis with the LAI2000 system _ . . . . . . . . 29

2.2.4 Statistical analysis . . . . . . . . . . . . . . . . . . 32

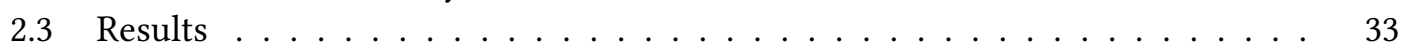

2.3.1 LAI from litter trapping . . . . . . . . . . . . . . . . . 33

2.3.2 Relationships between parameters characterizing the canopy structure 33

2.3.3 Influence of management on $\mathrm{LAI}_{e}$ and its heterogeneity $\ldots \ldots . . .34$

2.3.4 $\mathrm{LAI}_{\mathrm{e}}$ and canopy structural heterogeneity in the different forest development stages . . . . . . . . . . . . . . . . 36

2.4 Discussion . . . . . . . . . . . . . . . . . . . . . . . . 39

2.4.1 The LAI of beech forests and its measurement . . . . . . . . . . . 39

2.4.2 The influence of forest management on $\mathrm{LAI}_{\mathrm{e}} \ldots \ldots \ldots$. . . . . . . 40 
2.4.3 Leaf area dynamics across the forest development cycle . . . . . . 41

2.5 Conclusions . . . . . . . . . . . . . . . . . . . . 43

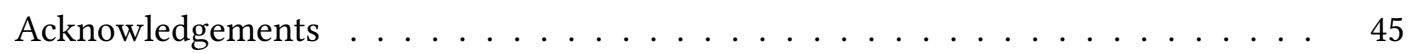

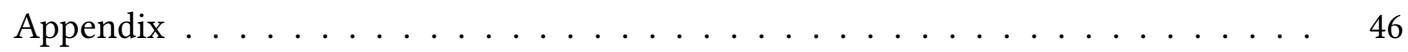

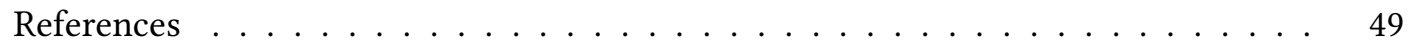

3 Biomass stock and productivity of primeval and production beech forests: Greater canopy structural diversity promotes productivity 53

3.1 Introduction . . . . . . . . . . . . . . . . . 54

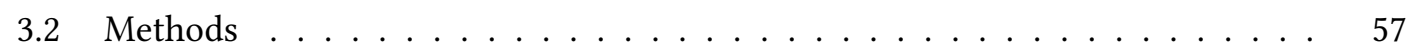

3.2 .1 Study Area . . . . . . . . . . . . . . . . . 57

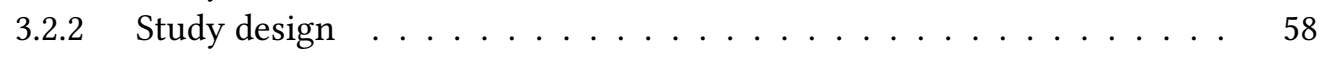

3.2.3 Live Plant and Deadwood Biomass . . . . . . . . . . . . . 60

3.2 .4 Tree Growth and Productivity . . . . . . . . . . . . . . . . . 61

3.2.5 Canopy structure . . . . . . . . . . . . . . . . 62

3.2.6 Microtopography as Productivity-Influencing Factor . . . . . . . . . 64

3.2.7 Statistical analysis ..................... . . 64

3.3 Results .............................. 65

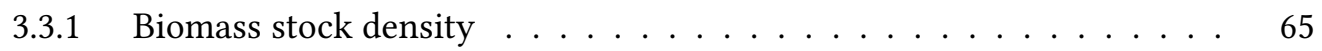

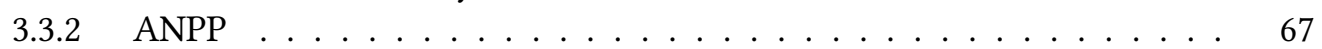

3.3.3 Factors Controlling Productivity: The Role of Canopy Structure . . . . 68

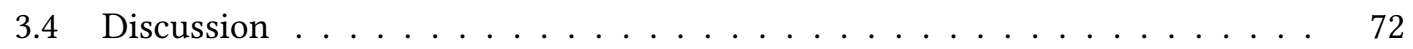

3.4.1 Biomass stocks of primeval and production forests . . . . . . . 72

3.4.2 Aboveground productivity . . . . . . . . . . . . 75

3.4.3 Dependence of the growth of single trees on canopy structure . . . . . 77

3.4.4 Dependence of $\mathrm{ANPP}_{\text {wood }}$ on canopy structure . . . . . . . . . 77

3.5 Conclusions .......................... 80

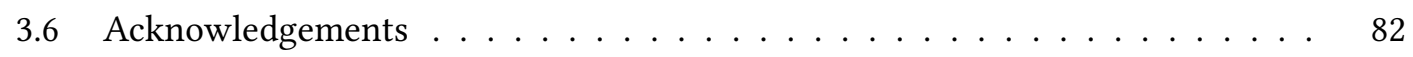

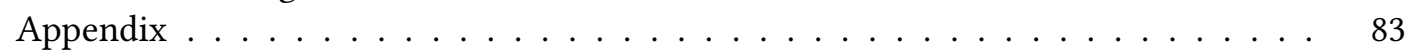

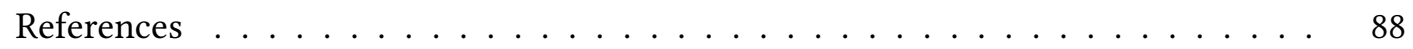

4 Classifying development stages of primeval European beech forests: is cluster$\begin{array}{ll}\text { ing a useful tool? } & 93\end{array}$

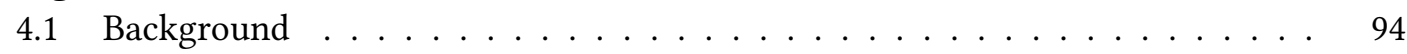

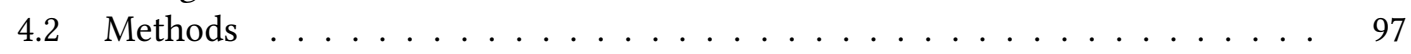

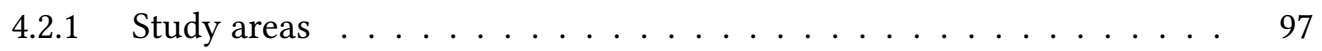

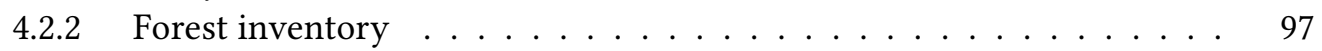

4.2 .3 Calculation of stand structural attributes . . . . . . . . . . . . . 98

4.2.4 Graphical display and clustering of the structural data . . . . . . . 100

4.3 Results .......................... . . 100

4.3.1 Emergence of clusters at different observation scales . . . . . . . 100

4.3 .2 Quality of the clustering ...................... 102

4.3.3 Between-cluster differences of stand structural attributes . . . . . . . 102

4.3.4 Spatial representation of clusters . . . . . . . . . . . . . . 102 
4.4 Discussion . . . . . . . . . . . . . . . . . . . . 105

4.5 Conclusions . . . . . . . . . . . . . . . . . . . . . . 110

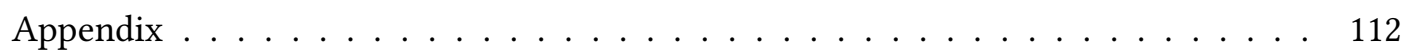

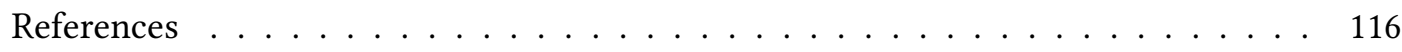

5 Synopsis $\quad 119$

5.1 Effects of forest management . . . . . . . . . . . . . . . . . . . . 119

5.2 Differences of stand structure and ecosystem functioning during natural forest development . . . . . . . . . . . . . . . . . . . . . 121

5.3 Canopy structure and productivity of forests . . . . . . . . . . . . . 123

5.4 Development stage separation . . . . . . . . . . . . . . . . . 126

References . . . . . . . . . . . . . . . . . . . 127 



\section{Chapter 1}

General Introduction

\subsection{Primeval European beech forests - history, importance, and distribution}

Between approximately 7000 and 5000 years before present, European beech (Fagus sylvatica L.) replaced due to a favourable climate mixed oak forests and in lower mountain elevations as well spruce mountain forests in central Europe (Burschel and Huss, 2003). This process shaped large connected primeval beech forests which would, without human intervention, still cover approximately one million square kilometers. About $25 \%$ of the natural range of beech forests lies within Germany, but the natural vegetation of other central European countries like France, Austria, Swiss, Poland, Denmark, Czechia and Slovakia is in large parts dominated by beech as well (Leuschner and Ellenberg, 2017). Due to forest degradation and tree species selection of faster growing species for commercial forestry, the distribution of beech in Germany was reduced to currently $7 \%$ of its potential range (ca. $17000 \mathrm{~km}^{2}$ ) according to the most recent national forest inventory in 2012, (BMEL, 2014). But as well in other central European countries shares of beech declined (Bublinec and Pichler, 2001; Hort et al., 1999; Průša, 1985; Leuschner and Ellenberg, 2017).

Primeval forests (without or only with very scarce management impact by humans) and old-growth forests (possibly affected by timber extraction in a more or less distant past) provide important habitat functions for many taxa, which cannot easily be sustained in younger, commercially used and logged production forests (Frank et al., 2009). The outstanding value of these forests is also well documented for other ecosystem services like carbon storage and water or air purification (e.g., Ninan and Kontoleon, 2016; Sutherland et al., 2016; Vincent et al., 2016). So, in terms of biodiversity conservation and environmental protection, the almost complete loss of old beech forests is even more critical than the reduction of the area of distribution of beech. In Germany, only $6 \%$ of the the remaining beech forests are older than 160 years (Hanstein, 
2000). In Slovakia, $90 \%$ of production forests are younger than 100 years (Green Report, 2009).

There exist some remnants of the once common beech primeval forests in particular in eastern European countries like Albania, Bulgaria, Croatia, Czechia, Romania, Slovakia, Slovenia, or Ukraine but the overall area of true primeval forests is reduced to only a tiny fraction of the total forested area (Diaci, 1999; Veen et al., 2010; Parviainen, 2005; Korpel, 1995). These forests are 'primeval' in the sense of that they do not have a management history with timber extraction and that they have the characteristic stand structure of primeval and old-growth forests: (1) the age-distribution is uneven, multimodal, or inverse J-shaped; (2) the mean age of the trees species reaches approximately half their maximum lifetime, (3) some trees are close to their maximum lifetime, (4) dying trees and standing and downed deadwood in various stages of decay does occur, and (5) the dominant tree species are naturally regenerating (Mosseler et al., 2003; Wirth et al., 2009). As with every other ecosystem in central Europe, there are indirect anthropogenic influences like for example increased deer densities (Diaci et al., 2011, 2010) and long-distance transport of air pollutants like nitrogen dioxide in the course of industrialization (Oulehle et al., 2010; Šebesta et al., 2011).

Additional to their outstanding importance for nature conservation, primeval forests are excellent study objects to empirically explore dynamics of stand structural attributes (SSA) during the natural forest development cycle and connections between SSA, ecosystem functioning and ecosystem services (Schulze et al., 2009, 2005). This is not only important for a sound ecological understanding of ecosystem processes under natural, undisturbed conditions but it is as well an important basis for the advancement and development of close-to-nature silvicultural systems (Larsen et al., 2010; Lindenmayer et al., 2006). Such alternatives to conventional silvicultural regimes, which avoid the creation of mono-layered and species poor stands, have been receiving increasing attention in many countries during the last decades (Puettmann et al., 2015).

\subsection{Biomass stocks and productivity of forest ecosystems}

Net ecosystem productivity $(N E P)$ is a key ecological function. It is defined as the difference between net primary production (NPP; whole plant growth per area) and heterotrophic respiration 
( $R H$ : respiration from microbes and animals): $N E P=N P P-R H$ (Chapin et al., 2011).

Forest productivity is relevant for timber production and the evaluation of carbon dioxide mitigation potentials of forested areas. In forestry, research about the productivity of forests has a long tradition and started in the $19^{\text {th }}$ century with the creation of the first yield tables (Assmann and Davis, 1970). The focus in forestry has usually been on the production of merchantable timber $\left(\mathrm{m}^{3} \mathrm{ha}^{-1} \mathrm{yr}^{-1}\right)$ over $7 \mathrm{~cm}$ in diameter and not on biomass dry weight or carbon stocks ( $\left.\mathrm{Mg} \mathrm{ha}^{-1} \mathrm{yr}^{-1}\right)$, as is the case in ecosystem ecology (Chapin et al., 2011; Pretzsch, 2005). But results from long-term data from forest yield studies, which in exceptional cases can date back as far as 1870, can be converted and interpreted from an ecological perspective as well (Pretzsch, 2005).

\subsubsection{Stand age and productivity}

Even though empirical long-term data is of great value for forest sciences and ecology, most of such studies are restricted to age-class forests. The structure of primeval forests is very different than the one of even-aged stands (Commarmot et al., 2005; Korpel, 1995; Merino et al., 2007) and findings about dependencies of ecosystem functioning on stand structure are not necessarily transferable. For example, in even-aged stands a declining NPP with age was found (He et al., 2012; Ryan et al., 1997). Following a short period of strong increase (He et al., 2012; Ryan et al., 1997) after stand establishment, NPP culminates early at ages between approximately 30 and 80 years and decreases again rapidly within several decades to values close to zero. These findings led to the formulation of the 'Odum-Hypothesis' (Odum, 1969), which states that NPP rates of post-climax ecosystems are close to zero. In contrast, more recent studies about NEP and NPP could show that old-growth forests are maintaining surprisingly high productivity rates (NEP and NPP alike) over long periods of time (Luyssaert et al., 2008).

A most of the time high NEP of forests irrespective of stand age can have at least four reasons (Chapin et al., 2011): (1) The 'steady state' of equal NPP and $R H$ is rarely reached between two disturbance events, (2) stimulation of photosynthesis through increasing anthropogenic $\mathrm{CO}_{2}$ and N-Deposition of the last decades, (3) unmeasured transfer of carbon out of the ecosystem (e.g., leaching), and (4) unintended biases due to sampling design or data analysis. One possible 
reason for unexpected high NEP and NPP in old-growth and primeval forests in contrast to even-aged stands is seen in a productivity promoting effect of biodiversity, which is usually lower in production forests.

\subsubsection{Biodiversity and productivity}

The effect of biodiversity on productivity (biodiversity-productivity relationship; BPR) is well studied for many taxonomic groups and plant functional types including different forest ecosystems (Naeem et al., 2012; Liang et al., 2016). A positive BPR in forests was found in different parts of the world, provided tree species were functionally complementary (e.g., Liang et al., 2016; Pretzsch et al., 2015). Complementarity due to positive interactions can arise from morphological traits (e.g., crown shapes, rooting depth) or from different physiological charactersitics (e.g., light/shade tolerance of leaves) (Williams et al., 2017; Pretzsch et al., 2015). But especially when one tree species is clearly superior to all others in terms of growth potential on a given site, beneficial interactions of tree species mixtures cannot compensate for the loss of productivity due to a reduction in stocking of the dominant species (Pretzsch, 2005).

\subsubsection{Structural diversity and its relevance for productivity}

Biodiversity describes the variability of all living beings (Lévêque and Mounolou, 2003). While traditionally the focus of biodiversity research was on the diversity of genes, taxonomic groups, and ecosystems, more recently the variability of morphological characteristics (e.g., tree size) or the spatial distribution (e.g., clumped, random, homogeneous distribution) of organisms received increasing attention. Under the umbrella terms 'structural diversity' and 'structural complexity' all sorts of measurable variability in the stand structure of forests are being summarized (e.g., Pommerening, 2002; von Gadow et al., 2012). If complementary effects on ecosystem functioning exist, this is potentially reflected by a changing structural diversity (von Gadow et al., 2012). For example, when mixing of tree species with varying light demand occurs, this usually results in increased vertical structuring with the light demanding species forming the top-layer and the shadow-tolerant species occupying the sub-canopy of the forest. This effect does not necessarily originate from genetic or species diversity. Different morphological or physiological 
characteristics can occur, for example, between different age classes of the same species. This is the case with young shadow-tolerant saplings and older light demanding F. sylvatica trees. So, in some cases, appropriate measures of structural diversity might even be better indicators for the presence of complementarity than species diversity. But there are only few and contradicting empirical studies which quantify the effect of different types of structural diversity on the productivity of forests (see chapter 2 for a list of studies).

Definitions for structural diversity are rather vague and usually encompass all sorts of measurable heterogeneity of SSA. The inevitable consequence is the existence of a vast amount of indices quantifying structural diversity ranging from rather simple measures like the variation coefficient of tree diameters to complex algorithms which include the spatial distribution of tree coordinates or data intensive remote sensing methods like laser scanning (von Gadow et al., 2012). The usefulness of each index is context dependent; a measure which successfully indicates the provision of habitats for some taxa is not necessarily as well a promoting factor for other ecosystem functions like productivity. When studying the relationships between structural diversity and ecosystem functioning, selection of variables with a causal connection to the specific function is crucial. Ishii et al. (2004) state that "processes that determine productivity of forest ecosystems, such as photosynthesis and nutrient uptake, occur in the soil and canopy, not at breast-height", meaning that measures of structural diversity which are related to the canopy or soil structure are more likely to be causally connected to the NPP of forests than indices which only make use, for example, of the diameter-distribution.

The description of canopy structural diversity in different stages of the natural forest development cycle and between primeval and production forests (commercially logged and harvested) is the focus of the first study presented by this thesis (chapter 2). The second study (chapter 3) deals with the assessment of biomass stocks, aboveground NPP (ANPP) and influences of management, development stage and canopy structural diversity on biomass and ANPP. 


\subsection{The natural development cycle of primeval forests}

To assess how productivity, stand structure, and biodiversity interact in the course of time and under forest succession, the parameter 'stand age' is, depending on the prevalent disturbance regime, not always appropriate. While large-scale, stand replacing disturbances lead to evenaged forests, cyclic recurring partial disturbances result in cohort dynamics with several tree groups of different ages being present at the same time (Shorohova et al., 2009; Oliver and Larson, 1996). If major disturbances are absent for longer time periods, mortality is caused by senescence of individual trees or small tree groups and a fine-scale mosaic of gap-dynamics develops. To describe the stand structure related to forest development, the elapsed time since the last stand replacing disturbance event is only meaningful for even-aged forests originating from large-scale disturbances like windthrow, fire, insect calamities, or logging in production forests. For cohort-like structures and when gap-dynamics are present, age differences on a small spatial scale within forests are usually too large (Trotsiuk et al., 2012).

Alternatively, the concept of recurring stages of forest development (Leibundgut, 1959; Oliver and Larson, 1996; Korpel, 1995) can act as a surrogate to stand age. According to this approach, several development stages (e.g., growth, optimum, or terminal stage) are represented by forest patches which do not entirely consist of, but are dominated by, young, mature, and senescent trees.

In early studies about the forest development cycle, it was common to subjectively select research plots where one stage was very dominant and assignment to individual development stages was straightforward (assignment by expert-knowledge; e.g. Leibundgut, 1959; Korpeí, 1995). With completely randomized study designs and potentially large plot numbers, at least some plots are likely to be dominated by all development stages to more or less equal parts and subjective assignment of development stages becomes irreproducible.

To overcome this problem, several methods have been developed since which assess development stages and their subdivision into development phases more objectively. Dichotomous keys use thresholds of predefined SSA (e.g., mean diameter at breast height $(D B H)$, maximum height, or amount of dead wood) for the assignment task (Drößler and Meyer, 2006; Tabaku, 2000; 
Winter and Brambach, 2011; Zenner et al., 2016). More sophisticated supervised algorithms were applied as well to automate the classification process further and reduce subjectivity through avoidance of manual selection of thresholds (Král et al., 2010; Huber, 2011).

Supervised classification methods always need some sort of 'training set' (i.e., plots whose development stage is known a priori) to detect patterns within a multivariate data matrix of SSA and to learn from these patterns how additional realizations of the involved stochastic processes can be classified accordingly (Venables and Ripley, 2007). Subjectivity is reduced compared to expert knowledge and dichotomous keys but the generation of a training set is to a certain degree subjective itself and results will inevitably be influenced by the predefined perceptions and ideas of the persons who perform the method. In the case of continuously and gradually changing SSA throughout natural stand development, this approach is well justified. In the case of homogeneously distributed multidimensional point clouds of SSA-data-matrices without any sign for data aggregation, methods to define thresholds and differences between development stages only have to be adapted to causal relationships between SSA, the specific research questions, and study designs. But in case of the existence of natural breakpoints in stand structural data which mark the transition from one stage to another, unsupervised classification methods to detect such thresholds may be more appropriate. Already the analysis of single characteristics of primeval beech forests revealed the existence of such thresholds: The $D B H$-distributions of primeval beech forests are divided in two parts with a distinct peak at mid-range $D B H$-classes (Westphal et al., 2006). This effect is presumably caused by an immediate drop of the mortality rate of trees as soon as trees reach the upper canopy and get access to direct light.

The next step in the advancement of methods to assess the development stage of forest patches is to test for the existence of an inherent data structure in SSA-data-matrices of primeval forests with unsupervised classification algorithms. If clusters with associations to forest development can be detected, this would reveal naturally existing thresholds between stages. In the opposite case, the currently existing practices would be confirmed. This knowledge gap is the motivation behind the third study presented by this thesis (chapter 4). To include potential effects of scale-dependencies of the variability of SSA, this has to be done under consideration off different 
observational scales.

\subsection{Scale-dependency of the stand structure in primeval forests}

Variability of SSA in primeval forests depends on the disturbance regime (Král et al., 2010; Zenner et al., 2015). While the disturbance regime of primeval beech forests is known to result in a small-scale pattern of gap dynamics (Drößler and von Lüpke, 2005), the best observational spatial scale (i.e., area of the research plots) to inventory the stand structure is not easily determined (Zenner et al., 2016). One of the smallest plot sizes suggested for the inventory of natural beech forests is the area covered by a single bigger F. sylvatica crown, which is estimated to be approximately $156.25 \mathrm{~m}^{2}$ (Meyer, 1999). Such small areas stress the importance of individual trees within the development cycle and the resolution is probably fine enough to reflect the on a small-scale shifting stand characteristics. High variability between plots might facilitate the detection of relationships between SSA. A major disadvantage of small plot sizes is a relatively high influence of features located directly outside of the plot borders on the stand structure. A small plot without any trees may be surrounded by big trees and completely covered by their crowns. The difference of such a plot to a real gap without any canopy cover cannot be detected with too small observational scales. Greater plot sizes are better capable of handling characteristics of tree compositions and edge effects decrease. But plot sizes larger than the extents of contiguous areas with a similar development history will result in a decrease of the variability of SSA between plots (Král et al., 2010) and differences between development stages will become indistinct (Zenner et al., 2016). As the precise local disturbance regime of a forest is site specific and not known beforehand, studies about the stand structure of forests should include the effect of different observational spatial scales.

\subsection{General study aims}

The two overall objectives of the work presented with this thesis are to progress our understanding of (1) effects of management for timber production and (2) influences of the natural development cycle on the stand and canopy structure, aboveground biomass stocks, and NPP of 
primeval European beech forests.

During several field campaigns in three vegetation periods (2013-2015) in three primeval European beech forests in eastern Slovakia the stand and canopy structure, aboveground biomass (live and dead), and all relevant parts of the ANPP (woody biomass increment and litter production) have been recorded in 150 plots. Additionally, all relevant parts of the stand structure of two large primeval European beech forest plots in Albania ( 5 ha and 6 ha) were completely mapped (Tabaku, 2000).

The canopy structure of the Slovakian forests was assessed through optical measurements of the leaf area index ( $L A I$, the projected one-sided leaf area per unit ground area) with a 'LAI2000 Plant Canopy Analyzer'. Measures for canopy density (mean of 21 LAI-estimates) and canopy structural diversity (dispersion of 21 LAI-estimates) were quantified at plot-level for two different vertical strata of the canopy (below and above $4.5 \mathrm{~m}$ ).

The thesis is divided in three separate parts, with each study testing several hypotheses related to the overall objectives:

1. Commercial management for timber production is impacting European beech forests in the following ways:

a) Canopy density and diversity is reduced (first study, chapter 2);

b) Biomass stocks (alive and dead) are reduced (second study, chapter 3);

c) ANPP remains equal (second study, chapter 3);

2. In the course of natural forest development, stand structure and ecosystem functions are shifting:

a) Canopy density remains equal, while canopy diversity is increasing in late successional stages (first study, chapter 2);

b) Biomass stocks are higher in late successional stages, while ANPP remains equal (second study, chapter 3);

3. Canopy structural diversity is a promoting factor of ANPP in primeval European beech forests (second study, chapter 3); 
4. The influence of the natural development cycle on European beech forests is shaping the stand structure in a way which reflects in multivariate datasets: Development stages are represented by clearly from one another separated clusters in higher-dimensional space (third study, chapter 4).

\subsection{Methods}

\subsubsection{Description of the Study areas}

\section{Slovakia}

\subsubsection{Study region and investigated stands}

Three beech primeval forests at montane elevation (550-950 m a.s.l.) in the Western Carpathians in eastern Slovakia $\left(48^{\circ} 1^{\prime}-49^{\circ} 8^{\prime} \mathrm{N}, 22^{\circ} 1^{\prime}-22^{\circ} 54^{\prime} \mathrm{E}\right)$ were studied. They are part of the forest reserves Havešová, Stužica (both inside Poloniny National Park), and Kyjov in the Vihorlat mountains, which belong to the UNESCO World Heritage Site 'Primeval Beech Forests of the Carpathians and the Ancient Beech Forests of Germany' (Table 2.1). The forests are true primeval forests with no human intervention for the past several hundred years (Korpel, 1995). However, the sites have been influenced by atmospheric deposition of nitrogen, acids, and other anthropogenic substances since the beginning of industrialization in a similar manner to many other woodland regions in the industrialized regions of the world. Three production forests were selected at similar elevation and within a distance of $1 \mathrm{~km}$ to the primeval forests for comparative study. The selected stands were managed in a shelterwood cutting system with two subsequent cuts within 10 years at the end of the production cycle.

\section{Albania}

The study site Mirdita (5 ha) lies in the Munella mountain range in northern Albania $\left(41^{\circ} 55^{\prime} \mathrm{N}-\right.$ $\left.42^{\circ} 7^{\prime} \mathrm{N} ; 20^{\circ} 3^{\prime} \mathrm{E}-20^{\circ} 15^{\prime} \mathrm{E}\right)$. The terrain is sloped $\left(25^{\circ}-30^{\circ}\right)$ and has a southeast exposition. Soil type is Cambisol with a good nutrient supply. There is a Mediterranean mountain climate with an annual mean temperature of ca. $6^{\circ} \mathrm{C}$, annual precipitation of ca. $2600 \mathrm{~mm}$ and high winter 
precipitation (values extrapolated from the closest weather station Domgjon at $5 \mathrm{~km}$ distance). F. sylvatica is the dominating tree species; there are minor shares of Abies alba Mill. and Acer pseudoplatanus L. The plant association is Fagetum-asperulotesum.

The study site Rajca (6 ha) is located in the Shebenik-Jabllanica mountain ranges in the east of middle Albania $\left(41^{\circ} 14^{\prime} \mathrm{N}, 21^{\circ} 7^{\prime} \mathrm{E}, 1400-1450 \mathrm{~m}\right.$ a.s.l.). There is no climate station close by to extrapolate annual temperature and precipitation, but climatic conditions should be similar to Mirdita. Soil type and plant association are, just like in Mirdita, Fagetum asperulotesum with minor shares of A. alba and A. pseudoplatanus.

\subsubsection{Study designs}

The studies in the Slovakian forests had a factorial design which was able to answer two different types of questions: (1) the primeval- production forest contrast and (2) differences between three stages of the forest development cycle (growth, optimal, and terminal stages). To obtain a balanced study design with equal plot numbers of each development stage, a stratified random sampling approach was applied. In a first step, 40 plots per primeval forest and 10 plots per managed stand were systematically sampled. A regular grid was placed over each forest and plots were established on each of the grid nodes with a minimum distance to the forest border (Fig. 1.1).

Basic attributes of all trees with a $D B H \geq 7 \mathrm{~cm}$ in the in total 150 'low intensity plots' (LIPs, first stratification level) were recorded (tree coordinates, $D B H$, heights). Heights were measured for a subsample of all trees within a plot with a Vertex IV height meter (Haglöf Sweden AB, Långsele, Sweden). Heights of the remaining trees were extrapolated from the empirically derived relationship between $D B H$ and heights of the subsample (species- and site-specific stand-height curves). For each of the primeval forest plots the development stage was assessed with the method proposed by Feldmann et al., 2018. The second step of the stratified random sampling was to select four plots per development stages in the primeval forests and four plots per production forest. In the in total 48 'high intensity plots' (HIPs, second stratification level), most of the more time- and labor intensive parameters like canopy structure or ANPP were recorded. 

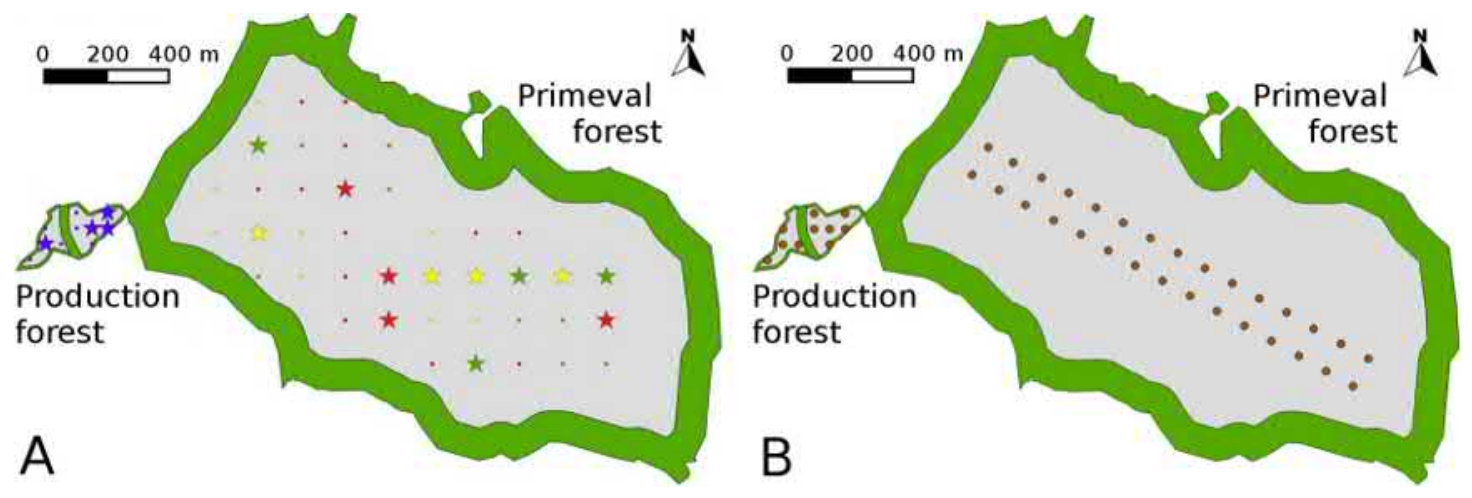

Figure 1.1: Study design in the primeval forest of Havešová. A: Circles and stars mark research plots where basic stand structural attributes were recorded (low intensity plots (LIPs)). Development stages and management type are represented by symbol colors (Green: growth, yellow: optimal, red: terminal stage, blue: production forests). Stars highlight plots where additional variables were inventoried (coarse and fine deadwood, regeneration, canopy structure; high intensity plots (HIPs)). B: Position of litter traps. Grey and green polygons mark the study area and buffer zone.

Litter fall was measured with litter traps with a circular opening of $60 \mathrm{~cm}$ diameter. 30 traps were installed in each primeval forest and 10 traps in each production forest (120 traps in total). For the selection of trap locations, a slightly different design was used than for the research plots. Unfortunately, litter fall in primeval forests with a small-scale disturbance regime is nearly impossible to record at plot-level. Similarly to atmospheric flux measurements, litter traps do as well have a 'footprint' of an unknown area and orientation, which is influenced by wind speed and direction during leaf fall and topography (litter trap position: depression vs. elevation). As a consequence, litter trap data can not be related to the data of the research plots in primeval beech forests and locations for the traps were chosen from a separate grid in some forests (Fig. 1.1).

In the Albanian forests, all relevant parts of the stand structure (standing tree coordinates and $D B H$, lying tree locations and diameters, regeneration polygons) of two large primeval European beech forest plots in Albania (5 ha and 6 ha) were completely mapped (Tabaku, 2000).

\subsubsection{Canopy structure}

In the Slovakian forests canopy structure was assessed on all HIPs through approximation of the leaf area index (LAI, projected one-sided leaf area per unit ground area) with a LAI2000 
Plant Canopy Analyzer (LiCor, Lincoln, NE, USA). Two synchronously operating light sensors measured light intensity for different sections of the hemisphere 'above' the canopy (on a large gap) and 'below' the canopy on the plot. The 'effective' $L A I_{e}$ was derived from the quotient of below- and above-canopy readings (transmission coefficient) (Chen et al., 1991; Miller, 1967). The term 'effective' discriminates between the 'true' $L A I$ and the optically measured $L A I_{e}$, which is biased due to clumping of canopy elements on scales below the sensor resolution.

Measures for canopy density (mean of 21 single $L A I$-estimates) and canopy structural diversity (dispersion of 21 LAI-estimates) were quantified at plot-level. Measurement points of the 'below'-readings were located every $1.5 \mathrm{~m}$ on two $15 \mathrm{~m}$ long transects crossing each other at the plot center. Readings were taken on two heights per sampling point, so $L A I_{e}$-estimates were derived for three different strata of the canopy: (1) the upper-canopy $\left(L A I_{e-u p}\right)$, the lower canopy $\left(L A I_{e-l o w}\right)$, and the total canopy $\left(L A I_{e-t o t}=L A I_{e-l o w}+L A I_{e-u p}\right)$.

\subsubsection{Biomass stocks}

Five different components of live and dead aboveground biomass stocks were estimated in each HIP: live tree mass, regeneration mass, litter mass, mass of coarse woody debris, and mass of fine woody debris.

Live tree mass of F. sylvatica and A. alba was derived from allometric equations based on DBH and tree height (Ruiz-Peinado et al., 2011; Wutzler et al., 2008). For all remaining tree species, the biomass was approximated by volume estimations and multiplication with their wood density (Chave et al., 2009).

Leaf and fruit mass was estimated from litter trap data (see below) averaged over three (primeval forests) and two seasons (production forests).

Woody biomass in the shrub layer of the forests was entirely composed of young trees and tree-saplings. Regeneration mass was measured in four $13 \mathrm{~m}^{2}$-subplots per plot. Biomass without leaves of every plant with a $D B H<7 \mathrm{~cm}$ was calculated from allometric equations based on plant height (Annighöfer et al., 2016). To speed up measurements, plant height was measured in four height-classes: 0-49 cm, 50-149 cm, 149-299 cm, and $\geq 300 \mathrm{~cm}$.

Biomass of whole standing trees was estimated with the methods described above. The 
volume of snags and logs was approximated by a frustum of a cone and their biomass was derived through multiplication with the respective wood density (Chave et al., 2009). The diameter of logs was measured at two positions for calculating log tapering. Tapering of snags was estimated to be $10 \mathrm{~mm} \mathrm{~m}^{-1}$. Correction factors to account for decay were applied (Albrecht, 1991).

The volume of fine woody debris was estimated from line intersect sampling (Böhl and Brändli, 2007) on four $6.5 \mathrm{~m}$ long transects. The diameter of each intersecting piece of debris with a base diameter between $2-20 \mathrm{~cm}$ was recorded. The biomass of fine deadwood was then estimated by multiplying the estimated volume with the wood density of beech and applying a correction factor of 0.8 to account for average decay.

\subsubsection{Productivity}

In beech forests the ANPP mainly consists of two parts: woody biomass increment of trees ( $A N P P_{\text {wood }}$; including brushwood and fine branches) and litter production ( $A N P P_{\text {litter }}$; sum of leave- and fruit production). The NPP of the herb- and shrub layer (including regeneration trees with a $D B H<7 \mathrm{~cm}$ ) are only marginally contributing to the overall productivity and were neglected.

$A N P P_{\text {wood }}$ was measured during the vegetation periods 2014 and 2015. Every tree with a $D B H \geq 7 \mathrm{~cm}$ was equipped with a permanent increment tape with a precision of $0.1 \mathrm{~mm}$ (type D1, UMS, Munich, Germany) and readings were taken once before the start and once after the end of the vegetation period. The height increment was estimated from the diameter increment with stand height curves (see section 1.6.3). Live biomass of each tree before and after the vegetation period was calculated with allometric biomass equations (see section 1.6.5). $A N P P_{\text {wood }}$ was calculated as the summed biomass increment of all trees in a plot during one vegetation period related to the plot area.

The litter traps were installed beginning of 2013 in the primeval forests and beginning of 2014 in the production forests. They were emptied in December of each year and subsequently sorted by species and litter type (leaves/fruits), oven-dried for $48 \mathrm{~h}$ at $70{ }^{\circ} \mathrm{C}$ and weighed. Fifty randomly selected beech leaves per trap were scanned and weighed separately to determine 
mean specific leaf area $\left(S L A\right.$, ratio of leaf area to dry mass $\left.\left(\mathrm{cm}^{2} \mathrm{~g}^{-1}\right)\right)$ of the beech foliage. SLA and total leaf mass of the litter samples were used to calculate the true LAI not affected by foliage clumping as the optically measured $L A I_{e}$. 


\section{References}

Albrecht, L., 1991. Die Bedeutung des toten Holzes im Wald. Forstwissenschaftliches Centralblatt vereinigt mit Tharandter Forstliches Jahrbuch 110 (1), 106-113.

Annighöfer, P., Ameztegui, A., Ammer, C., Balandier, P., Bartsch, N., Bolte, A., Coll, L., Collet, C., Ewald, J., Frischbier, N., Gebereyesus, T., Haase, J., Hamm, T., Hirschfelder, B., Huth, F., Kändler, G., Kahl, A., Kawaletz, H., Kuehne, C., Lacointe, A., Lin, N., Löf, M., Malagoli, P., Marquier, A., Müller, S., Promberger, S., Provendier, D., Röhle, H., Sathornkich, J., Schall, P., Scherer-Lorenzen, M., Schröder, J., Seele, C., Weidig, J., Wirth, C., Wolf, H., Wollmerstädt, J., Mund, M., 2016. Species-specific and generic biomass equations for seedlings and saplings of European tree species. European Journal of Forest Research 135 (2), 313-329.

Assmann, E., Davis, P.W., 1970. The Principles of Forest Yield Study: Studies in the Organic Production, Structure, Increment and Yield of Forest Stands. Elsevier Science, Burlington.

BMEL, 2014. The Forests in Germany. Federal Ministry of Food and Agriculture (BMEL).

Böhl, J., Brändli, U.B., 2007. Deadwood volume assessment in the third Swiss National Forest Inventory: Methods and first results. European Journal of Forest Research 126 (3), 449-457.

Bublinec, E., Pichler, V., eds., 2001. Slovak Primeval Forests. Slovak Academy of Sciences, Zvolen.

Burschel, P., Huss, J., 2003. Grundriss des Waldbaus: Ein Leitfaden für Studium und Praxis : 207 Tabellen. Ulmer, Stuttgart, 3., unveränd. aufl. edition.

Chapin, I.F.S., Matson, P.A., Vitousek, P.M., 2011. Principles of Terrestrial Ecosystem Ecology. Springer Science+Business Media LLC, New York, NY.

Chave, J., Coomes, D., Jansen, S., Lewis, S.L., Swenson, N.G., Zanne, A.E., 2009. Towards a worldwide wood economics spectrum. Ecology Letters 12 (4), 351-366.

Chen, J.M., Black, T.A., Adams, R.S., 1991. Evaluation of hemispherical photography for determining plant area index and geometry of a forest stand. Agricultural and Forest Meteorology 56 (1-2), 129-143.

Commarmot, B., Bachofen, H., Bundziak, Y., Bürgi, A., Ramp, B., Shparyk, Y., Sukhariuk, D., Viter, R., Zingg, A., 2005. Structures of virgin and managed beech forests in Uholka (Ukraine) and Sihlwald (Switzerland): a comparative study. For. Snow Landsc. Res. 79 (1/2), 45-56.

Diaci, J., ed., 1999. Virgin forests and forest reserves in Central and East European countries: History, present status and furture development ; proceedings of the invited lecturers' reports presented at the COST E4 management committee and working groups meeting in Ljubljana, Slovenia, 25 - 28 Aril 1998. Department of Forestry and Renewable Forest Resources - Biotechnical Faculty, Ljubljana.

Diaci, J., Rozenbergar, D., Anic, I., Mikac, S., Saniga, M., Kucbel, S., Visnjic, C., Ballian, D., 2011. Structural dynamics and synchronous silver fir decline in mixed old-growth mountain forests in Eastern and Southeastern Europe. Forestry 84 (5), 479-491.

Diaci, J., Rozenbergar, D., Boncina, A., 2010. Stand dynamics of Dinaric old-growth forest in Slovenia: Are indirect human influences relevant? Plant Biosystems - An International Journal Dealing with all Aspects of Plant Biology 144 (1), 194-201.

Drößler, L., von Lüpke, B., 2005. Canopy gaps in two virgin beech forest reserves in Slovakia. Journal of Forest Science 10 (51), 446-457.

Drößler, L., Meyer, P., 2006. Forest development stages in two virgin beech reserves in Slovakia. Forstarchiv 77, 155-161.

Feldmann, E., Glatthorn, J., Hauck, M., Leuschner, C., 2018. A novel empirical approach for determining the extension of forest development stages in temperate old-growth forests. European Journal of Forest Research , 1-15.

Frank, D., Finckh, M., Wirth, C., 2009. Impacts of Land Use on Habitat Functions of Old-Growth Forests and their Biodiversity. In: C. Wirth, G. Gleixner, M. Heimann, eds., Old-Growth Forests: Function, Fate and Value, Ecological Studies, Analysis and Synthesis, volume 207. Springer-Verlag Berlin Heidelberg, Berlin, Heidelberg, pp. 429-450. 
von Gadow, K., Chun, Y.Z., Wehenkel, C., Arne Pommerening, Javier Corral-Rivas, Mykola Korol, Stepan Myklush, Gang Ying Hui, Andres Kiviste, Xiu Hai Zhao, 2012. Forest Structure and Diversity. In: T. Pukkala, K. von Gadow, eds., Continuous Cover Forestry, Managing Forest Ecosystems. Springer Netherlands, Dordrecht, pp. 29-83.

Green Report, 2009. Report on the status of forestry in the Slovak Republic of 2009. Ministry of Agriculture of the Slovak Republic, Bratislava.

Hanstein, U., 2000. Vom Geheimnis des Alters - am Beispiel nordwestdeutscher Tiefland-Buchenwälder. Forst und Holz , 477-480.

He, L., Chen, J.M., Pan, Y., Birdsey, R., Kattge, J., 2012. Relationships between net primary productivity and forest stand age in U.S. forests. Global Biogeochemical Cycles 26 (3).

Hort, L., Tesař, V., Vrška, T., 1999. Forest reserve research network - the Czech Republic country report. In: J. Diaci, ed., Virgin forests and forest reserves in Central and East European countries. Department of Forestry and Renewable Forest Resources - Biotechnical Faculty, Ljubljana, pp. 25-44.

Huber, M.O., 2011. Statistical models to identify stand development stages by means of stand characteristics. Canadian Journal of Forest Research 41 (1), 111-123.

Ishii, H.T., Tanabe, S., Hiura, T., 2004. Exploring the relationships among canopy structure, stand productivity, and biodiversity of temperature forest ecosystems. Forest Science 50 (3), 342-355.

Korpeĺ, Š., 1995. Die Urwälder der Westkarpaten. Gustav Fischer Verlag, Stuttgart.

Král, K., Janík, D., Vrška, T., Adam, D., Hort, L., Unar, P., Šamonil, P., 2010a. Local variability of stand structural features in beech dominated natural forests of Central Europe: Implications for sampling. Forest Ecology and Management 260 (12), 2196-2203.

Král, K., Vrška, T., Hort, L., Adam, D., Šamonil, P., 2010b. Developmental phases in a temperate natural spruce-firbeech forest: Determination by a supervised classification method. European Journal of Forest Research 129 (3), 339-351.

Larsen, J.B., Hahn, K., Emborg, J., 2010. Forest reserve studies as inspiration for sustainable forest management Lessons learned from Suserup Skov in Denmark. Forstarchiv 2 (81), 28-33.

Leibundgut, H., 1959. Über Zweck und Methodik der Struktur- und Zuwachsanalyse von Urwäldern. Schweizerische Zeitschrift für Forstwesen (110), 111-124.

Leuschner, C., Ellenberg, H., 2017. Ecology of Central European Forests - Vegetation Ecology of Central Europe, Vol. I. Springer, Dordrecht.

Lévêque, C., Mounolou, J.C., 2003. Biodiversity. Wiley, Chichester.

Liang, J., Crowther, T.W., Picard, N., Wiser, S., Zhou, M., Alberti, G., Schulze, E.D., McGuire, A.D., Bozzato, F., Pretzsch, H., de Miguel, S., Paquette, A., Herault, B., Scherer-Lorenzen, M., Barrett, C.B., Glick, H.B., Hengeveld, G.M., Nabuurs, G.J., Pfautsch, S., Viana, H., Vibrans, A.C., Ammer, C., Schall, P., Verbyla, D., Tchebakova, N., Fischer, M., Watson, J.V., Chen, H.Y.H., Lei, X., Schelhaas, M.J., Lu, H., Gianelle, D., Parfenova, E.I., Salas, C., Lee, E., Lee, B., Kim, H.S., Bruelheide, H., Coomes, D.A., Piotto, D., Sunderland, T., Schmid, B., Gourlet-Fleury, S., Sonke, B., Tavani, R., Zhu, J., Brandl, S., Vayreda, J., Kitahara, F., Searle, E.B., Neldner, V.J., Ngugi, M.R., Baraloto, C., Frizzera, L., Balazy, R., Oleksyn, J., Zawila-Niedzwiecki, T., Bouriaud, O., Bussotti, F., Finer, L., Jaroszewicz, B., Jucker, T., Valladares, F., Jagodzinski, A.M., Peri, P.L., Gonmadje, C., Marthy, W., O’Brien, T., Martin, E.H., Marshall, A.R., Rovero, F., Bitariho, R., Niklaus, P.A., Alvarez-Loayza, P., Chamuya, N., Valencia, R., Mortier, F., Wortel, V., Engone-Obiang, N.L., Ferreira, L.V., Odeke, D.E., Vasquez, R.M., Lewis, S.L., Reich, P.B., 2016. Positive biodiversity-productivity relationship predominant in global forests. Science 354 (6309), 196.

Lindenmayer, D.B., Franklin, J.F., Fischer, J., 2006. General management principles and a checklist of strategies to guide forest biodiversity conservation. Biological Conservation 131 (3), 433-445.

Luyssaert, S., Schulze, E.D., Borner, A., Knohl, A., Hessenmoller, D., Law, B.E., Ciais, P., Grace, J., 2008. Old-growth forests as global carbon sinks. Nature 455 (7210), 213-215.

Merino, A., Real, C., Álvarez-González, J.G., Rodríguez-Guitián, M.A., 2007. Forest structure and C stocks in natural 
Fagus sylvatica forest in southern Europe: The effects of past management. Forest Ecology and Management 250 (3), 206-214.

Meyer, P., 1999. Bestimmung der Waldentwicklungsphasen und der Texturdiversität in Naturwäldern. Allgemeine Forst und Jagd-Zeitung 10-11 (170), 203-211.

Miller, J.B., 1967. A formula for average foliage density. Australian Journal of Botany 15 (1), 141-\&.

Mosseler, A., Lynds, J.A., Major, J.E., 2003. Old-growth forests of the Acadian Forest Region. Environmental Reviews 11 (S1), S47-S77.

Naeem, S., Duffy, J.E., Zavaleta, E., 2012. The Functions of Biological Diversity in an Age of Extinction. Science (336), 1401-1406.

Ninan, K.N., Kontoleon, A., 2016. Valuing forest ecosystem services and disservices - Case study of a protected area in India. Ecosystem Services 20, 1-14.

Odum, E.P., 1969. The strategy of ecosystem development. Science (164), 262-270.

Oliver, C.D., Larson, B.C., 1996. Forest Stand Dynamics. Wiley, New York.

Oulehle, F., Hleb, R., Houska, J., Samonil, P., Hofmeister, J., Hruska, J., 2010. Anthropogenic acidification effects in primeval forests in the Transcarpathian Mts., western Ukraine. The Science of the total environment 408 (4), 856-864.

Parviainen, J., 2005. Virgin and natural forests in the temperate zone of Europe. For. Snow Landsc. Res. 79, 9-18.

Pommerening, A., 2002. Approaches to quantifying forest structures. Forestry 75 (3), 305-324.

Pretzsch, H., 2005. Diversity and productivity in forests: evidence from long-term experimental Plots. In: M. SchererLorenzen, C. Körner, E.D. Schulze, eds., Forest Diversity and Function: Temperate and Boreal Systems. Springer Berlin Heidelberg, Berlin, Heidelberg, pp. 41-64.

Pretzsch, H., del Río, M., Ammer, C., Avdagic, A., Barbeito, I., Bielak, K., Brazaitis, G., Coll, L., Dirnberger, G., Drössler, L., Fabrika, M., Forrester, D.I., Godvod, K., Heym, M., Hurt, V., Kurylyak, V., Löf, M., Lombardi, F., Matović, B., Mohren, F., Motta, R., den Ouden, J., Pach, M., Ponette, Q., Schütze, G., Schweig, J., Skrzyszewski, J., Sramek, V., Sterba, H., Stojanović, D., Svoboda, M., Vanhellemont, M., Verheyen, K., Wellhausen, K., Zlatanov, T., Bravo-Oviedo, A., 2015. Growth and yield of mixed versus pure stands of Scots pine (Pinus sylvestris L.) and European beech (Fagus sylvatica L.) analysed along a productivity gradient through Europe. European Journal of Forest Research 134 (5), 927-947.

Průša, E., 1985. Die böhmischen und mährischen Urwälder - ihre Struktur und Ökologie - Vegetace CSSR A15. Academia Verlag der Tschechoslowakischen Akademie der Wissenschaften, Praha.

Puettmann, K.J., Wilson, S.M., Baker, S.C., Donoso, P.J., Drössler, L., Amente, G., Harvey, B.D., Knoke, T., Lu, Y., Nocentini, S., Putz, F.E., Yoshida, T., Bauhus, J., 2015. Silvicultural alternatives to conventional even-aged forest management - what limits global adoption? Forest Ecosystems 2 (1), 611.

Ruiz-Peinado, R., Del Rio, M., Montero, G., 2011. New models for estimating the carbon sink capacity of Spanish softwood species. Forest Syst. (Forest Systems) 20 (1), 176-188.

Ryan, M.G., Binkley, D., Fownes, J.H., 1997. Age-Related Decline in Forest Productivity: Pattern and Process. In: D.B. Nedwell, A.H. Fitter, eds., Advances in Ecological Research, Advances in Ecological Research, volume v.27. Elsevier Textbooks, s.l., pp. 213-262.

Schulze, E.D., Hassenmoeller, D., Knohl, A., Luyssaert, S., Boerner, A., Grace, J., 2009. Temperate and boreal oldgrowth forests: how do their growth dynamics and biodiversity differ from young stands and managed forests? In: C. Wirth, G. Gleixner, M. Heimann, eds., Old-Growth Forests: Function, Fate and Value, Ecological Studies, Analysis and Synthesis, volume 207. Springer-Verlag Berlin Heidelberg, Berlin, Heidelberg, pp. 343-366.

Schulze, E.D., Wirth, C., Mollicone, D., Ziegler, W., 2005. Succession after stand replacing disturbances by fire, wind throw, and insects in the dark Taiga of Central Siberia. Oecologia 146 (1), 77-88.

Šebesta, J., Šamonil, P., Lacina, J., Oulehle, F., Houška, J., Buček, A., 2011. Acidification of primeval forests in the 
Ukraine Carpathians: Vegetation and soil changes over six decades. Forest Ecology and Management 262 (7), $1265-1279$.

Shorohova, E., Kuuluvainen, T., Kangur, A., Jõgiste, K., 2009. Natural stand structures, disturbance regimes and successional dynamics in the Eurasian boreal forests: A review with special reference to Russian studies. Annals of Forest Science 66 (2), 201.

Sutherland, I.J., Gergel, S.E., Bennett, E.M., 2016. Seeing the forest for its multiple ecosystem services: Indicators for cultural services in heterogeneous forests. Ecological Indicators 71, 123-133.

Tabaku, V., 2000. Struktur von Buchen-Urwäldern in Albanien im Vergleich mit deutschen BuchenNaturwaldreservaten und-Wirtschaftswäldern. Dissertation. Cuvillier Verlag, Göttingen.

Trotsiuk, V., Hobi, M.L., Commarmot, B., 2012. Age structure and disturbance dynamics of the relic virgin beech forest Uholka (Ukrainian Carpathians). Forest Ecology and Management 265, 181-190.

Veen, P., Fanta, J., Raev, I., Biriş, I.A., de Smidt, J., Maes, B., 2010. Virgin forests in Romania and Bulgaria: Results of two national inventory projects and their implications for protection. Biodiversity and Conservation 19 (6), 1805-1819.

Venables, W.N., Ripley, B.D., 2007. Modern applied statistics with S. Statistics and computing. Springer, New York, NY, 4. ed., corr. print edition.

Vincent, J.R., Ahmad, I., Adnan, N., Burwell, W.B., Pattanayak, S.K., Tan-Soo, J.S., Thomas, K., 2016. Valuing Water Purification by Forests: An Analysis of Malaysian Panel Data. Environmental and Resource Economics 64 (1), $59-80$.

Westphal, C., Tremer, N., Oheimb, G.v., Hansen, J., von Gadow, K., Härdtle, W., 2006. Is the reverse J-shaped diameter distribution universally applicable in European virgin beech forests? Forest Ecology and Management 223 (1-3), $75-83$.

Williams, L.J., Paquette, A., Cavender-Bares, J., Messier, C., Reich, P.B., 2017. Spatial complementarity in tree crowns explains overyielding in species mixtures. Nature Ecology \& Evolution 1, 0063.

Winter, S., Brambach, F., 2011. Determination of a common forest life cycle assessment method for biodiversity evaluation. Forest Ecology and Management 262 (12), 2120-2132.

Wirth, C., Messier, C., Bergeron, Y., Frank, D., 2009. Old-Growth Forest Definitions: a Pragmatic View. In: C. Wirth, G. Gleixner, M. Heimann, eds., Old-Growth Forests: Function, Fate and Value, Ecological Studies, Analysis and Synthesis, volume 207. Springer-Verlag Berlin Heidelberg, Berlin, Heidelberg, pp. 11-33.

Wutzler, T., Wirth, C., Schumacher, J., 2008. Generic biomass functions for Common beech (Fagus sylvatica) in Central Europe: Predictions and components of uncertainty. Canadian Journal of Forest Research 38 (6), 1661-1675.

Zenner, E.K., Peck, J.E., Hobi, M.L., Commarmot, B., 2015. The dynamics of structure across scale in a primaeval European beech stand. Forestry 88 (2), 180-189.

Zenner, E.K., Peck, J.E., Hobi, M.L., Commarmot, B., Ewald, J., 2016. Validation of a classification protocol: Meeting the prospect requirement and ensuring distinctiveness when assigning forest development phases. Applied Vegetation Science 19 (3), 541-552. 



\title{
Effects of forest management on stand leaf area: Comparing beech production and primeval forests in Slovakia
}

\author{
- Jonas Glatthorn - Viliam Pichler - Markus Hauck - \\ - Christoph Leuschner -
}

Forest Ecology and Management 389 (2017), 76-85

\begin{abstract}
The productivity and water consumption of forests depend on stand leaf area, which may vary with tree age, forest structure, and environment. How forest management affects leaf area and whether production forests have different leaf areas than unmanaged natural forests, is not clear. We compared the leaf area index (LAI) of production forests of European beech (Fagus sylvatica) with that of primeval forests (three forests in each case) in Slovakia and analyzed the $L A I$ change from early to late stages of the natural forest development cycle. Optically determined LAI (LAI2000 Plant Canopy Analyzer) was on average $7.1 \mathrm{~m}^{2} \mathrm{~m}^{-2}\left(2.8-11.0 \mathrm{~m}^{2} \mathrm{~m}^{-2}\right)$ in the primeval forests and $7.4 \mathrm{~m}^{2} \mathrm{~m}^{-2}\left(4.3-11.2 \mathrm{~m}^{2} \mathrm{~m}^{-2}\right)$ in the production forests. Model results show that transforming beech primeval forests into even-aged production forests would reduce $L A I$ by $\sim 1.6$ units, if stem density is kept constant. Complex primeval forest canopies thus promote the formation of higher LAIs. However, this effect was compensated for by the higher stem densities of the production forests, resulting on average in similar LAIs of production and primeval forests. In the terminal stage of natural forest development with tree death and gap formation, plot-level $L A I$ was not lower than in the earlier growth and optimal stages, probably because neighboring beech trees were rapidly filling gaps with foliage. This suggests that stand-level productivity is not reduced in the terminal stage of forest development, since
\end{abstract}


$L A I$ is rapidly restored after the death of individual trees. Our results provide insights into the functional role of structural complexity in temperate forest canopies and how European beech maintains dominance across the full forest development cycle.

Keywords: Fagus sylvatica, Forest dynamics, Leaf area index, Litter traps, Canopy structure, LAI-2000.

\subsection{Introduction}

Leaf area is the surface through which plants exchange most energy, $\mathrm{CO}_{2}$, and water vapor with the environment. The productivity of plant communities and their water loss are closely linked to stand leaf area, typically measured as leaf area index ( $L A I)$, i.e., the projected one-sided leaf area per unit ground area. Carbon assimilation and biogeochemical fluxes depend not only on leaf area but also on the spatial arrangement of the foliage in canopy space. This is especially the case in forests with their large canopy volume, where light intensity steeply decreases from canopy top to bottom.

It has been recognized that forest canopy structure and the associated leaf area index vary with tree species, tree age, and forest management regime (e.g., Bequet et al., 2011; Davi et al., 2008; Derose and Seymour, 2010; Gonzalez-Benecke et al., 2012; Le Dantec et al., 2000), but the relationship is not precisely known. Deeper understanding of these relationships is crucial for predicting productivity, water consumption, and forest dynamics under changing climatic conditions and altered forest management.

About 30 percent of the forest area on earth is managed with conventional silvicultural systems, which typically lead to single-layered, even-aged stands (FAO, 2010; Puettmann et al., 2015). Alternative management concepts with a focus on ecosystem services other than timber production have been developed and are receiving increasing attention (Puettmann et al., 2015). Several of these concepts promote the creation of more complex canopies, avoiding structurally simple even-aged stands. To advance this development, knowledge about the effects of management on forest canopy structure is mandatory. In production forests (commercially managed and logged forests), final harvest usually takes place at a time when the rate of timber 
accumulation decreases. In this phase, stand development is still far from the stage of tree senescence, where dying trees create gaps, structural diversity greatly increases, and deadwood accumulates (Drössler and Meyer, 2006; Oliver and Larson, 1996).

Most knowledge about the canopy structure and leaf area of forests has been collected in production forests during the initial and growth stages of stand development, while not much is known about old-growth or primeval forests without management impact. In particular, there is poor understanding of the complex canopy structure of the terminal stage of forest development, when individual trees or groups of trees die of age.

European beech (Fagus sylvatica L.) is the most important tree species of Central European natural forest vegetation (Bohn et al., 2003) and it is also one of the economically most valuable timber species. Across its distribution range, beech dominates many forest communities in particular on acid soils, forming quasi- monocultures due to its high competitive strength (Leuschner, 2015). A characteristic of this typical late-successional species is its extended shade crown, which reduces light transmission to the ground to 1-25\% of incident light or less (Mayer et al., 2002; Leuschner and Ellenberg, 2017). This is achieved by several layers of highly shadetolerant leaves aligned horizontally in the lower part of the crown. How this complex canopy architecture changes with tree age and responds to management interventions is best studied by comparing beech primeval forests with production forests.

We studied canopy light transmission and gap fraction in three Slovakian beech primeval forests with no management impact for the past several hundred years and compared these oldgrowth forests to nearby beech production forests shortly before harvest. Based on measurement campaigns with the LAI2000 Plant Canopy Analyzer at two height levels in the stand, we derived the effective leaf area index $L A I_{e}$ and its spatial variation across different development stages in the primeval forests and the mature production forests. Since optical LAI data typically represent underestimates of true leaf area, we compared our $L A I_{e}$ means with the results of a litter trapping study in the same stands, which may give more reliable stand-level averages, while the assignment of these leaf area data to individual plots or forest development stages is difficult.

The objectives of the study were (i) to quantify differences between primeval and production 
Table 2.1: Physiography of the three study sites in eastern Slovakia. Due to the sloping terrain, ranges are given for altitude, precipitation, and temperature.

\begin{tabular}{|c|c|c|c|}
\hline & Havešová & Kyjov & Stužica \\
\hline Altitude (m a.s.l.) & $550-650$ & $700-820$ & $700-950$ \\
\hline Precipitation $\left(\mathrm{mm} \mathrm{yr}^{-1}\right)$ & $800-850$ & $950-1000$ & $900-1200$ \\
\hline Mean temperature $\left({ }^{\circ} \mathrm{C}\right)$ & $6.0-6.5$ & $5.2-5.7$ & $4.0-5.0$ \\
\hline Parent material & Carpathian flysh & Andesite & Carpathian flysh \\
\hline Soil type (FAO/WRB) & Eutric Cambisol & Dystric Cambisol & Eutric Cambisol \\
\hline Aspect & South to east & North to east & $\begin{array}{r}\text { South-east to } \\
\text { south-west }\end{array}$ \\
\hline $\begin{array}{l}\text { Slope }\left(^{\circ}\right) \\
\quad \text { (primeval/production) }\end{array}$ & 15.4 & 11.9 & 12.9 \\
\hline Plant community & \multicolumn{3}{|c|}{ Assoc. Fagetum dentariosum glandulosae } \\
\hline
\end{tabular}

forests in leaf area and its spatial distribution and (ii) to explore changes in $L A I_{e}$ across the development stages of a forest development cycle. We tested the hypotheses that the horizontal distribution of foliage is more heterogeneous in the primeval forest canopy and that the multilayered structure results in a larger leaf area than in the production forests. Our assessment of canopy structural diversity through optical and biomass-related measurements on a large number of plots represents an alternative to the classical approach of canopy analysis with a focus on stem position, tree size, and crown projection area (Pommerening, 2002; von Gadow et al., 2012).

\subsection{Methods}

\subsubsection{Study region and investigated stands}

Three beech primeval forests at montane elevation (550-950 m a.s.l.) in the Western Carpathians in eastern Slovakia $\left(48^{\circ} 1^{\prime}-49^{\circ} 8^{\prime} \mathrm{N}, 22^{\circ} 1^{\prime}-22^{\circ} 54^{\prime} \mathrm{E}\right)$ were studied. They are part of the forest reserves Havešová, Stužica (both inside Poloniny National Park), and Kyjov in the Vihorlat mountains, which belong to the UNESCO World Heritage Site 'Primeval Beech Forests of the Carpathians and the Ancient Beech Forests of Germany' (Table 2.1). The forests are true 
primeval forests with no human intervention for the past several hundred years (Korpel, 1995). However, the sites have been influenced by atmospheric deposition of nitrogen, acids, and other anthropogenic substances since the beginning of industrialization in a similar manner to many other woodland regions in the industrialized regions of the world.

Three production forests were selected at similar elevation and within a distance of $1 \mathrm{~km}$ to the primeval forests for comparative study. The selected stands were managed in a shelterwood cutting system with two subsequent cuts within 10 years at the end of the production cycle. This system is the most widespread beech forest management regime in Slovakia and is practiced in strips parallel to the slope, structuring the production forest in longitudinal sections of beech cohorts of similar age and relatively high stem density, as the stands are normally thinned only about 10 years before final harvest (Green Report, 2009; Marušák, 2007). The rotation period is in most cases relatively short (typically 80-100 years) with the consequence that more than $90 \%$ of the Slovakian beech production forests are less than 100 years old (National Forest Centre, 2009).

While the primeval and managed stands had similar total basal areas $\left(32-43 \mathrm{~m}^{2} \mathrm{ha}^{-1}\right.$, stem density in Havešová and Stužica was markedly higher in the managed than in the primeval forests. Except for Kyjov, the quadratic mean stem diameter and dominant height were lower in the production forests (Table 2.2).

All six forests belong to the Fagetum dentarietosum glandulosae community (Bohn et al., 2003), with presence of a larger number of acidity- indicating species in the Kyjov stands on Dystric Cambisols. The canopy of the primeval forests in Havešová and Kyjov consisted nearly entirely of F. sylvatica (except for a few Acer pseudoplatanus L., Acer platanoides L. and Fraxinus excelsior L. trees), whereas the Stužica forest contained about $10 \%$ Abies alba MiLL. at elevations $>1000 \mathrm{~m}$ a.s.l. In the production forest of Kyjov about $94 \%$ of the canopy trees were beech. The production forests of Stužica and Havešová had higher proportions (23 and 39\%) of $A$. platanoides, A. pseudoplatanus, F. excelsior and other broad-leaved tree species. The beech trees in the primeval forests reached maximum ages of up to 400 years (R. Coventry, unpublished), while the trees in the production forests were cohorts of relatively similar age (ca. 90-100 years in Kyjov and Stužica and ca. 70 years in Havešová). The production forests were close to final 


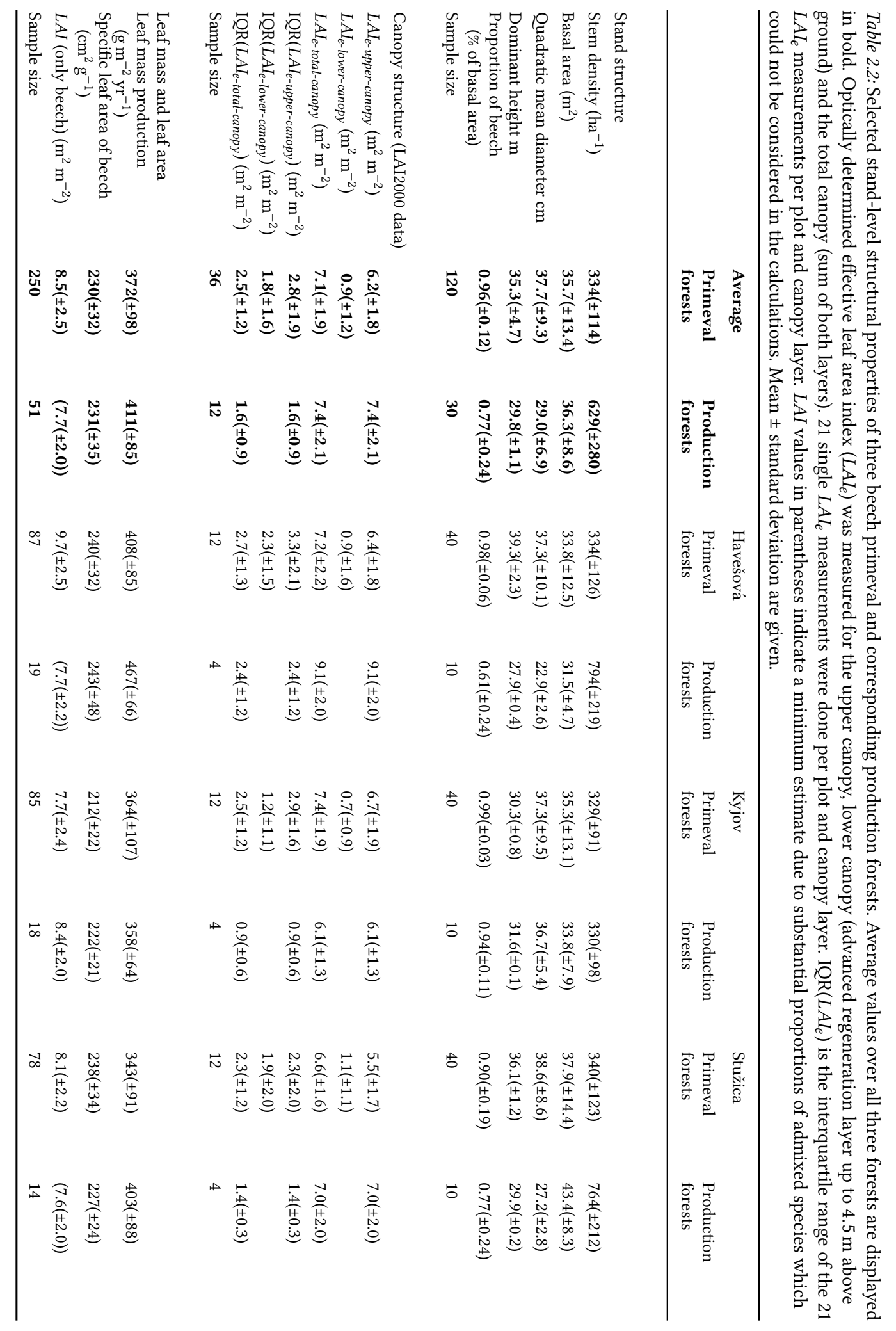


harvest and thus had reached their maximum biomass in the production cycle.

\subsubsection{Study design}

To analyze changes in canopy structure throughout the forest development cycle, research plots were first selected in each of the primeval forests and assigned to one of the three following main development stages: growth, optimal, or terminal stage. A regular grid was placed in each of the three primeval forests and 40 circular plots of $500 \mathrm{~m}^{2}$ size (25.24 $\mathrm{m}$ in diameter) were established on the grid nodes. Grid spacing was chosen so that the 40 plots were located within the reserves and no plot was within $100 \mathrm{~m}$ distance to the nearest reserve border. In the plots, basic stand structural parameters were recorded and used to assign each plot to one of the development stages (see below). Four plots per development stage and primeval forest were then selected for an in-depth analysis of canopy structure.

The production forests were smaller-sized than the primeval forests, therefore ten plots were selected in each and inventoried in the same manner as in the primeval forest plots. Again, four of the ten plots were selected for the analysis of canopy structure. This stratified random sampling approach ensured a precise quantification of basic stand structural parameters in all six forests and a balanced study design with equal representation of all development stages in the dataset for the analysis of canopy structure. Basic stand structural parameters were recorded in 150 plots in total: 40 plots per primeval forest and 10 plots per production forest. The in-depth canopy analysis was conducted in a subset of 48 plots: four plots per development stage and primeval forest and four plots per production forest. The minimum distance between two neighboring plots was defined by the size of the six forests. Grid spacing was $65 \mathrm{~m}$ in Kyjov, $100 \mathrm{~m}$ in Stužica, and $140 \mathrm{~m}$ in Havešová, but only $50 \mathrm{~m}$ in the three production forests.

Basic stand structural parameters were recorded in October 2013 and March/April 2014 in all 150 plots. All live and dead trees with a diameter at breast height $(D B H) \geq 7 \mathrm{~cm}$ in the plots were inventoried, and the following parameters were calculated at plot level: stem density, basal area, quadratic mean diameter at breast height, and dominant height (Table 2.2). Dominant height is the extrapolated height of the quadratic mean diameter of the $20 \%$ of trees with largest diameters. After measuring $D B H$ and height in a subsample of trees using a dendrometer tape 
and a Vertex IV height meter (Haglöf Sweden AB, Långsele, Sweden), the tree height of the remaining trees was extrapolated from $D B H$ with stand height curves established on the basis of the empirical data.

The assignment of the plots to development stages (DS) followed an approach developed by (Feldmann et al., 2018), which allows for the co-occurrence of different stages within a single plot, as is characteristic for beech primeval forests. To do so, every tree in a plot was assigned to one of three $D B H$ classes: $7-39.9 \mathrm{~cm}, 40-69.9 \mathrm{~cm}$ and $\geq 70 \mathrm{~cm}$. These $D B H$ classes were selected from a silvicultural point of view. The first diameter class contains premature trees, the second mature trees of harvestable size in production forests, and the third large trees of a size not found in production forests. The diameter classes are thought to be characteristic of the growth, optimal and terminal stages, respectively.

We calculated a dominance index $\operatorname{dom}_{D S i}$ for the different development stages present in a plot and compared their relative importance by relating the abundance of trees of the corresponding $D B H$ class in this plot to the $85 \%$ quantile of the respective abundances in all plots of a primeval forest $(\mathrm{n}=40)$. The $85 \%$ quantile was chosen as a robust measure of the abundance of a development stage in the forest when it dominated a plot nearly exclusively.

To express the importance of a development stage in a plot, we averaged over two measures of stand density for the trees in the respective diameter class: stem density $\left(t n_{D S i}\right.$, in $\left.\mathrm{n} \mathrm{ha}{ }^{-1}\right)$ and stem volume $\left(\right.$ vol $_{D S i}$, in $\left.\mathrm{m}^{3}\right)$. Subsequently, the relative dominance $\left(\operatorname{dom}_{D S i}\right)$ of a development stage in a plot was obtained from

$$
\operatorname{dom}_{D S i}=\frac{1}{2}\left(\frac{v o l_{D S i}}{v o l_{D S_{0.85}}}+\frac{t n_{D S i}}{t n_{D S_{0.85}}}\right) \text { for all plots } i \text { with } i \in\{1,2,3, \ldots, \mathrm{n}\}
$$

The development stage with highest relative dominance in terms of stem density and wood volume was then taken to define the prevalent (quantitatively most important) stage of that plot. Apart from assigning the plots to development stages, dom $_{D S}$ was also used as a covariate in linear regression models to explore its direct influence on canopy structure. 


\subsubsection{Canopy structural analysis with the LAI2000 system}

In all 48 plots, gap fraction measurements were carried out by synchronously operating two LAI2000 Plant Canopy Analyzers (LiCor, Lincoln, NE, USA). One sensor was placed in the center of a large forest gap (at least $100 \mathrm{~m}$ in diameter) to estimate above-canopy radiation, while the second one was used to measure below-canopy radiation at several positions in the plots. The quotient of above- and below-canopy radiation intensity (transmission coefficient) was taken as an approximation of canopy gap fraction. The measurements were taken systematically along two $15 \mathrm{~m}$-long transects in the plots, which were placed perpendicular to each other. One instrument reading was taken every $1.5 \mathrm{~m}$, resulting in 21 sampling points per plot (the central point with crossing transects was measured only once). On each sampling point, two readings were taken: one $30 \mathrm{~cm}$ above ground and a second one above the regeneration layer, if present. For the latter measurements, a $3 \mathrm{~m}$-long pole was used which allowed a maximal measuring height of $4.5 \mathrm{~m}$. This procedure allowed gap fractions to be calculated for three different canopy layers:

1. $P_{0-u p p e r-c a n o p y}\left(P_{0-u p}\right)$ : gap fraction of the upper canopy layer without regeneration;

2. $P_{0-\text { total-canopy }}\left(P_{0-t o t}\right):$ gap fraction of the whole canopy;

3. $P_{0-\text { lower-canopy }}\left(P_{0-\text { low }}=P_{0-\text { total-canopy }} / P_{0-\text { upper-canopy }}\right)$ : gap fraction of the advanced regeneration layer.

\section{Calculation of effective leaf area index $\mathrm{LAI}_{e}$}

Inversion models were used to estimate effective leaf area index $\left(L A I_{e}\right)$ from the measured gap fraction according to the equation of Miller (1967):

$$
L A I_{e}=-2 \int_{0}^{\pi / 2} \ln P_{0}(\Theta) \cos \Theta \sin \Theta \mathrm{d} \Theta
$$

with $P_{0}$ being gap fraction and $\Theta$ the zenithal angle of the gap fraction measured. The underlying model makes several assumptions about canopy structure, notably random distribution of canopy elements in the crown space, which are rarely met in natural stands. Clumping of leaves 
at spatial scales smaller than the sensor field of view results in underestimation of the true leaf area, because leaves are shaded by others more than is expected from a random distribution (Nilson, 1971). Clumping at scales larger than the sensor field of view can be considered in the LAI calculation by using the average of the logarithm of all gap fraction estimates in Eq. 2.2; we adopted this logarithm averaging method and refer to the calculated leaf area indices as effective $L A I$ ( $L A I_{e}$; Chen et al., 1991 and Jonckheere et al., 2004 for more details).

Since stand density, canopy structure, and the associated $L A I$ change in primeval forests at small scales, we restricted the field of view of the LAI2000 Analyzer by using only the innermost ring of the instrument for analysis, which reduces the maximal zenithal angle to $12.3^{\circ}$ and the top radius at $40 \mathrm{~m}$ to be considered in the analysis to $8.72 \mathrm{~m}$. This has the consequence that only sectors of the canopy in direct vicinity of the plot center were considered in the calculation of $L A I_{e}$.

\section{Analysis of canopy heterogeneity}

To quantify the small-scale canopy heterogeneity, as resulting from the presence of multiple leaf layers and the existence of small and large gaps, we used the interquartile range of all 21 $L A I_{e}$ measurements in a plot (IQR $\left.\left(L A I_{e}\right)\right)$. This measure expressed the small-scale diversity of light regimes and estimated leaf area densities in the stand. We preferred the IQR over other measures of dispersion such as standard deviation, the coefficient of variation or the absolute range of values because of its smaller sensitivity to outliers.

Using this measure of dispersion for quantifying canopy heterogeneity with the LAI2000 system presents a scaling problem due to variable canopy heights. The opening angle of the system's sensor causes the spatial scale to increase with increasing height above the sensor. In low canopies, even small gaps are sufficient to cover a large part of the sensor field of view. In tall canopies, gaps have to be much wider to cause similar transmission estimates. The opposite effect is generated beneath very dense canopy patches, which can be of much smaller size in low canopies to cause individual very high $L A I_{e}$ records. If the sample size is large enough, there will be no biasing effect when calculating average $L A I_{e}$. Nevertheless, measures of dispersion like the $\operatorname{IQR}\left(L A I_{e}\right)$ will be larger in low-stature stands than in tall ones, given that all other 
structural properties are the same. To account for this bias, we weighted the $\operatorname{IQR}\left(L A I_{e}\right)$ of the upper and the total canopy (sum of upper and lower layer) by the dominant height of the plot divided by the average dominant height of all primeval forest plots $(36.1 \mathrm{~m})$. In the calculation of the $\operatorname{IQR}\left(L A I_{e}\right)$ of the lower canopy (regeneration layer), dominant height was not considered, as the measurements refer to only $3-4 \mathrm{~m}$ above ground.

\section{LAI derived from litter trapping}

To record $L A I$ values with an independent method not affected by foliage clumping, we used data from litter traps with a circular opening of $60 \mathrm{~cm}$ diameter $\left(2826 \mathrm{~cm}^{2}\right)$. As we assumed a higher heterogeneity of litter production in the primeval forests, we set up 30 traps in a regular grid in each primeval forest and 10 traps in each production forest.

The litter collected in the traps in the spatially heterogeneous primeval forests cannot be reliably assigned to a specific plot or development stage. Thus, we arranged the traps in a systematic grid to obtain average litter mass estimates for the whole stand but did not attempt to distinguish between the different forest development stages in the stand. As a consequence, the litter trap locations did not necessarily coincide with the position of the tree inventory plots.

Leaf litter was collected from the traps in December of the years 2013 to 2015 in the primeval forests and in 2014 and 2015 in the production forests. The litter was subsequently sorted by species and litter type (leaves/fruits), oven-dried for $48 \mathrm{~h}$ at $70^{\circ} \mathrm{C}$ and weighed. Fifty randomly selected beech leaves per trap were scanned and weighed separately to determine mean specific leaf area (SLA, ratio of leaf area to dry mass $\left.\left(\mathrm{cm}^{2} \mathrm{~g}^{-1}\right)\right)$ of the beech foliage.

$S L A$ and total leaf mass of the litter samples were used to calculate the LAI. In the case of non-beech leaves in the traps, a correction factor derived from the relative basal area of the admixed species was applied for estimating the $L A I$ of a hypothetical pure beech stand. This was necessary especially in the primeval forest of Stužica with a basal area share of A. alba of $10 \%$. In case of the production forests in Stužica and Havešová, we refrained from extrapolating to a monospecific beech forest because the proportions of other trees species were too high. 


\subsubsection{Statistical analysis}

To identify possible determinants of $L A I_{e}$, we conducted two types of data analysis. In the first, we quantified direct effects of management and development stage on $L A I_{e}$ by accounting for potential indirect effects of a variable stand structure (stem density, basal area) using generalized linear models (GLMs) and a bidirectional selection procedure for covariates to identify the best model according to the AIC. To avoid multicollinearity, all numeric covariates with a variance inflation factor higher than three were dropped from the models (Zuur et al., 2010). This procedure led to the exclusion of the factors dominant height and quadratic mean diameter as structural parameters from all analyses, because their relation to stem density and basal area was too tight $\left(\mathrm{r}^{2}>0.8\right)$.

The second approach quantified the cumulative impact of direct and indirect effects on the canopy structure (Figs. 2.1 and 2.3). GLMs were used as well, but only the categorical covariates describing management, forest development stage, and study area were used to fit the models and no parameter selection procedure was applied. We report the results separately for each study area and for the pooled data of the three sites. Confidence intervals of group means and adjusted p-values were calculated with the R-package multcomp (Hothorn et al., 2008). For single group comparisons between production and primeval forests, the single-step method was applied. To test for significant differences between any of the possible combinations of the three development stages, global F-tests were used, again applied to each study area separately and to the pooled data. Adjustment of p-values due to multiple testing was done with the Bonferroni-Holm method.

Depending on the distribution of model residuals, GLMs of the Gaussian or the gamma family type with identity links were used in both approaches. All analyses were conducted with $\mathrm{R}$ software version 3.3.1 (R Core Team, 2016) using a confidence level of 0.95 throughout. 


\subsection{Results}

\subsubsection{LAI from litter trapping}

Litter trapping gave an average $8.5 \mathrm{~m}^{2} \mathrm{~m}^{-2}$ in the primeval forests (range of annual means in the different forests: $6.2-10.6 \mathrm{~m}^{2} \mathrm{~m}^{-2}$; Table 2.2 and Figure 2.A1). Differences between sites and years were caused by variation in both leaf mass production (range of plot means: $301-460 \mathrm{~g} \mathrm{~m}^{2}$ ) and SLA of beech (range: $199-276 \mathrm{~cm}^{2} \mathrm{~g}^{-1}$ ). Both parameters varied independently from each other across sites and years.

Litter trapping in the production forests in 2014 and 2015 gave $L A I$ values of 7.8 and $8.8 \mathrm{~m}^{2} \mathrm{~m}^{-2}$ in Kyjov, which are similar to the figures from the nearby primeval forests. In the stands in Havešová and Stužica with significant contribution of Acer pseudoplatanus, A. platanoides and $F$. excelsior, the measured LAIs for beech $\left(6.9-8.5 \mathrm{~m}^{2} \mathrm{~m}^{-2}\right)$ were underestimates of the total leaf area index.

The optically determined $L A I_{e}$ underestimated the $L A I$ calculated from litter trapping by ca. $25 \%$ (see Appendix and Fig. 2.A1 for more details).

\subsubsection{Relationships between parameters characterizing the canopy structure}

The $L A I_{e}$ values of the upper canopy and of the total canopy (including regeneration layer) were significantly correlated to each other $(r=0.78, \mathrm{p}<0.001$; Table 2.3$)$, but not to any of the other $L A I_{e}$-related parameters. A higher light transmission of the upper canopy layer did not result in a higher effective leaf area of the lower canopy layer $(r=-0.29, p=0.74)$, when analyzed across the whole data set. However, a significant relationship was found for the dependence of the lower canopy $L A I_{e}$ on the $L A I_{e}$ heterogeneity of the lower $(\mathrm{r}=0.71, \mathrm{p}<0.001)$ and the upper canopy $(\mathrm{r}=0.66, \mathrm{p}<0.001)$, i.e., the regeneration layer produced a greater $L A I_{e}$ when canopy and understory were more heterogeneous. The heterogeneity of $L A I_{e}$ of the lower and the total canopy were significantly related to each other $(r=0.48, p=0.048)$. The leaf area of the regeneration layer (lower canopy) contributed with on average $13 \%(0-54 \%)$ to the $L A I_{e}$ stand total. 
Table 2.3: Pearson correlation coefficients $r$ (below main diagonal) and p-values (above main diagonal) of the relationships between three optically determined $L A I_{e}$ parameters and their spatial heterogeneity (interquartile range, $\operatorname{IQR}\left(L A I_{e}\right)$ in the three studied beech primeval forests $(\mathrm{n}=36$ measurements per stand). Adjustment of $\mathrm{p}$-values for multiple comparisons were done with permutation resampling. Significant relationships are displayed in bold.

\begin{tabular}{lllllll}
\hline & $L A I_{e-\text { up }}$ & $L A I_{e-\text { low }}$ & $L A I_{e-\text { tot }}$ & $\operatorname{IQR}\left(L A I_{e-u p}\right)$ & $\operatorname{IQR}\left(L A I_{e-\text { low }}\right)$ & $\operatorname{IQR}\left(L A I_{e-t o t}\right)$ \\
\hline$L A I_{e-\text { upper-canopy }}$ & & $\mathrm{p}=0.74$ & $\mathbf{p}<\mathbf{0 . 0 0 1}$ & $\mathrm{p}=1.00$ & $\mathrm{p}=1.00$ & $\mathrm{p}=1.00$ \\
LAI $_{\text {e-lower-canopy }}$ & -0.29 & & $\mathrm{p}=0.34$ & $\mathbf{p}<\mathbf{0 . 0 0 1}$ & $\mathbf{p}<\mathbf{0 . 0 0 1}$ & $\mathrm{p}=0.61$ \\
LAI $_{\text {e-total-canopy }}$ & $\mathbf{0 . 7 8}$ & 0.37 & & $\mathrm{p}=0.28$ & $\mathrm{p}=0.37$ & $\mathrm{p}=1.00$ \\
$\operatorname{IQR}\left(L A I_{e-\text { upper-canopy }}\right)$ & -0.04 & $\mathbf{0 . 6 6}$ & 0.38 & & $\mathbf{p}<\mathbf{0 . 0 0 1}$ & $\mathbf{p}<\mathbf{0 . 0 0 1}$ \\
$\operatorname{IQR}\left(L A I_{\text {e-lower-canopy }}\right)$ & -0.09 & $\mathbf{0 . 7 1}$ & 0.36 & $\mathbf{0 . 6 8}$ & & $\mathbf{p}=\mathbf{0 . 0 5}$ \\
$\operatorname{IQR}\left(L A I_{\text {e-total-canopy }}\right)$ & -0.12 & 0.32 & 0.09 & $\mathbf{0 . 6 5}$ & $\mathbf{0 . 4 8}$ & \\
\hline
\end{tabular}

\subsubsection{Influence of management on $\mathrm{LAI}_{e}$ and its heterogeneity}

Two of the production forests had a much higher stem density than the nearby primeval forests and this structural difference influenced $L A I_{e}$ positively $(\beta=1.6$ and 1.4 for upper and lower canopy, respectively; $\mathrm{p}<0.001$; Table 2.4 ). In contrast to stem density, stand basal area had no significant influence on $L A I_{e}$ and thus was dropped from the models. The $L A I_{e}$ of the upper canopy differed significantly between the three sites (significant effect of region in the model). By accounting for stand structural effects, the model predicted a by $1.6 \mathrm{~m}^{2} \mathrm{~m}^{-2}$ lower $L A I_{e}$ (total canopy) of the production forests as compared to the primeval forests ( $p=0.03)$. In the upper canopy, in contrast, the predicted $L A I_{e}$ reduction by $1.0 \mathrm{~m}^{2} \mathrm{~m}^{-2}$ from the primeval to the production forests was not significant $(\mathrm{p}=0.1)$.

Opposing effects of stem density and management resulted in only small differences between the $L A I_{e}$ means of the primeval and production forests (Fig. 2.1A and B).

In the regions Havešová and Stužica, the average $L A I_{e}$ (upper canopy) and $L A I_{e}$ (total canopy) tended to be higher in the production forests than in the primeval forests, which contrasts with the situation in Kyjov. Differences between primeval and production forests were significant only for the upper canopy in Havešová ( $\mathrm{p}=0.03 ; L A I_{e}$ higher in production forest). Across all sites, the upper canopy $L A I_{e}$ of the production forests tended to be somewhat higher (by $1.2 \mathrm{~m}^{2} \mathrm{~m}^{-2}$ ) than that of the primeval forests, but the difference was not significant.

The spatial heterogeneity of leaf area in the canopy as expressed by the interquartile ranges 
Table 2.4: Influence of stand structural parameters (stem density, basal area per plot), region, and management (production vs. primeval forest) on the $L A I_{e}$ and its spatial heterogeneity (interquartile range, $\operatorname{IQR}\left(L A I_{e}\right)$ ) analyzed with GLMs. F and p-values and standardized regression coefficients $(\beta)$ of the covariates are given. Only covariates with a positive influence on the AIC were considered in the models. Factor levels are abbreviated by first letters for the three regions (Havešová, Kyjov, Stužica) and management type (Primeval, Production forest). Degrees of freedom are denoted by $\mathrm{dfm}$ (model) and dfe (error). Significant relationships are displayed in bold.

\begin{tabular}{|c|c|c|c|c|}
\hline \multirow[t]{2}{*}{ Regressor } & \multicolumn{4}{|c|}{ Model covariates } \\
\hline & & $\mathrm{F}(\mathrm{dfm} / \mathrm{dfe})$ & $\mathrm{p}$ & $\beta$ \\
\hline \multicolumn{5}{|l|}{ Canopy density } \\
\hline \multirow[t]{3}{*}{$L A I_{e-\text { upper-canopy }}$} & Stem density & $30.27(1,43)$ & $<0.001$ & 1.6 \\
\hline & Region & $5.03(2,43)$ & 0.011 & H: $0, K: 0.59, S:-1.07$ \\
\hline & Management & $2.72(1,43)$ & 0.106 & Prim: 0, Prod: -1.04 \\
\hline \multirow[t]{3}{*}{$L A I_{e-t o t a l-c a n o p y}$} & Stem density & $17.07(1,43)$ & $<0.001$ & 1.37 \\
\hline & Region & $2.07(2,43)$ & 0.139 & $\mathrm{H}: 0, \mathrm{~K}: 0.34, \mathrm{~S}:-0.85$ \\
\hline & Management & $4.91(1,43)$ & 0.032 & Prim: 0, Prod: $\mathbf{- 1 . 6 0}$ \\
\hline \multicolumn{5}{|l|}{ Canopy heterogeneity } \\
\hline \multirow[t]{3}{*}{$\operatorname{IQR}\left(L A I_{e-u p p e r-c a n o p y}\right)$} & Basal area & $4.42(1,44)$ & 0.041 & -0.47 \\
\hline & Stem density & $2.09(1,44)$ & 0.156 & 0.35 \\
\hline & Management & $6.88(1,44)$ & 0.012 & Prim: 0, Prod: $\mathbf{- 1 . 9 0}$ \\
\hline \multirow[t]{3}{*}{$\operatorname{IQR}\left(L A I_{e-t o t a l-c a n o p y}\right)$} & Basal area & $2.32(1,43)$ & 0.135 & -0.23 \\
\hline & Region & $2.77(2,43)$ & 0.074 & $\mathrm{H}: 0, \mathrm{~K}:-0.91, \mathrm{~S}:-0.43$ \\
\hline & Management & $11.25(1,43)$ & 0.002 & Prim: 0, Prod: -1.16 \\
\hline
\end{tabular}

$\left(\operatorname{IQR}\left(L A I_{e}\right)\right)$ for upper and total canopy in the plots showed significant effects of management (i.e., the primeval forest - production forest contrast) and basal area, but not of stem density. An increase in basal area decreased the $L A I_{e}$ heterogeneity in both the upper canopy $(\beta=-0.5$, $\mathrm{p}=0.04$ ) and the total canopy (not significant, $\beta=-0.2, \mathrm{p}=0.1$ ). By accounting for stand structural effects, the model predicted a reduction in $L A I_{e}$ heterogeneity (lower $\left.\operatorname{IQR}\left(L A I_{e}\right)\right)$ ) by $1.2 \mathrm{~m}^{2} \mathrm{~m}^{-2}(\mathrm{p}=0.002)$ of the total canopy in the production forests as compared to the primeval forests. When only the upper canopy is considered, a reduction of $1.9 \mathrm{~m}^{2} \mathrm{~m}^{-2}(\mathrm{p}=0.01)$ of the $\operatorname{IQR}\left(L A I_{e}\right)$ was predicted. The $L A I_{e}$ heterogeneity across the plots was not different between the three sites (no significant region effect in the models).

When stand structure is not accounted for in the models, the $\operatorname{IQR}\left(L A I_{e}\right)$ values (all three regions pooled) were significantly larger in the primeval forests than in the production forests 
A

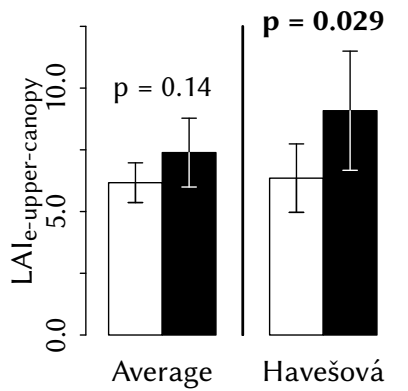

C

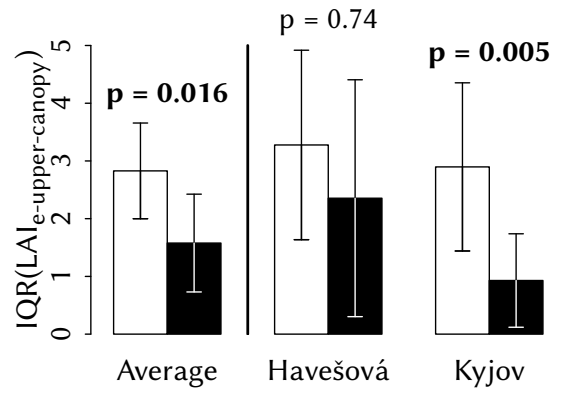

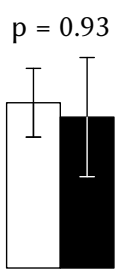

Kyjov

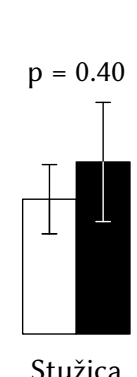

Stužica

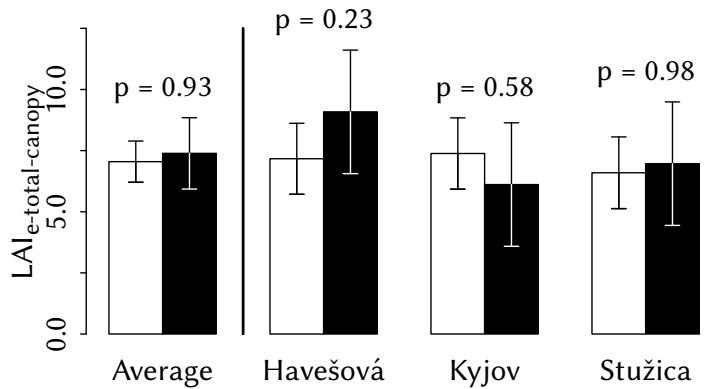

D
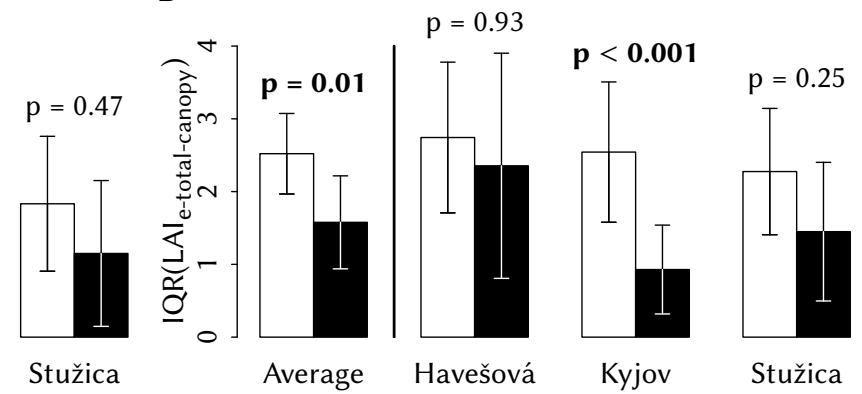

Figure 2.1: Effective leaf area index ( $L A I_{e}$, upper panels) and its spatial heterogeneity (interquartile range, $\left.\operatorname{IQR}\left(L A I_{e}\right)\right)$, lower panels) in three primeval (white bars) and corresponding production beech forests (black bars). Left panels represent the upper canopy (without advanced regeneration); right panels represent the total canopy. 21 single optical $L A I_{e}$ measurements were done per plot and canopy layer with a $L A I 2000$ system. $\operatorname{IQR}\left(L A I_{e}\right)$ is the interquartile range of the $21 L A I_{e}$ measurements per plot and canopy layer. Significant relationships between corresponding primeval and production forests are displayed with bold p-values. Sample sizes are 12 plots per primeval and 4 plots per production forest (36 and 12 plots for the average).

$\left(\mathrm{IQR}\left(L A I_{e}\right)\right)$ difference: 1.25 and $0.94 \mathrm{~m}^{2} \mathrm{~m}^{-2}$ for upper and total canopy; $\mathrm{p}$-value: 0.02 and 0.01 ;

Fig. 2.1C and D). However, when the regions were considered separately, the differences in heterogeneity between primeval and production forests were only significant in Kyjov $(p=0.006$ for upper and $\mathrm{p}<0.001$ for lower canopy).

\subsection{4 $\mathrm{LAI}_{\mathrm{e}}$ and canopy structural heterogeneity in the different forest development stages}

We used the relative dominance of a forest development stage in a plot (expressed by the dominance index; $\left.d o m_{D S i}\right)$ as a covariate in models exploring the influence of the development stage (growth, optimal and terminal stages) on $L A I_{e}$. The dominance index of the 'growth stage' correlated with the stem density in the plots and thus the variance inflation factor exceeded 3 , 
Table 2.5: Influence of stand structural parameters (stem density, basal area), region and the terminal index (abundance of the terminal stage in the plots as expressed by the terminal index) on the $L A I_{e}$ and its spatial heterogeneity (interquartile range, $\operatorname{IQR}\left(L A I_{e}\right)$ in the three primeval forests according to analyses with GLMs. F and p-values and standardized regression coefficients $(\beta)$ of the covariates are given. Only covariates with a positive influence on the AIC were considered in the models. Factor levels are abbreviated by first letters for the three regions (Havešová, Kyjov, Stužica). Degrees of freedom are denoted by dfm (model) and dfe (error). Significant relationships are displayed in bold.

\begin{tabular}{|c|c|c|c|c|}
\hline \multirow[t]{2}{*}{ Regressor } & \multicolumn{4}{|l|}{ Model covariates } \\
\hline & & $\mathrm{F}(\mathrm{dfm} / \mathrm{dfe})$ & $\mathrm{p}$ & $\beta$ \\
\hline \multicolumn{5}{|l|}{ Canopy density } \\
\hline \multirow[t]{2}{*}{$L A I_{\text {e-upper-canopy }}$} & Stem density & $14.09(1,32)$ & $<\mathbf{0 . 0 0 1}$ & 0.98 \\
\hline & Region & $2.85(2,32)$ & 0.073 & $\mathrm{H}: 0, \mathrm{~K}: 0.48, \mathrm{~S}:-0.99$ \\
\hline \multirow[t]{2}{*}{$L A I_{e-\text { lower-canopy }}$} & Basal area & $4.77(1,33)$ & 0.036 & -0.42 \\
\hline & Terminal index & $11.77(1,33)$ & 0.002 & 0.47 \\
\hline \multirow[t]{3}{*}{$L A I_{e-\text { total-canopy }}$} & Basal area & $2.48(1,32)$ & 0.125 & -0.5 \\
\hline & Stem density & $10.71(1,32)$ & 0.003 & 1 \\
\hline & Terminal index & $7.57(1,32)$ & 0.01 & 0.92 \\
\hline \multicolumn{5}{|l|}{ Canopy heterogeneity } \\
\hline \multirow[t]{2}{*}{$\operatorname{IQR}\left(L A I_{\text {e-upper-canopy }}\right)$} & Basal area & $7.27(1,33)$ & 0.011 & -0.84 \\
\hline & Terminal index & $9.25(1,33)$ & 0.005 & 0.95 \\
\hline \multirow[t]{2}{*}{$\operatorname{IQR}\left(L A I_{\text {e-lower-canopy }}\right)$} & Region & $2.42(2,32)$ & 0.105 & $\mathrm{H}: 0, \mathrm{~K}:-1.23, \mathrm{~S}:-0.61$ \\
\hline & Terminal index & $5.31(1,32)$ & 0.028 & 0.56 \\
\hline $\operatorname{IQR}\left(L A I_{\text {e-total-canopy }}\right)$ & Stem density & $2.29(1,34)$ & 0.14 & -0.25 \\
\hline
\end{tabular}

which led us to exclude the factor 'growth stage' from further analysis. The dominance indices of the 'optimal' and 'terminal stages' were related to each other, and their influence on the canopy thus had to be analyzed with separate models. The models for the optimal stage showed no significant influence of the index on canopy structure (results not shown).

The largest direct influence on canopy structure, when analyzed together with other stand structural parameters (stem density, basal area), was exerted by the dominance index of the terminal stage (Table 2.5). The models show that the $L A I_{e}$ of the total canopy and that of the lower canopy (regeneration layer) increased significantly with a higher dominance of the terminal stage ( $\mathrm{p}=0.002$ and 0.01 ), i.e., by $1.2 \mathrm{~m}^{2} \mathrm{~m}^{-2}$ in the total canopy and by $0.6 \mathrm{~m}^{2} \mathrm{~m}^{-2}$ in the lower canopy from plots with low to plots with high dominance of the terminal stage (Fig. 
A
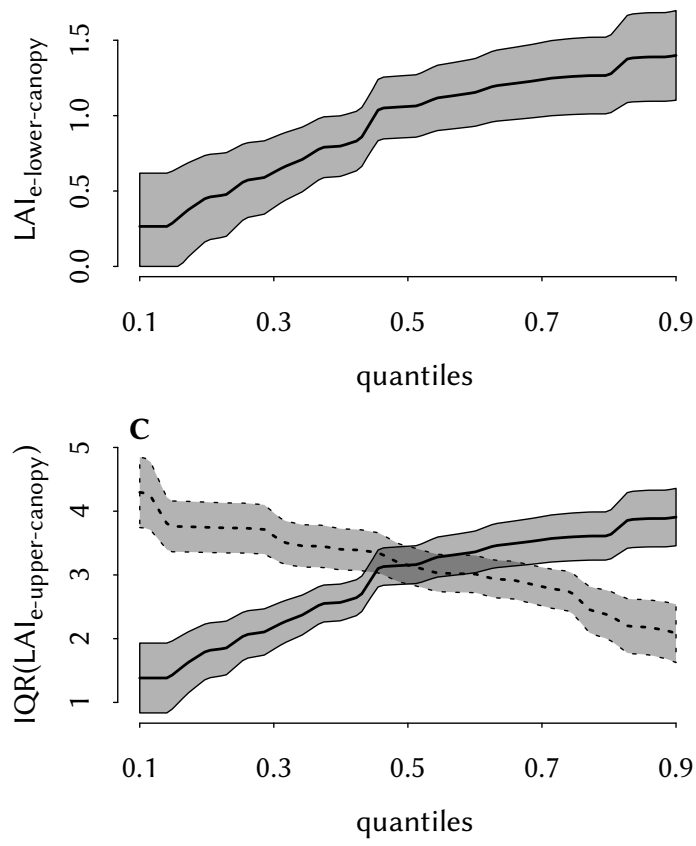

B

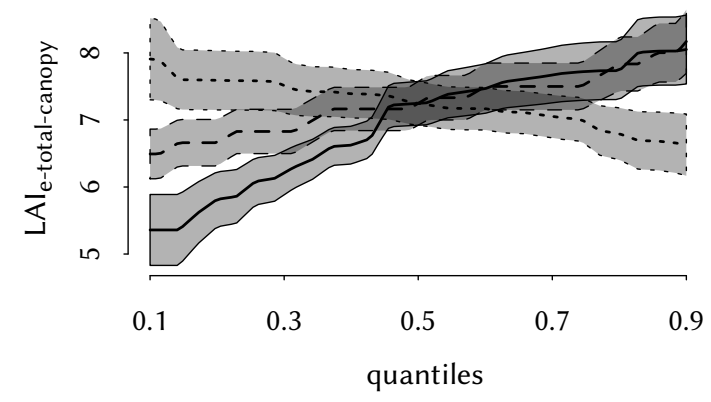

D

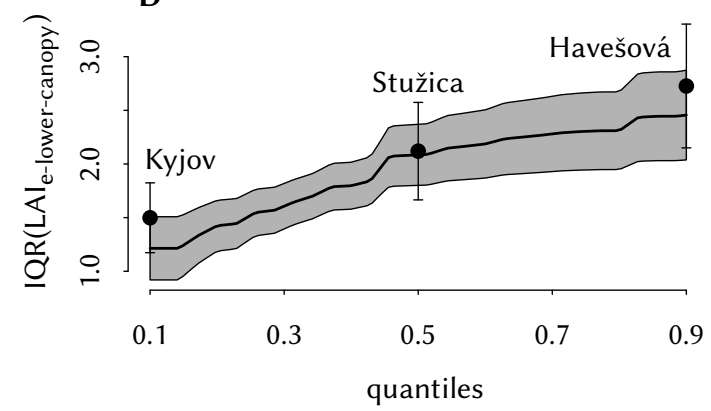

Figure 2.2: Influence of structural parameters (basal area - dotted; stem density - dashed), terminal index (abundance of the terminal stage in the plots as expressed by the terminal dominance index - solid) and region (points) on the $L A I_{e}$ of the lower canopy (A) or total canopy (B), and the spatial heterogeneity of $L A I_{e}$ (interquartile range, $\left.\operatorname{IQR}\left(L A I_{e}\right)\right)$ of the upper (C) and lower canopy (D). Graphical illustration of the output of four of the models (GLMs) in Table 2.5. The graphs display the predicted influence of individual covariates (basal area, stem density, region and terminal index) on $L A I_{e}$ and $\mathrm{IQR}\left(L A I_{e}\right)$. Model coefficients were used to predict the expected value of the respective response variable ( $y$-axis) for different combinations of the covariates. Model predictions were calculated for the range of all observed values of the respective focal covariate (quantiles, $\mathrm{x}$-axis). For all other covariates than the focal one their median was used to calculate the predictions. The point where all lines cross is the parameter combination where all covariates are at their median. Shaded areas show the standard error of the predictions.

2.2). Similarly, the $L A I_{e}$ variability $\left(\operatorname{IQR}\left(L A I_{\text {-upper-canopy }}\right)\right.$ and $\left.\operatorname{IQR}\left(L A I_{\text {e-lower-canopy }}\right)\right)$ increased significantly (by 1.3 and $0.8 \mathrm{~m}^{2} \mathrm{~m}^{-2}, \mathrm{p}=0.005$ and 0.03 ) with a higher dominance of the terminal stage.

A surprising result is that the average leaf area indices $\left(L A I_{\text {e-upper-canopy }}, L A I_{\text {e-total-canopy }}\right)$ did not change from the growth to the optimal and the terminal stages in the three primeval forests (Fig. 2.3A-C).

In Stužica, we found a non-significant increase in the $L A I_{e}$ of the regeneration layer from the growth to the terminal stage. Similarly, the spatial heterogeneity of $L A I_{e} \operatorname{did}$ not change systematically across the forest development cycle; a nonsignificant trend to higher $\operatorname{IQR}\left(L A I_{e}\right)$ 

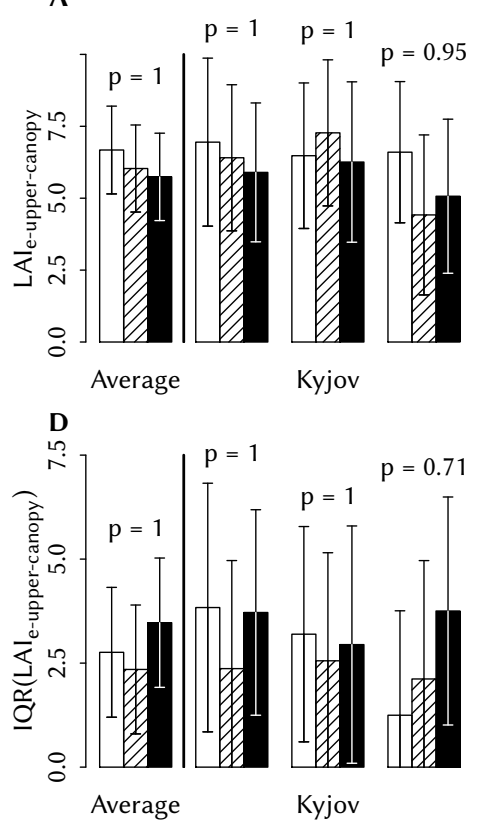

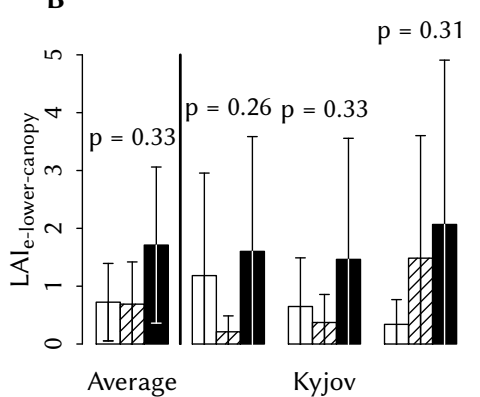

E

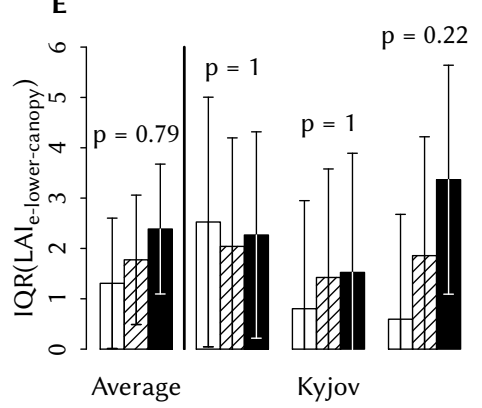

C

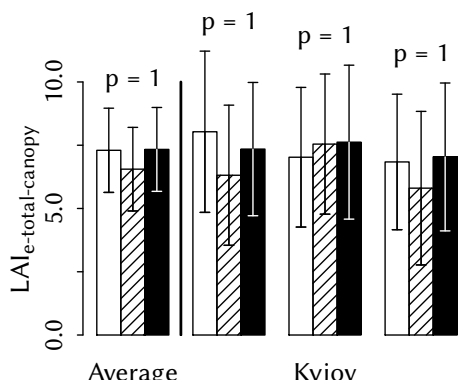

$\mathbf{F}$

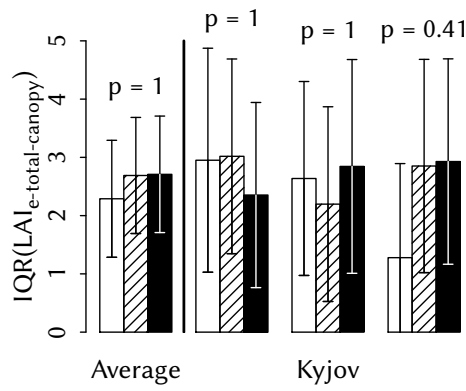

Figure 2.3: Effective leaf area index ( $L A I_{e}$, upper panels) and its spatial heterogeneity $\left(\mathrm{IQR}\left(L A I_{e}\right)\right.$, lower panels) in three development stages of three beech primeval forests (growth stage - white bars, optimal stage - hatched bars, terminal stage black bars). Left panels represent the upper canopy; middle panels represent the lower canopy (advanced regeneration layer up to $4.5 \mathrm{~m}$ above ground); right panels represent the total canopy (sum of both layers). 21 single optical LAI e measurements were done per plot and canopy layer with a LAI2000 system. $\operatorname{IQR}\left(L A I_{e}\right)$ is the interquartile range of the $21 L A I_{e}$ measurements per plot and canopy layer. None of the differences were significant at $\mathrm{p}<0.05$. Sample sizes were 4 plots per development stage and region (12 plots per development stage for the average).

values in the terminal stage was observed in Stužica (Fig. 2.3D-F).

\subsection{Discussion}

\subsubsection{The LAI of beech forests and its measurement}

With an average $L A I$ of $8.5 \mathrm{~m}^{2} \mathrm{~m}^{-2}$ in the primeval forests, our litter trapping data from montane beech forests are very similar to previously reported leaf areas for F. sylvatica forests (range 5.0-8.45 $\mathrm{m}^{2} \mathrm{~m}^{-2}$ ) (Bartelink, 1997; Chianucci et al., 2015; Leuschner et al., 2006; Meier and Leuschner, 2008; Leuschner and Ellenberg, 2017). This is also valid for our optical $L A I_{e}$ data (7.1 and $7.4 \mathrm{~m}^{2} \mathrm{~m}^{-2}$ in the primeval and production forests), which exceeded the data of other 
studies based on optical methods (LAIs of 3-6 $\mathrm{m}^{2} \mathrm{~m}^{-2}$ ) as well (Bequet et al., 2011; Chianucci et al., 2015; Lukasová et al., 2014). However, comparison with these studies is often difficult, because a variety of methodological approaches have been applied (Beckschäfer et al., 2013; Chason et al., 1991; Chianucci et al., 2015; Dufrêne and Bréda, 1995). Since high LAIs were found not only in the primeval forests but also in the production forests, we speculate that the montane elevation with its humid climate (Spinoni et al., 2015) favoring beech might be one factor causing particularly large leaf areas in our stands. The authors of previous studies on beech leaf area often included lower montane or lowland forests in their samples, where the precipitation regime and air humidity conditions are generally less favorable.

\subsubsection{The influence of forest management on $\mathrm{LAI}_{\mathbf{e}}$}

We found a non-significant tendency for a slightly higher leaf area index in the production forests than in the primeval forests, which is caused by particularly high $L A I_{e}$ values in the production forests in Havešová and Stužica (but not in Kyjov). In accordance, leaf biomass production was generally higher in the production forests (means of 411 and $372 \mathrm{~g} \mathrm{~m}^{-2}$ for production and primeval forests over all sites and years). According to the models, which explored the effects of stand structure and management on $L A I_{e}$, this was a result of the high stem density in the two aforementioned production forests. The Slovakian beech forest management system generates tree cohorts in which stem densities remain high until harvest $\left(>750 \mathrm{ha}^{-1}\right)$ in Havešová and Stužica compared to $\sim 330 \mathrm{ha}^{-1}$ in the primeval forests).

In agreement with earlier studies (Bequet et al., 2011; Le Dantec et al., 2000), our modeling analysis revealed a positive relationship between stem density and $L A I_{e}$. This can be explained by enhanced competition for light in such dense stands, demanding optimal utilization of the available light by trees of similar age and size. In addition, stands of younger trees of smaller size often have higher LAIs than older stands with larger individuals (Mund et al., 2002; Nock et al., 2008; Oren and Zimmermann, 1989), which is supported by the very high LAIs $\left(>15 \mathrm{~m}^{2} \mathrm{~m}^{-2}\right)$ measured by Konôpka et al. (2016) in 12-14 yr-old beech stands in southern Slovakia. Thus, both ontogeny and high competition intensity are likely explanations of the particularly high $L A I_{e}$ values in the two production forests with high stem density. 
Besides the stem density effect, stand management for timber production itself was identified as an important determinant of $L A I_{e}$ with a clear negative effect on leaf area. Accordingly, at equal stem densities, primeval forests with their complex, multi-layered canopies achieve higher effective leaf area indices than production forests with a simpler canopy structure. This canopy structure effect is observed despite a likely greater leaf clumping in the heterogeneous primeval forest canopy, which should reduce measured $L A I_{e}$. Model results and the data from the Kyjov site indicate that the larger canopy volume in the primeval forests in which leaves and branches can be arranged may promote the formation of larger leaf areas, in particular by extending the shade foliage in multi-layered canopies. A detailed empirical analysis of stand leaf area by functional leaf types is needed to test this hypothesis.

Indeed, one of the most striking effects of forest management in our study was a reduction in canopy structural heterogeneity, as reflected in the decrease in $\operatorname{IQR}\left(L A I_{e}\right)$ by ca. $40 \%$ from the primeval to the production forests. This figure was derived for the specific management regime practiced in Slovakian beech forests, it may be different in other types of forest management. In our study, the practice of forest management with the creation of tree cohorts was the single most important factor determining the heterogeneity of leaf area; this factor exceeded the influence of basal area and stem density (not significant). Other more invasive techniques of forest management such as regular selection cutting may well create a more heterogeneous leaf area distribution and below-canopy light regime, in which structural uniformity is lower than in the Slovakian production forests.

\subsubsection{Leaf area dynamics across the forest development cycle}

Previous studies on the relationship between $L A I$ and stand age in forests of variable species composition found a rapid increase of leaf area during the first years after stand establishment, which was followed by a steady decline of $L A I$ in older forests (e. g., Gratani et al., 2015; He et al., 2012; Ryan et al., 1997). While most studies dealt with even-aged forests, not much is known about leaf area dynamics in old-growth or primeval forests of the temperate zone. One example are the coastal temperate rainforests of British Columbia, where Frazer et al. (2000) found a declining $L A I$ in late-successional stands similar to the pattern observed in even-aged 
forests.

In apparent contrast to the above-mentioned studies, $L A I_{e}$ changed only little from the growth to the terminal stage of forest development in the primeval forests, even though gaps of different size had formed in the upper canopy of the terminal stage plots owing to the death of whole trees or crown parts. In the gaps of these plots, increased light transmission to the ground has promoted the growth of dense carpets of $F$. sylvatica seedlings, which is visible in elevated $L A I_{e}$ values of the regeneration layer in the terminal stage of all three primeval forests, even though the differences to the other stages were not significant.

In the upper canopy, the old $F$. sylvatica trees surrounding the gap must have rapidly expanded their lateral branches in particular in the shade crown, thereby mostly compensating the leaf area loss of the dead trees on the plot level within a few years. As a result of rapid leaf area expansion in the lower and upper canopy layers, plots mainly characterized by the terminal stage did not have reduced $L A I_{e}$ s, but, according to the model, generated higher total leaf areas. This result is remarkable as it demonstrates the frequently discussed high plasticity of canopy space filling at the stand level for old-growth beech forests. Moreover, it shows that the terminal stage of beech forest development apparently is not a period of reduced productivity, since leaf area is rapidly restored at the stand level after the death of senescent trees. This pattern is probably characteristic for old-growth forests with presence of small gaps due to tree senescence as is found in the studied Slovakian primeval forests. If larger disturbance events occur like heavy windthrows (or large-scale clear-cuts in production forests), rapid gap-filling by adjacent trees is unlikely, and leaf area recovery will depend on the establishment of a regeneration layer which will take longer.

Productivity measurements have to show whether increased growth of adjacent surviving trees does indeed compensate for the productivity loss caused by tree death during gap formation. At least in the montane belt of the Central European mountain ranges, beech is capable of maintaining high leaf area indices throughout the full forest dynamics cycle. This explains why other more light-demanding tree species are disadvantaged in many natural beech forests not only in the optimal but also in the terminal stage.

Our approach of investigating $L A I_{e}$ in a large number of plots assigned to different forest 
development stages by applying the dominance index was informative, as it expresses the development stage through a continuous number between 0 and ca. 2.0 and not by a predefined category (i.e., growth, optimal, terminal stages). In fact, due to the small-scale structural heterogeneity in beech primeval forests, all three pre-defined development stages are present with variable size in most of the $500 \mathrm{~m}^{2}$-plots (Feldmann et al., 2018) and assigning the whole plot to a certain stage is in many cases difficult. This urged us to use the dominance index as a measure of stand development in the model analysis. The models indicate a significant and strong effect on $L A I_{e}$ of a higher dominance of the terminal stage. They further suggest that stand leaf area is in fact greater with a higher dominance of terminal stage characteristics on the plots. This is an important addition to the conclusions drawn from the analysis with plots assigned to a single forest development stage only, where no significant $L A I_{e}$ difference between growth, optimal and terminal stages was found (Fig. 2.3).

Our findings regarding the vertical and horizontal structure of leaf area in the canopy of primeval and production forests would not have been possible with classical methods of stand structure analysis focusing on stem density and two-dimensional tree position and crown size mapping. Optical $L A I_{e}$ estimation across different development stages and at different heights in the crown can provide valuable insights into leaf area heterogeneity and they may indicate leaf area shifts from the upper to the lower crown layers, which are not visible in studies of stem and branch structures. Moreover, small-sized trees with diameters below arbitrarily chosen thresholds are included in our approach, which are lacking in classical stand structural analyses.

\subsection{Conclusions}

Our study shows that optical $L A I_{e}$ measurements conducted at fine spatial scales across oldgrowth forests can produce insights into the heterogeneity of foliage distribution in canopy space and they may help to understand the causality of spatial and temporal $L A I_{e}$ gradients. While absolute differences in average $L A I_{e}$ between primeval and production forests were relatively small, stem density and horizontal and vertical heterogeneity of crown structure were identified as main determinants of $L A I_{e}$ variation in the studied beech forests. On plots with 
comparable stem density, $L A I_{e}$ was lower in the production forests with cohort structure than in the primeval forests with a small-scale mosaic of development stages. We argue that this is caused by the much higher crown structural heterogeneity of the primeval forest canopy and its typically greater vertical extension up to maximum tree heights $>50 \mathrm{~m}$. This setting enables the development of a multi-layered shade canopy, which is simpler in even-aged and more homogeneous production forests as expressed by lower $\operatorname{IQR}\left(L A I_{e}\right)$ values.

Further, our data provide a new perspective on the functional role of the terminal stage of forest dynamics, in which tree senescence and gap formation are taking place. Owing to the highly plastic canopy space exploration of beech after disturbance and gap formation, this species maintains a high $L A I_{e}$ even in the terminal stage. This finding counters the assumption of a productivity decline in late stages of the forest development cycle. The capability of this late-successional species to conserve high leaf areas through the stand decay stage is viewed as a key trait for its competitive superiority in many regions of Central Europe, which allows the successful suppression of competitors in the absence of large-scale disturbance (e.g., windthrow). Our results also support the assumption that beech (and other late-successional tree species) may remain highly productive until ages close to the species' maximum lifespan. This would contradict the assumption that leaf area and productivity are declining at tree ages of about $120-150$ years, as is generally assumed for production forests of beech and other species (Chen et al., 2002; He et al., 2012).

The contrasting leaf area heterogeneities in the canopy of primeval and production forests indicate that results on canopy structure obtained in managed forests cannot be meaningfully extrapolated to primeval forests and the dynamics of old-growth stands. Our approach of measuring $L A I_{e}$ separately for two canopy layers (upper canopy and regeneration layer) should be extended to differentiate between further crown sections and it should ideally be combined with litter trapping to analyze the variable proportion of sun and shade leaves. Terrestrial and airborne laser scanning could be used to describe the three-dimensional structure of primeval forest canopies and to relate it to patterns of leaf area distribution. 


\section{Acknowledgements}

This study was made possible by a grant of the Stemmler Foundation, a member of the Stifterverband für die Deutsche Wissenschaft, to C. Leuschner and M. Hauck. This support is gratefully acknowledged. We are also grateful to the Poloniny National Park authority, the local forest administrations and the Ministry of Defense of the Slovak Republic for the permits to conduct the study and for technical support during the fieldwork. We thank two anonymous reviewers whose comments helped to improve an earlier version of this manuscript. 

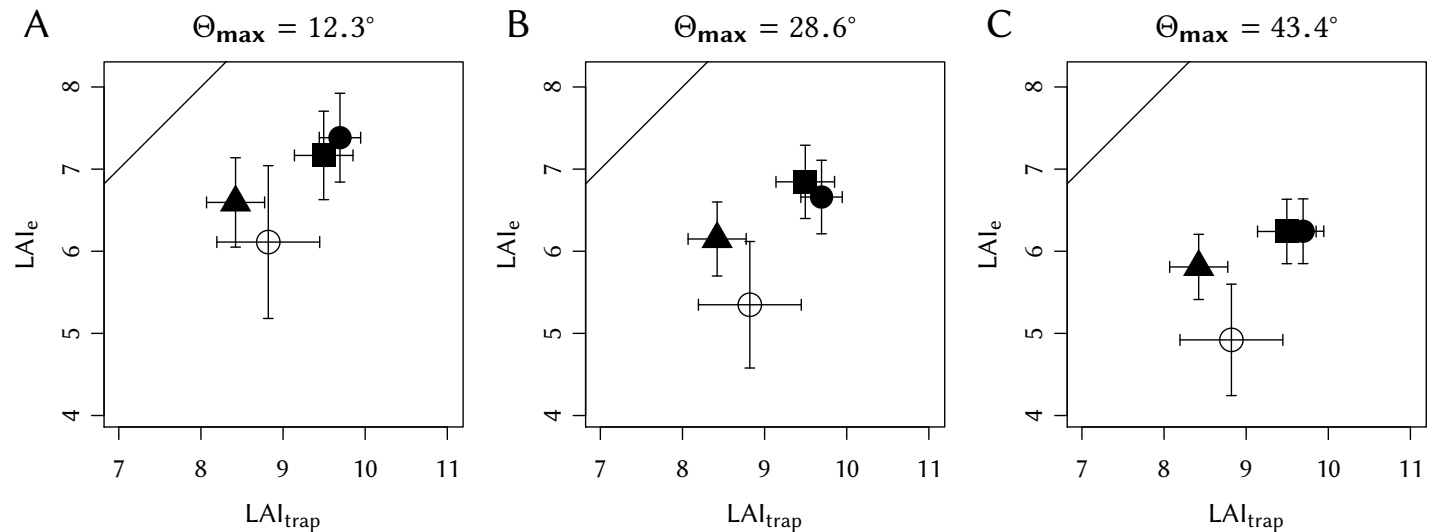

Figure 2.A1: Relation between $L A I$ values determined by litter trapping and optically determined $L A I_{e}$ values in the three primeval beech forests (square: Havešová, filled circle: Kyjov, triangle: Stužica) and one production forest (open circle: Kyjov). The line marks the 1:1 relation. The three panels show $L A I_{e}$ calculations for three different maximum zenithal angles $\left(\Theta_{\max }\right)$ considered in the Plant Canopy Analyzer measurements when only the one $(A)$, two (B) or three (C) of the innermost rings were used. $n=30$ (primeval forests) or 10 (production forests) for the litter traps. $\mathrm{n}=12$ plots with 21 measuring points per primeval forest, or 4 plots with 21 measuring points in the production forests for $L A I_{e}$-measurements.

\section{Appendix}

Comparison of $L A I$ derived from litter trapping with $L A I_{e}$ from the LAI2000. As both methods to measure $L A I$ and $L A I_{e}$ were conducted on different grids, only stand-level means were compared. The $L A I_{e}$ as derived from the LAI2000 measurements was on average by $2.3 \mathrm{~m}^{2} \mathrm{~m}^{-2}(25 \%)$ lower than the corresponding mass-based LAI values when only the innermost ring of the LAI2000 was used (data from four stands, excluding the production forests Havešová and Stužica; Figure 2.A1 A). The underestimation increased to 2.9 and $3.3 \mathrm{~m}^{2} \mathrm{~m}^{-2}$ (31\% and $\left.36 \%\right)$, when the second and third rings were included in the analysis (Figure 2.A1 A, B, and C). The trend for underestimation was similar in the primeval and production forests. Previous studies found that optical methods underestimate the true LAI by up to 40 \% (e.g., Breda, 2003; Dufrêne and Bréda, 1995; Olivas et al., 2013). This is in agreement with our study. One possible explanation for the underestimation is that all six stands of our study sites had relatively high LAIs and the recorded below-canopy light was low. Due to the logarithmic nature of the equations used to infer from transmission data on LAI, under low-light conditions, already small deviations from ideal conditions (such as 
specific patterns of light scattering or alteration of the spectral absorptivity of the leaves) may have a relatively large effect on the calculated $L A I_{e}$. Pronounced foliage clumping on spatial scales below the sensor range of view might be another influential factor. 


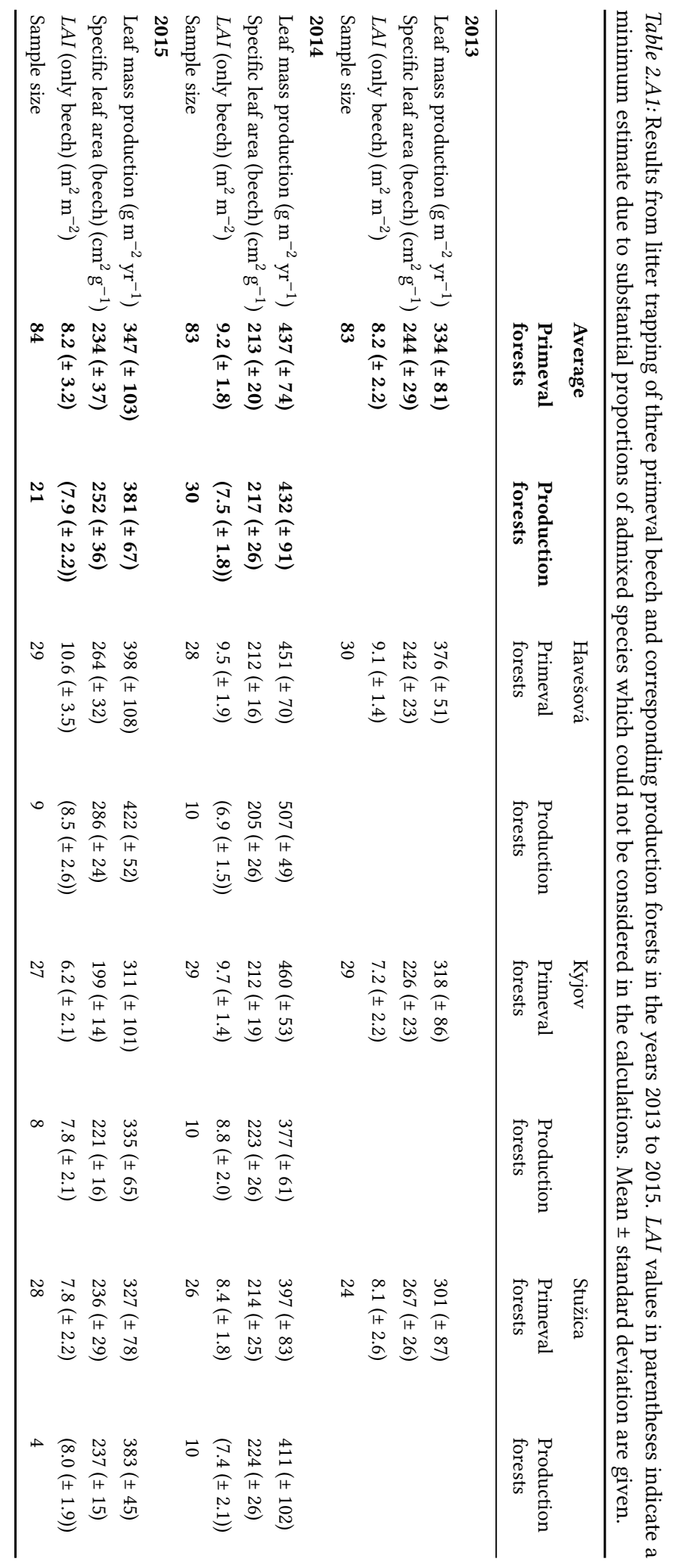




\section{References}

Bartelink, H.H., 1997. Allometric relationships for biomass and leaf area of beech (Fagus sylvatica L). Annales des Sciences Forestieres 54, 39-50.

Beckschäfer, P., Seidel, D., Kleinn, C., Xu, J., 2013. On the exposure of hemispherical photographs in forests. iForest Biogeosciences and Forestry 6 (4), 228-237.

Bequet, R., Campioli, M., Kint, V., Vansteenkiste, D., Muys, B., Ceulemans, R., 2011. Leaf area index development in temperate oak and beech forests is driven by stand characteristics and weather conditions. Trees 25 (5), 935-946.

Bohn, U., Neuhäusl, R., Gollub, R., Hettwer, C., Neuhäuslova, Z., Schlüter, H., Weber, H., 2003. Karte der natürlichen Vegetation Europas. Teil 1: Erläuterungstext. Landwirtschaftsverlag, Münster.

Breda, N.J.J., 2003. Ground-based measurements of leaf area index: a review of methods, instruments and current controversies. Journal of Experimental Botany 54 (392), 2403-2417.

Chason, J.W., Baldocchi, D.D., Huston, M.A., 1991. A comparison of direct and indirect methods for estimating forest canopy leaf area. Agricultural and Forest Meteorology 57 (1-3), 107-128.

Chen, J.M., Black, T.A., Adams, R.S., 1991. Evaluation of hemispherical photography for determining plant area index and geometry of a forest stand. Agricultural and Forest Meteorology 56 (1-2), 129-143.

Chen, W., Chen, J.M., Price, D.T., Cihlar, J., 2002. Effects of stand age on net primary productivity of boreal black spruce forests in Ontario, Canada. Canadian Journal of Forest Research 32 (5), 833-842.

Chianucci, F., MacFarlane, C., Pisek, J., Cutini, A., Casa, R., 2015. Estimation of foliage clumping from the LAI-2000 Plant Canopy Analyzer: effect of view caps. Trees 29 (2), 355-366.

Davi, H., Baret, F., Huc, R., Dufrêne, E., 2008. Effect of thinning on LAI variance in heterogeneous forests. Forest Ecology and Management 256 (5), 890-899.

Derose, R.J.J., Seymour, R.S., 2010. Patterns of leaf area index during stand development in even-aged balsam fir red spruce stands. Canadian Journal of Forest Research 40 (4), 629-637.

Drössler, L., Meyer, P., 2006. Forest development stages in two virgin beech reserves in Slovakia. Forstarchiv 77 (5), $155-161$.

Dufrêne, E., Bréda, N., 1995. Estimation of deciduous forest leaf area index using direct and indirect methods. Oecologia 104 (2), 156-162.

FAO, 2010. Global forest resources assessment 2010. Food and Agricultural Organization of the United Nations, Rome.

Feldmann, E., Glatthorn, J., Hauck, M., Leuschner, C., 2018. A novel empirical approach for determining the extension of forest development stages in temperate old-growth forests. European Journal of Forest Research , 1-15.

Frazer, G.W., Trofymow, J.A., Lertzman, K.P., 2000. Canopy openness and leaf area in chronosequences of coastal temperate rainforests. Canadian Journal of Forest Research 30 (2), 239-256.

von Gadow, K., Chun, Y.Z., Wehenkel, C., Arne Pommerening, Javier Corral-Rivas, Mykola Korol, Stepan Myklush, Gang Ying Hui, Andres Kiviste, Xiu Hai Zhao, 2012. Forest Structure and Diversity. In: T. Pukkala, K. von Gadow, eds., Continuous Cover Forestry, Managing Forest Ecosystems. Springer Netherlands, Dordrecht, pp. 29-83.

Gonzalez-Benecke, C.A., Jokela, E.J., Martin, T.A., 2012. Modeling the effects of stand development, site quality, and silviculture on leaf area index, litterfall, and forest floor accumulations in loblolly and slash pine Plantations. Forest Science 58 (5), 457-471.

Gratani, L., Crescente, M.F., Varone, L., Bonito, A., Tinelli, A., 2015. Pinus pinea L. plant trait variations in response to tree age and silvicultural management and carbon storage capability. Rendiconti Lincei 26 (S3), 507-515.

Green Report, 2009. Report on the status of forestry in the Slovak Republic of 2009. Ministry of Agriculture of the Slovak Republic, Bratislava. 
He, L., Chen, J.M., Pan, Y., Birdsey, R., Kattge, J., 2012. Relationships between net primary productivity and forest stand age in U.S. forests. Global Biogeochemical Cycles 26 (3).

Hothorn, T., Bretz, F., Westfall, P., 2008. Simultaneous inference in general parametric models. Biometrical Journal 50 (3), 346-363.

Jonckheere, I., Fleck, S., Nackaerts, K., Muys, B., Coppin, P., Weiss, M., Baret, F., 2004. Review of methods for in situ leaf area index determination. Agricultural and Forest Meteorology 121 (1-2), 19-35.

Konôpka, B., Pajtík, J., Marušák, R., Bošela, M., Lukac, M., 2016. Specific leaf area and leaf area index in developing stands of Fagus sylvatica L. and Picea abies KARst. Forest Ecology and Management 364, 52-59.

Korpeĺ, Š., 1995. Die Urwälder der Westkarpaten. Gustav Fischer Verlag, Stuttgart.

Le Dantec, V., Dufrêne, E., Saugier, B., 2000. Interannual and spatial variation in maximum leaf area index of temperate deciduous stands. Forest Ecology and Management 134 (1), 71-81.

Leuschner, C., 2015. Monospecific and mixed stands of Fagus and Nothofagus species in the temperate zones of the world. Berichte der Reinhold-Tüxen Gesellschaft 22, 49-63.

Leuschner, C., Ellenberg, H., 2017. Ecology of Central European Forests - Vegetation Ecology of Central Europe, Vol. I. Springer, Dordrecht.

Leuschner, C., Voß, S., Foetzki, A., Clases, Y., 2006. Variation in leaf area index and stand leaf mass of European beech across gradients of soil acidity and precipitation. Plant Ecology 186 (2), 247-258.

Lukasová, V., Lang, M., Škvarenina, J., 2014. Seasonal changes in NDVI in relation to phenological phases, LAI and PAI of beech forests. Baltic forestry 20 (2), 248-262.

Marušák, R., 2007. Alternative harvest scheduling for final cut with respect to silvicultural requirements. Lesnícky časopis-Forestry Journal 53, 117-127.

Mayer, H., Holst, T., Schindler, D., 2002. Microclimate within beech stands - part I: photosynthetically active radiation. Forstwissenschaftliches Centralblatt vereinigt mit Tharandter Forstliches Jahrbuch 121 (6), 301-321.

Meier, I.C., Leuschner, C., 2008. Microclimate within beech stands-part I: photosynthetically active radiation. Ecosystems 11 (5), 655-669.

Miller, J.B., 1967. A formula for average foliage density. Australian Journal of Botany 15 (1), 141-\&.

Mund, M., Kummetz, E., Hein, M., Bauer, G.A., Schulze, E.D., 2002. Growth and carbon stocks of a spruce forest chronosequence in central Europe. Forest Ecology and Management 171 (3), 275-296.

National Forest Centre, 2009. Forests in Slovakia. Ministry of Agriculture of the Slovak Republic, Bratislava.

Nilson, T., 1971. A theoretical analysis of the frequency of gaps in plant stands. Agricultural Meteorology 8, 25-38.

Nock, C.A., Caspersen, J.P., Thomas, S.C., 2008. Large ontogenetic declines in intra-crown leaf area index in two temperate deciduous tree species. Ecology 89 (3), 744-753.

Olivas, P.C., Oberbauer, S.F., Clark, D.B., Clark, D.A., Ryan, M.G., O’Brien, J.J., Ordoñez, H., 2013. Comparison of direct and indirect methods for assessing leaf area index across a tropical rain forest landscape. Agricultural and Forest Meteorology 177, 110-116.

Oliver, C.D., Larson, B.C., 1996. Forest Stand Dynamics. Wiley, New York.

Oren, R., Zimmermann, R., 1989. CO2 assimilation and the carbon balance of healthy and declining Norway spruce stands. In: E.D. Schulze, O.L. Lange, R. Oren, eds., Forest Decline and Air Pollution: A Study of Spruce (Picea abies) on Acid Soils. Springer Berlin Heidelberg, Berlin, Heidelberg, pp. 352-369.

Pommerening, A., 2002. Approaches to quantifying forest structures. Forestry 75 (3), 305-324.

Puettmann, K.J., Wilson, S.M., Baker, S.C., Donoso, P.J., Drössler, L., Amente, G., Harvey, B.D., Knoke, T., Lu, Y., Nocentini, S., Putz, F.E., Yoshida, T., Bauhus, J., 2015. Silvicultural alternatives to conventional even-aged forest management - what limits global adoption? Forest Ecosystems 2 (1), 611. 
R Core Team, 2016. R: A Language and Environment for Statistical Computing. Vienna, Austria.

Ryan, M.G., Binkley, D., Fownes, J.H., 1997. Age-Related Decline in Forest Productivity: Pattern and Process. In: D.B. Nedwell, A.H. Fitter, eds., Advances in Ecological Research, Advances in Ecological Research, volume v.27. Elsevier Textbooks, s.l., pp. 213-262.

Spinoni, J., Szalai, S., Szentimrey, T., Lakatos, M., Bihari, Z., Nagy, A., Németh, Á., Kovács, T., Mihic, D., Dacic, M., Petrovic, P., Kržič, A., Hiebl, J., Auer, I., Milkovic, J., Štepánek, P., Zahradnícek, P., Kilar, P., Limanowka, D., Pyrc, R., Cheval, S., Birsan, M.V., Dumitrescu, A., Deak, G., Matei, M., Antolovic, I., Nejedlík, P., Štastný, P., Kajaba, P., Bochnícek, O., Galo, D., Mikulová, K., Nabyvanets, Y., Skrynyk, O., Krakovska, S., Gnatiuk, N., Tolasz, R., Antofie, T., Vogt, J., 2015. Climate of the Carpathian Region in the period 1961-2010: Climatologies and trends of 10 variables. International Journal of Climatology 35 (7), 1322-1341.

Zuur, A.F., Ieno, E.N., Elphick, C.S., 2010. A protocol for data exploration to avoid common statistical problems: Data exploration. Methods in Ecology and Evolution 1 (1), 3-14. 



\title{
CHAPTER
}

\section{Biomass stock and productivity of primeval and production beech forests: Greater canopy structural diversity promotes productivity}

\author{
- Jonas Glatthorn - Eike Feldmann - Viliam Pichler - \\ - Christoph Leuschner - Markus Hauck -
}

Ecosystems 2017 - http://dx.doi.org/10.1007/s10021-017-0179-z

\begin{abstract}
Our knowledge of temperate broadleaf forest ecology is based mostly on the study of production forests, which lack the terminal stage of forest development and have a simpler stand structure than old-growth and primeval forests. How primeval and production forests differ in net primary production $(N P P)$ is not well known. In three primeval and three nearby production forests of European beech (Fagus sylvatica) in the Slovakian Carpathians, we measured aboveground biomass stocks (live and dead), aboveground NPP (ANPP) and parameters characterizing canopy structural diversity (leaf area index and its spatial variation). Our study aims were (1) to explore the role of canopy structural diversity for ANPP and (2) to assess evidence of a productivity decline in the terminal stage. While aboveground live biomass stocks were on average $20 \%$ greater in the primeval forests (386 vs. $320 \mathrm{Mg} \mathrm{ha}^{-1}$; insignificant difference at two sites), deadwood mass stocks were on average four times larger than in the production forests ( $86 \mathrm{vs} .19 \mathrm{Mg} \mathrm{ha}^{-1}$ ). ANPP was similarly high in the primeval and production forests (10.0 vs. $\left.9.9 \mathrm{Mg} \mathrm{ha}^{-1} \mathrm{y}-1\right)$ and did not decrease towards the terminal stage. Production models indicate that, in the primeval forests, about $10 \%$ of ANPP (ca. $1 \mathrm{Mg} \mathrm{ha}^{-1} \mathrm{yr}^{-1}$ ) was generated by effects related to leaf area heterogeneity, evidencing a positive effect of structural diversity on forest productivity, even though species diversity was low. This study helps to better understand the impact of forest
\end{abstract}


management on the productivity and carbon storage in temperate woodlands.

Keywords: Age-related productivity decline, Canopy structural diversity, Fagus sylvatica, Forest development stage, Leaf area index, NPP, Slovakia, Wood production, Old-growth forests, Biomass stock.

\subsection{Introduction}

True old-growth forests with century-long natural development have survived in only a tiny fraction of the temperate forest biome area (Parviainen, 2005). This is one of the reasons that much more is known about the functioning of temperate production forests than of old-growth or primeval forests. However, many old-growth forests store large amounts of biomass carbon, are characterized by a species-rich and specialized flora and fauna and are the only places where natural processes of tree senescence, gap formation and closure, and patch dynamics can be studied.

Although most studies in old-growth forests were descriptive and focused on structural properties, functional research in these complex systems has a much shorter history. A more recent finding in old- growth forests refers to their ability to accumulate biomass and thus retain a positive net ecosystem production (NEP) up to surprisingly high ages (Luyssaert et al., 2008). In contrast, biomass accumulation typically declines with age in production forests with cohort structure (Assmann and Davis, 1970; Odum, 1969). It appears that temperate old-growth forests maintain high rates of net primary production $(N P P)$ far longer than is expected from the study of production forests (Gough et al., 2016).

To understand the long-term carbon sequestration potential of unmanaged forests, it is necessary to investigate changes in biomass storage and NPP across the full development cycle of old-growth or primeval forests. Further, effects of forest management on productivity and biomass accumulation can be studied by comparing this information with NPP data from nearby production forests. This question is linked to the contrasting stand structure of production and primeval forests, with the latter exhibiting a higher heterogeneity in terms of stem sizes, tree 
age and canopy three-dimensional structure (Commarmot et al., 2005; Korpeĺ, 1995; Merino et al., 2007). So far, stand dynamics and related carbon cycling have been studied in unmanaged old-growth forests of the boreal zone (for example, Schulze et al., 2009, 2005), whereas equivalent research in primeval forests of the temperate broadleaf forest biome is lacking. In contrast, comprehensive databases exist for biomass chronosequences of temperate managed forests (for example, Lichstein et al., 2009). However, better understanding of C cycling in temperate primeval forests is important for forestry, as multifunctional forest management partly mimics the structure of natural forests to meet biodiversity conservation goals (Larsen et al., 2010; Lindenmayer et al., 2006).

Through a positive effect on leaf area index, greater canopy structural heterogeneity could influence the productivity of forests in a positive way, independently of the well-studied species diversity effect on productivity (for example, Liang et al., 2016); this is suggested by a detailed analysis of canopy structural diversity in primeval and production forests of European beech in Slovakia (Glatthorn et al., 2017). A positive influence of canopy heterogeneity on productivity could thus exist in species-poor forests as well, providing a possible incentive to increase the structural diversity of production forests. However, the relationship between forest structural diversity and productivity is only poorly understood. The few existing studies are contradictory and cover only a few forest types. Although Danescu et al. (2016), Gadow et al. (2016), Hardiman et al. (2013), Lei et al. (2009) and Ishii et al. (2004) found a positive relationship between structural diversity and productivity in forests, Bourdier et al. (2016) and Soares et al. (2016) reported a negative one. Long and Shaw (2010) detected neither a positive nor a negative effect of structural diversity on productivity. In North-American old-growth forests, Fahey et al. (2015) found a positive relationship between canopy structural diversity and productivity only in stands which had recently been disturbed, not in undisturbed ones.

A multitude of methods is available for quantifying various aspects of structural diversity in forests. Simple structural indices address single-tree characteristics as the variation in stem diameter or height in a stand, whereas more complex parameters describe the spatial distribution of trees (von Gadow et al., 2012). More recent approaches often employed ground- or air-borne LiDAR systems to analyse stand and canopy structure (for example, Ehbrecht et al., 2016; Mura 
et al., 2015; Hardiman et al., 2013). Physiologically most meaningful is information on the threedimensional distribution of leaf area in the canopy, because plants exchange light, water and $\mathrm{CO}_{2}$ through this surface, and leaf area index $(L A I)$ is generally closely related to productivity. The size and placement of leaf area in the canopy also determines how much light can penetrate to lower canopy strata and to the ground, where it controls the growth of small trees and the survival of tree seedlings and saplings. Relating leaf area distribution to tree growth and forest productivity in stands differing in structural complexity may help to understand the influence of structural diversity on productivity.

Here, we present the results of a comparative study in six forests of European beech (Fagus sylvatica L.) in the Slovakian Carpathians, three primeval forests and three nearby production forests with cohort structure (commercially managed and logged), which differed greatly in structural diversity. Study aims were (1) to measure differences in biomass stocks and productivity between the managed and unmanaged stands and (2) to analyse the role of canopy structural diversity for stand-level productivity and the growth of individual trees by employing multiple linear regression analysis.

F. sylvatica is the most widespread tree species of Central Europe's natural forest vegetation, and it plays an important role in forestry (Leuschner and Ellenberg, 2017). The last remaining primeval beech forests are promising objects for studying the relation between structural diversity and productivity, as they are monospecific, but highly heterogeneous in canopy structure with the presence of early and late forest development stages in close proximity to each other. Based on an earlier investigation in these forests, which showed similar LAI means in primeval and production forests (Glatthorn et al., 2017), we hypothesize that (1) primeval forests have a similarly high NPP as production forests, (2) productivity does not decline in the optimal and terminal stages of the forest development cycle when trees get older and (3) structural diversity as expressed by leaf area variability is a factor promoting productivity in the primeval forests. We measured aboveground biomass stocks (live and dead), aboveground NPP (ANPP, that is, woody biomass increment plus litter production) and parameters characterizing canopy structural diversity in 48 plots located in the six stands. Canopy density and its spatial variation in the stands was quantified through measurement of the effective leaf area index 
$\left(L A I_{e}\right)$ of upper and lower canopy strata with a LAI2000 Plant Canopy Analyzer.

\subsection{Methods}

\subsubsection{Study Area}

The study was conducted in three beech primeval forests at montane elevation (550-950 m a.s.l.) in the Western Carpathians in eastern Slovakia $\left(48^{\circ} 1^{\prime}-49^{\circ} 8^{\prime} \mathrm{N}, 22^{\circ} 1^{\prime}-22^{\circ} 54^{\prime} \mathrm{E}\right)$, which have not been affected by human intervention for several hundred years (Korpel, 1995). The forests thus resemble 'virgin forests', even though the sites have been influenced by atmospheric deposition of nitrogen, acids and other anthropogenic substances since the beginning of industrialization in a similar manner to many other woodland regions in the industrialized regions of the world. The stands are part of the forest reserves Havešová, Stužica (both inside Poloniny National Park and part of the UNESCO World Heritage Site "Primeval Beech Forests of the Carpathians and the Ancient Beech Forests of Germany") and Kyjov in the Vihorlat mountains (Table 2.1).

We also selected three production forests at similar elevation and within a distance of $1 \mathrm{~km}$ to the primeval forests for comparative study. The stands were managed in a shelterwood cutting system with two subsequent cuts within 10 years at the end of the production cycle. This system is the most widespread beech forest management regime in Slovakia and is practiced in strips parallel to the slope, structuring the production forest in longitudinal sections of beech cohorts of similar age and relatively high stem density, as the stands are normally thinned only about 10 years before final harvest (Green Report, 2009; Marušák, 2007). In most cases, the rotation period is relatively short (typically $80-100$ years) with the consequence that more than $90 \%$ of the Slovakian beech production forests are less than 100 years old (National Forest Centre, 2009).

All six forests belong to the Fagetum dentarietosum glandulosae community (Bohn et al., 2003). In the Kyjov stands on Dystric Cambisols, soil acidity is somewhat higher than in the other sites, which is indicated by the presence of a larger number of acidity-indicating herb species. Although the primeval and production forests had similar total basal areas (32-43 $\mathrm{m}^{2} \mathrm{ha}^{-1}$ ), stem density in Havešová and Stužica was markedly higher in the managed than in the primeval 
forests. Except for Kyjov, the quadratic mean stem diameter and dominant height were lower in the production forests (Table 2.2). The canopy layer of the primeval forests in Havešová and Kyjov was composed nearly entirely by F. sylvatica (98 and $99 \%$ of basal area, except for a few Acer pseudoplatanus L., Acer platanoides L. and Fraxinus excelsior L. trees), whereas the Stužica forest contained about $10 \%$ Abies alba MiLl. at elevations of about 1000-m a.s.l. In the production forest of Kyjov, about $94 \%$ of the canopy trees were beech. The production forests of Stužica and Havešová had higher proportions (23 and $39 \%$ ) of A. platanoides, A. pseudoplatanus, F. excelsior and other broad-leaved tree species. The beech trees in the primeval forests reached maximum ages of up to 400 years (R. Coventry, unpublished), while the trees in the production forests were cohorts of relatively similar age (ca. 90-100 years in Kyjov and Stužica and ca. 70 years in Havešová). The production forests were close to final harvest and thus had reached their maximum biomass in the production cycle.

\subsubsection{Study design}

Rectangular grids were placed in the three primeval forests, and 40 circular plots of $500 \mathrm{~m}^{2}$ size (25.24 $\mathrm{m}$ in diameter) were established on the grid nodes. Grid spacing was chosen so that the 40 plots were located within each of the reserves and no plot was within $100 \mathrm{~m}$ distance to the nearest reserve border. In all 120 plots, basic stand structural parameters were recorded and used to assign each plot to one of three development stages as defined below. To analyse changes in productivity throughout the forest development cycle, four plots per development stage and primeval forest $(4 \times 3 \times 3=36$ plots $)$ were then selected for an in-depth analysis of productivity and deadwood pools.

The production forests were smaller in size than the primeval forests. We thus selected each ten plots on a rectangular grid in these stands and inventoried them for basic stand structural parameters in the same manner as in the primeval forest plots. Again, four of the ten plots were selected for the analysis of canopy structure (12 plots in total). This stratified random sampling approach ensured a precise quantification of basic stand structural parameters in all six forests and a balanced study design with equal representation of all development stages in the dataset for the analysis of productivity and deadwood. The minimum distance between two 
neighbouring plots was defined by the size of the six forests. Grid spacing was $65 \mathrm{~m}$ in Kyjov, $100 \mathrm{~m}$ in Stužica and $140 \mathrm{~m}$ in Havešová, but only $50 \mathrm{~m}$ in the three production forests.

Although the basic stand structural parameters were recorded in 150 plots in total, the indepth productivity and deadwood analysis was conducted in a subset of 48 plots. Basic stand structural parameters were recorded in October 2013 and March/April 2014 in all 150 plots. All live and dead trees with a diameter at breast height $(D B H) \geq 7 \mathrm{~cm}$ in the plots were inventoried and the following parameters calculated at the plot level: stem density, basal area, quadratic mean diameter at breast height and dominant height (see (Glatthorn et al., 2017) for a detailed description of stand structure). Dominant height is the extrapolated height corresponding to the quadratic mean diameter of the $20 \%$ of trees with largest diameters. After measuring $D B H$ and height in a subsample of trees using a dendrometer tape and a Vertex IV height meter (Haglöf Sweden AB, Långsele, Sweden), the tree height of the remaining trees was extrapolated from $D B H$ with stand height curves established on the basis of the empirical data.

The assignment of the plots to development stages (DS) followed an approach developed by Feldmann et al. (2018), which allows for the co-occurrence of different stages within a single plot, as is characteristic for beech primeval forests. To do so, every tree in a plot was assigned to one of three $D B H$ classes: $7-39.9 \mathrm{~cm}, 40-69.9 \mathrm{~cm}$ and at least $70 \mathrm{~cm}$. These $D B H$ classes were selected from a silvicultural point of view. The first diameter class contains premature trees, the second mature trees of harvestable size in production forests, and the third large trees of a size not found in production forests. The diameter classes are thought to be characteristic of the growth, optimal and terminal stages, respectively.

We calculated a dominance index $d_{0} m_{D S i}$ for the different development stages present in a plot and compared their relative importance by relating the abundance of trees of the corresponding $D B H$ class in this plot to the $85 \%$ quantile of the respective abundances in all plots of a primeval forest $(\mathrm{n}=40)$. The $85 \%$ quantile was chosen as a robust measure of the abundance of a development stage in the forest when it dominated a plot nearly exclusively.

To express the importance of a development stage in a plot, we averaged over two measures of stand density for the trees in the respective diameter class: stem density $\left(\operatorname{tn}_{D S i}\right.$, in $\left.\mathrm{n} \mathrm{ha}^{-1}\right)$ and stem volume $\left(v_{D} l_{D S i}\right.$, in $\left.\mathrm{m}^{3}\right)$. Subsequently, the relative dominance $\left(\operatorname{dom}_{D S i}\right)$ of a development 
stage in a plot was obtained from

$$
\operatorname{dom}_{D S i}=\frac{1}{2}\left(\frac{v o l_{D S i}}{v o l_{D S_{0.85}}}+\frac{t n_{D S i}}{t n_{D S_{0.85}}}\right) \text { for all plots } i \text { with } i \in\{1,2,3, \ldots, \mathrm{n}\}
$$

The development stage with highest relative dominance in terms of stem density and wood volume was then taken to define the prevalent (quantitatively most important) stage of that plot.

\subsubsection{Live Plant and Deadwood Biomass}

\section{Live Plant Biomass}

Three different components of aboveground live plant biomass were recorded: (1) the woody biomass (timber and brushwood) of all trees with a $D B H$ of at least $7 \mathrm{~cm},(2)$ the biomass of leaves and fruits and (3) the biomass of trees in the regeneration layer which comprised all woody plants with a $D B H$ less than $7 \mathrm{~cm}$.

Specific allometric equations established for European beech and silver fir based on $D B H$ and tree height were used to calculate the woody biomass (without leaves) of each F. sylvatica (and in Stužica: A. alba) tree with a DBH of at least $7 \mathrm{~cm}$ (Ruiz-Peinado et al., 2011; Wutzler et al., 2008). For a subsample of at least three trees per species and plot, tree height was measured (Vertex IV). The height of the remaining trees was extrapolated with stand height curves. The woody biomass of admixed tree species was approximated through volume estimation and multiplication with wood density values taken from the global wood density database (Chave et al., 2009). The biomass of leaves and fruits was obtained from litter trap data averaged over all seasons (see below).

The biomass of tree regeneration and understory treelets was measured in four rectangular subplots $\left(4 \times 6.5 \mathrm{~m} \times 2 \mathrm{~m}=52 \mathrm{~m}^{2}\right)$ established in each plot. Every sapling and young tree with $D B H$ less than $7 \mathrm{~cm}$ in the subplots was counted and assigned to one of four height classes $(0-49 \mathrm{~cm}, 50-149 \mathrm{~cm}, 150-299 \mathrm{~cm}, \geq 300 \mathrm{~cm})$. The aboveground biomass without leaves of these small trees was estimated for every individual from empirically established species-specific allometric equations following Annighöfer et al. (2016). 


\section{Deadwood Mass}

The dry mass of whole standing dead trees was estimated with the same methods as used for live plant biomass described above. The volume of logs with a base diameter at least $20 \mathrm{~cm}$ and snags with a $D B H$ at least $7 \mathrm{~cm}$ was approximated by a frustum of a cone citepProdMeyer.1999b, Kramer.2008. Only log sections lying inside the plot borders were considered. The diameter of lying logs was measured at two positions for calculating log tapering. The tapering of standing snags was assumed to be $10 \mathrm{mmm}-1$. The biomass of logs and snags was then estimated from the calculated volume multiplied with the wood density, which was taken from the global wood density database (Chave et al., 2009). To account for wood decay, correction factors were applied (Albrecht, 1991).

The volume of fine woody debris with base diameters of $2-20 \mathrm{~cm}$ was estimated from line intersect sampling (Bohl and Brandli 2007). Similar to the regeneration sampling, four $6.5 \mathrm{~m}$ long transects were placed in each plot. The diameter of each piece of debris was recorded if it was intersecting the transect and if its diameter was within the specified range. The biomass of fine deadwood was then estimated by multiplying the estimated volume with the wood density of beech and applying a correction factor of 0.8 to account for average decay.

\subsubsection{Tree Growth and Productivity}

Two components of ANPP were measured: woody biomass increment and litter production $\left(A N P P_{\text {wood }} ; A N P P_{\text {litter }}\right)$. The productivity of the herb and shrub layers including tree regeneration $(D B H<7 \mathrm{~cm})$ was neglected.

$A N P P_{\text {litter }}$ was measured with litter traps with a circular opening of $60 \mathrm{~cm}$ in diameter $\left(2826 \mathrm{~cm}^{2}\right)$. As we assumed a higher heterogeneity of litter fall in the primeval forests, we set up 30 traps in each primeval forest and 10 traps in each production forest on the nodes of a regular grid. Leaf litter was collected from the traps in December of the years 2013-2015 in the primeval forests and in 2014 and 2015 in the production forests. The litter was subsequently sorted by species and litter type (leaves/ fruits), oven-dried for $48 \mathrm{~h}$ at $70^{\circ} \mathrm{C}$ and weighed.

Litter collected in litter traps in primeval forests with high spatial heterogeneity cannot be 
assigned to a specific plot area or development stage. Therefore, we placed the traps on the nodes of the rectangular grid to obtain average biomass estimates for the whole stand but did not attempt to distinguish between the different forest development stages within the stand. Thus, the litter trap locations do not necessarily coincide with the position of the tree inventory plots.

To measure the woody biomass increment of the trees, the radial increment of all live trees with a $D B H$ of at least $7 \mathrm{~cm}$ was recorded in the years 2014 and 2015 by repeated reading of permanently installed dendrometer tapes with a precision of $0.1 \mathrm{~mm}$ (type D1, UMS, Munich, Germany). In contrast to repeated $D B H$ measurements with calipers or measuring tapes, this approach avoids measurement errors due to slightly differing measurement heights. Thus, the $D B H$ increment can be precisely measured on an annual basis. Four plots per development stage and primeval forest and four plots per production forest were equipped with dendrometer tapes (except for the production forests of Havešová and Stužica, where due to high stem numbers only two (Havešová) and three plots (Stužica) could be equipped). Fitted height curves were used to estimate the height increment of individual trees in this interval. Tree growth was then approximated by calculating the woody biomass difference of each tree between two tape readings using the allometric equations presented above. Plot-level $A N P P_{\text {wood }}$ was obtained by summing up the woody biomass increment of all trees in a plot.

\subsubsection{Canopy structure}

We estimated canopy gap fraction through synchronous measurement with two LAI2000 Plant Canopy Analyzers (LiCor, Lincoln, NE, USA). One sensor was placed in the centre of a large forest gap or clear-cut area (at least $100 \mathrm{~m}$ in diameter) for estimating above-canopy radiation, the other beneath the canopy at different positions in each plot. The quotient of above-canopy and below-canopy radiation intensity (transmission coefficient) was taken as an approximation of canopy gap fraction.

The inversion model proposed by Miller (1967) was used to derive effective leaf area index $\left(L A I_{e}\right)$ from gap fraction. Because gap fraction methods of estimating canopy leaf area are affected by foliage clumping, we subsequently refer to effective leaf area index $\left(L A I_{e}\right)$ and not 
true leaf area index (LAI), which is defined as projected one-sided leaf area per unit ground area (Chen et al., 1991; Jonckheere et al., 2004).

LAI2000 measurements were taken systematically along two $15 \mathrm{~m}$-long transects that were placed perpendicular to each other in the plot centre. One instrument reading was taken every $1.5 \mathrm{~m}$ resulting in 21 sampling points per plot (the central point with crossing transects was measured only once). On each sampling point, two readings were taken, one $30 \mathrm{~cm}$ above ground and a second one above the regeneration layer, if present. For the latter measurements, a $3 \mathrm{~m}$-long pole was used which allowed a maximal measuring height of $4.5 \mathrm{~m}$. This procedure allowed calculating the $L A I_{e}$ for three different canopy layers:

1. $L A I_{e-\text { upper-canopy }}\left(L A I_{e-u p}\right): L A I_{e}$ of the upper layer of the canopy above the regeneration layer.

2. $L A I_{e-\text { total-canopy }}\left(L A I_{e-t o t}\right): L A I_{e}$ of the whole canopy including regeneration layer.

3. $L A I_{\text {e-lower-canopy }}\left(L A I_{e-l o w}=L A I_{e-t o t}-L A I_{e-u p}\right): L A I_{e}$ of the advanced regeneration layer and the lower shade crown of taller trees.

At plot-level, the average $L A I_{e}$ (arithmetic mean) and the dispersion of $L A I_{e}$ values (interquartile range $\left.\operatorname{IQR}\left(L A I_{e}\right)\right)$ were used to characterize average canopy density and canopy structural heterogeneity. Due to a biasing effect of canopy height on the dispersion of the $L A I_{e-u p}$ and $L A I_{e-t o t}$ values, the IQRs were weighted by the dominant tree height in a plot. The methods and parameters used for canopy structural analysis and some related key results are presented in Glatthorn et al. (2017).

Certainly, $L A I_{e}$ measurement at two heights in the canopy done in this way does not generate as precise information on vertical leaf area distribution in the canopy as they are possible, for example, with ground-based LiDAR-scans. Yet, our approach with LAI2000 measurements at two heights allows recording at a large number of sample points, thus providing a picture of spatial variation in canopy density at high resolution. 


\subsubsection{Microtopography as Productivity-Influencing Factor}

We measured slope and aspect of each plot and used them as proxies of local climatic and hydrologic conditions in multiple linear regression models to describe $A N P P_{\text {wood }}$ and tree growth in its dependence on environmental and stand structural variables. In the absence of local climatic and hydrologic data, these microtopographical variables were thought to best reflect variation in the physical environment. In the models, the factor 'region' (Stužica, Havešová and Kyjov) introduces site differences in geology, soil chemistry and elevation as well as regional differences in climate.

Because tree growth and plot-level productivity will not react linearly to slope or aspect, both variables had to be transformed for linear regression analysis. We adopted the approach of Stage (1976) which uses the sine and cosine of aspect to describe the 'eastness' and 'northness' of plot topography. Because in level terrain and in slightly sloping plots, aspect is not influential, it was weighted by the tangents of the slope. Three transformed variables were used to characterize the microtopography of a plot:

1. north $=\tan ($ slope $) \cos ($ aspect $)$,

2. south $=\tan ($ slope $) \sin ($ aspect $)$,

3. $\tan ($ slope $)$.

The three variables are treated as one group and are not used independently in the regression analysis.

\subsubsection{Statistical analysis}

To calculate standard errors of group means and for significance testing, nonparametric bootstrap methods were applied (Davison and Hinkley, 2009). We adopted a resampling procedure instead of using more classical approaches, as the former typically performs better with data of complex structure and unknown distribution of test statistics.

We used bootstrapping with 9999 replicates for all analyses except for the analysis of the influence of stand and canopy structure and microtopography on $A N P P_{\text {wood }}$ and tree growth. For 
the latter, we used multiple linear regression analyses and a bidirectional selection procedure of covariates to find the best models in terms of AIC. To test for the influence of the physical and chemical environment and stand structure on productivity, we analysed the proxy variables microtopography (slope and aspect) and region, which reflect site differences in insolation, soil moisture, geology, soil chemistry and temperature, and introduced stem density and basal area into the models. In a first step, a base model without canopy parameters was fitted with the data from the 36 primeval forest plots, using $A N P P_{\text {wood }}$ and the growth rate of individual trees in the year 2014 as response variables (Tables 3.1 and 3.2).

In a second step, we extended the model by adding parameters quantifying canopy density $\left(L A I_{e}\right)$ and canopy heterogeneity $\left(\operatorname{IQR}\left(L A I_{e}\right)\right.$; the interquartile range of multiple $L A I_{e}$ measurements per plot). Separate models were fitted for the upper and lower canopy (regeneration layer and lowermost shade crown). To avoid multicollinearity, all numeric covariates with a variation inflation factor greater than 3 were dropped from the models (Zuur et al., 2010). This procedure led to the exclusion of the factors dominant height and quadratic mean diameter as structural parameters from all analyses, because their relation to stem density and basal area was too close $\left(r^{2}>0.8\right)$.

All analyses were done with R version 3.2.2 (R Core Team, 2017) using a confidence level of 0.95 throughout. Bootstrapping was done with the R-package boot (Canty and Ripley, 2016). Adjustment of $\mathrm{p}$ values for multiple testing was done with the Bonferroni-Holm method.

\subsection{Results}

\subsubsection{Biomass stock density}

Aboveground live biomass stocks (dry matter) in the primeval forests were on average $20 \%$ larger than in the production forests (386 vs. $320 \mathrm{Mg} \mathrm{ha}^{-1} ; \mathrm{p}=0.01$; Figure 3.1, Tables 3.A1 and 3.A2). However, the difference was significant only in Havešová, with a $60 \%$ greater value than in the nearby production forest $(\mathrm{p}=0.001)$. Production and primeval forests reached similar biomass stocks in Kyjov and Stužica.

In comparison with the three development stages of the primeval forests, the live biomass of 

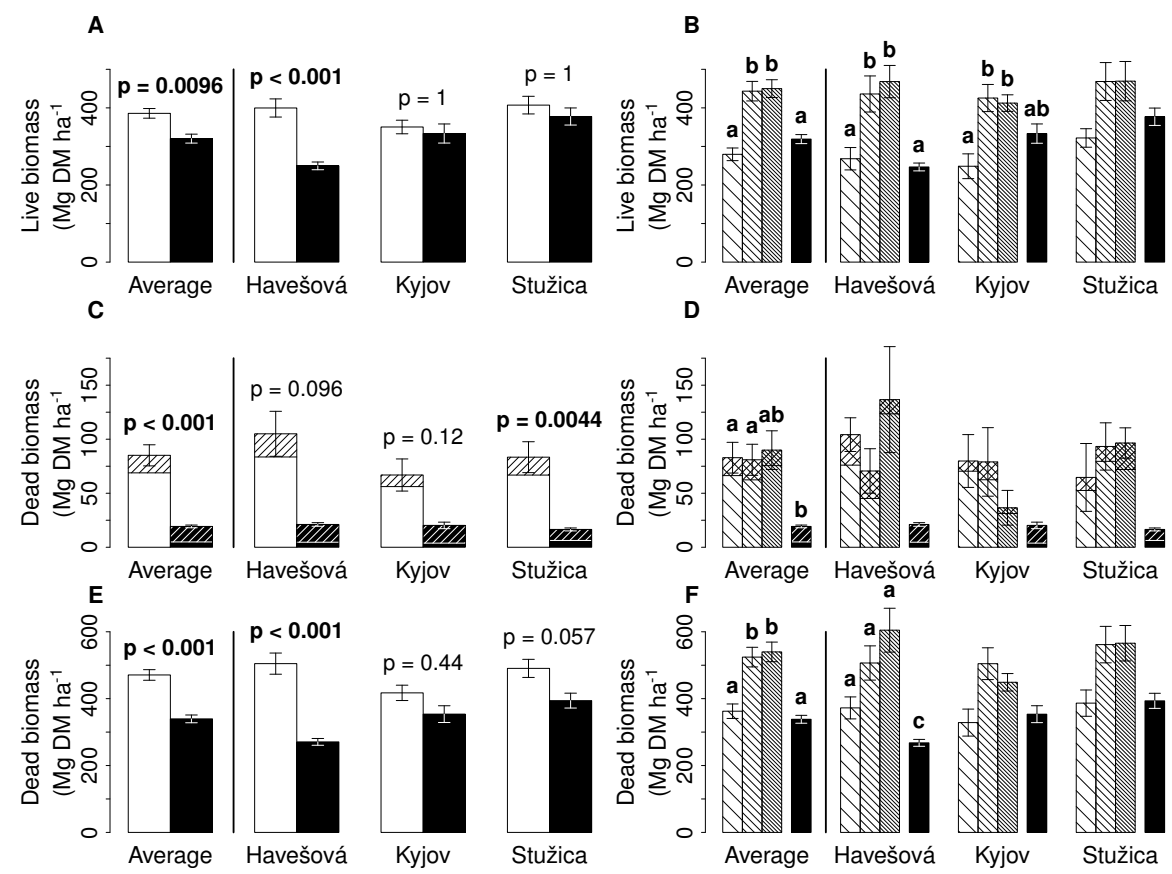

Figure 3.1: Aboveground stocks of live (A, B), dead (C, D) and total biomass (live and dead; E, F) in the three primeval (white bars) and three production forests (black bars) (means \pm bootstrap standard error). In B, D and F, the data are given separately for the three development stages of the primeval forests (growth stage: first bar, optimum stage: second bar, terminal stage: third bar). The data from the production forests (black bar at distance) are depicted for comparison. Hatched bar tips in figures $\mathrm{C}$ and $\mathrm{D}$ give the stocks of fine woody debris, whereas the remainder refers to the stocks of coarse deadwood. $p$ values denote significance of differences between primeval and production forests. Letters denote significance of differences between the three development stages and the corresponding production forest. $\mathrm{n}=4$ plots per development stage and region and $\mathrm{n}=4$ plots per production forest and region (total $n=48$ plots).

the production forests shortly before harvest corresponded best to the biomass of the growth stage (in Havešová) or the transition between growth and optimal stage of the primeval forests (in Kyjov and Stužica). Deadwood mass stocks were on average more than four times larger in the primeval than in the production forests ( 86 vs. $19 \mathrm{Mg} \mathrm{ha}^{-1} ; \mathrm{p}<0.001$ ). About SIrange $1520 \%$ of the deadwood pool in the primeval forests was contributed by fine woody debris with diameters of $2-20 \mathrm{~cm}$, whereas in the production forests, this was the dominant deadwood component (60-80 percent). This difference to the primeval forests was mainly caused by the very low amount of large-sized deadwood with diameters above $20 \mathrm{~cm}$ in the production forests (70 vs. $5 \mathrm{Mg} \mathrm{ha}^{-1}$; p < 0.001), whereas the amount of fine woody debris was not different between production and primeval forests. 

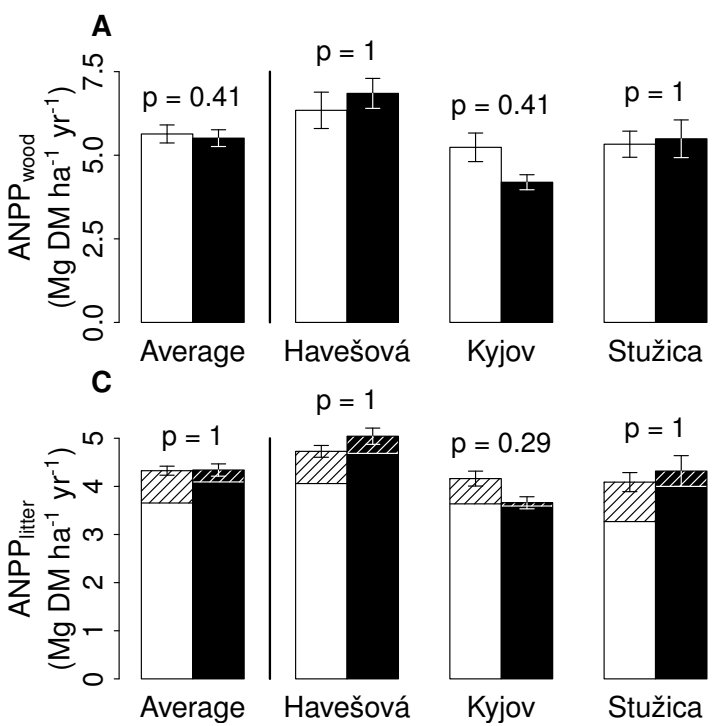
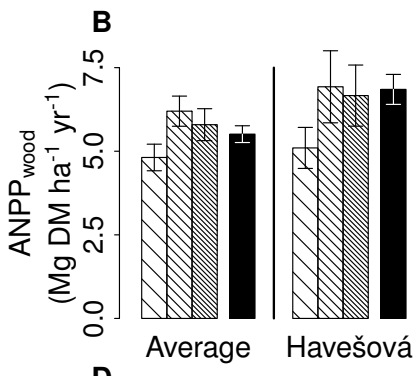

Average

Havešová

$p=1$

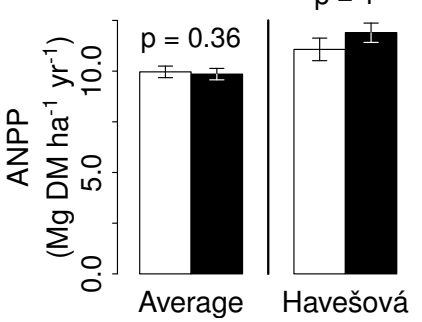

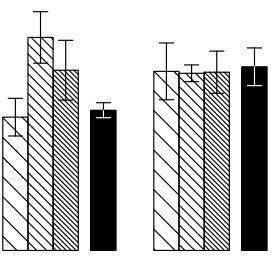

Kyjov

Stužica

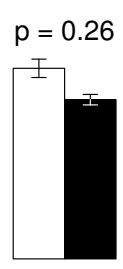

$p=1$

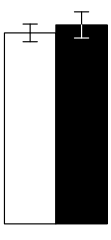

Stužica

Figure 3.2: $A N P P_{\text {wood }}(\mathbf{A}, \mathbf{B}), A N P P_{\text {litter }}(\mathbf{C})$ and total $A N P P(\mathbf{D})$ of primeval (white bars) and production forests (black bars) in the three regions (means \pm bootstrap standard error). In $\mathrm{B}, A N P P_{\text {wood }}$ is given separately for the three development stages of the primeval forests (growth stage: first bar, optimum stage: second bar, terminal stage: third bar). The data from the production forests (black bar at distance) are depicted for comparison. Differences between development stages are not significant. Hatched bar tips in panel C show fruit production, and the remainders of the bars show leaf mass production. $\mathrm{P}$ values denote differences between primeval and production forests. $\mathrm{n}=4$ plots per development stages and region and $\mathrm{n}=4$ plots per production forest and region (total $\mathrm{n}=48$ plots).

The large stocks of coarse deadwood in the primeval forests resulted in a $39 \%$ larger total biomass (live and dead) in the primeval as compared to the production forests $(\mathrm{p}<0.001)$. The difference was largest in Havešová $(p<0.001)$ but much smaller in Kyjov and Stužica (not significant).

Compared to the optimal and terminal stage, the growth stage had an on average 37 and $32 \%$ lower live and total biomass $(\mathrm{p}<0.001)$. This trend existed in all study areas but was significant only in Havešová and Kyjov. In contrast, no difference existed between optimal and terminal stage with respect to the live and total biomass. Contrary to expectation, the deadwood stocks showed no significant differences between the three stages.

\subsubsection{ANPP}

Primeval and production forests showed similar aboveground productivities (Figure 3.2, Table 3.A3). 
Both measured components of $A N P P, A N P P_{\text {wood }}$ and $A N P P_{\text {litter }}$, were nearly equal in all six forests. Only the composition of the litter fraction differed between production and primeval forests. Beech fruit production was 2.7 times larger in the primeval forests (Figure 3.2B, $\mathrm{p}=0.045$ ). The lower fructification in the production forests was compensated by a higher leaf mass production, resulting in similar litter production rates in both forest types.

A comparison of productivity among the three development stages of the primeval forests was only possible for $A N P P_{\text {wood }}$, as the litter production data could not be assigned to the different development stages. In Havešová and Kyjov, $A N P P_{\text {wood }}$ tended to be lowest in the growth stage with 30 and $20 \%$ higher values in the optimal and terminal stages, but the trend was not significant. In Stužica, $A N P P_{\text {wood }}$ was very similar in the three stages.

\subsubsection{Factors Controlling Productivity: The Role of Canopy Structure}

\section{Growth rate of individual trees}

The regression analysis showed that the effects of canopy structure differed for tall trees ( $\geq 66 \%)$ of dominant height in the plot) and smaller understory trees (Table 3.1), which contributed on average with about 88 and $12 \%$ to total $A N P P_{\text {wood }}$. Although the wood production of both tree groups was significantly influenced by tree biomass (that is, size) and slope and aspect, canopy structure played different roles for the two groups. For tall trees, the model showed a significant influence of the density of the lower canopy $\left(L A I_{e-l o w}\right)$, whereas small trees were dependent on the $L A I_{e}$ of the upper canopy and its spatial heterogeneity $\left(L A I_{e-u p}\right.$ and $\left.\operatorname{IQR}\left(L A I_{e-u p}\right)\right)$.

\section{Stand-Level $A N P P_{\text {wood }}$}

According to the base model (Table 3.2 top) without canopy structure parameters $\left(r^{2}=0.56\right)$, $A N P P_{\text {wood }}$ depended significantly on the slope and aspect of the primeval forest plots $(\mathrm{p}=0.03)$. Sloping terrain with plot exposition to the east influenced tree growth positively, while western exposition had a negative effect (Fig. 3.3). In plots with low inclination (slope $<10^{\circ}$ ), microtopography lost its influence on wood production. Basal area and stem density tended to influence wood production positively ( $\beta=1.1$ and 0.4 , respectively), but only the effect of basal area was 

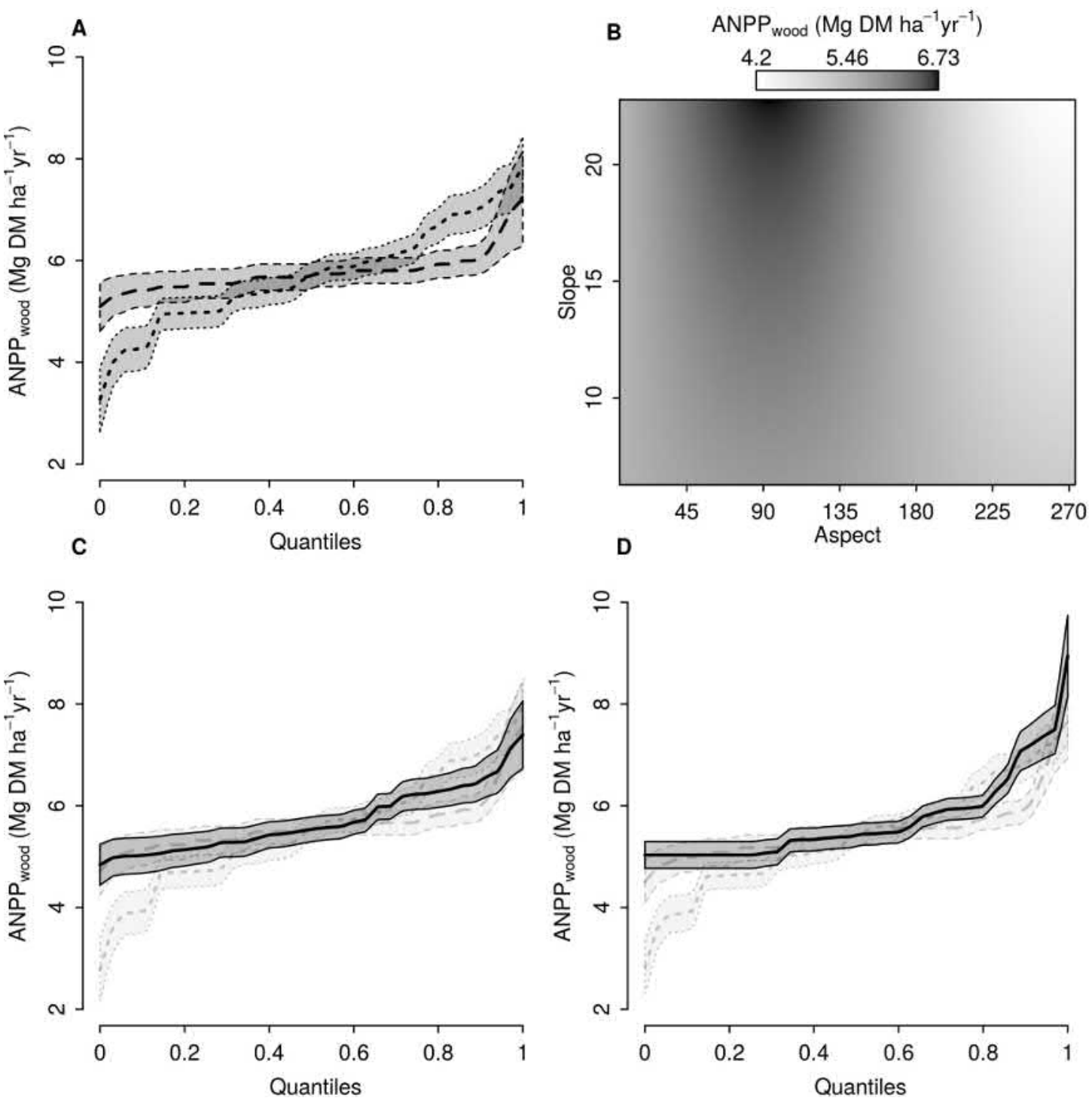

Figure 3.3: Predicted relationship between stand density (basal area-dotted; stem density-dashed) and interaction of slope and aspect on $A N P P_{\text {wood }}$ according to the regression models ( $\mathbf{A}$ and $\mathbf{B}$, base model, $\mathrm{r}^{2}=0.56$, Table 3.2). Additional covariates quantifying canopy structure were added to the base model: the spatial heterogeneity of $L A I_{e}$ of the upper canopy $\left(\mathbf{C}, \operatorname{IQR}\left(L A I_{e-u p}\right), \mathrm{r}^{2}=0.64\right)$, or $L A I_{e}$ of the lower canopy $\left(\mathbf{D}, L A I_{e-l o w}, \mathrm{r}^{2}=0.73\right)$. Model predictions were calculated for the range of all observed values of the respective focal covariate (quantiles, $\mathrm{x}$-axis). For all other covariates than the focal one, their medians were used in the model runs. Shaded areas show the standard error of the predictions. A scatterplot matrix of the used variables is presented in supplemental Figure 3.A1. 
Table 3.1: Influence of stand density (stem density, basal area), region, the three transformed microtopography parameters north, east and slope (see methods section), and canopy structure as reflected in $L A I_{e}$ and $L A I_{e}$-variability $\operatorname{IQR}\left(L A I_{e}\right)$ ) on the growth of small and large trees (woody biomass increment) as derived from linear models.

\begin{tabular}{|c|c|c|c|}
\hline \multicolumn{4}{|l|}{ Model covariates } \\
\hline & $\mathrm{F}(\mathrm{dfm} / \mathrm{dfe})$ & $\mathrm{p}$ & $\beta$ \\
\hline \multicolumn{4}{|c|}{ Small-tree model (trees $<2 / 3$ of dominant height) } \\
\hline Region & $4.26(2,343)$ & 0.015 & H: 0, K: -0.0009, S: -0.0008 \\
\hline Biomass & $235.18(1,343)$ & $<0.001$ & 0.61 \\
\hline Microtopography & $5.02(3,343)$ & 0.002 & north: 0.01 , east: 0.09 , slope: 0.01 \\
\hline $\operatorname{IQR}\left(L A I_{e-u p}\right)$ & $15.85(1,343)$ & $<0.001$ & 0.09 \\
\hline$L A I_{e-u p}$ & $6.57(1,343)$ & 0.011 & -0.06 \\
\hline \multicolumn{4}{|c|}{ Large-tree model (trees $=2 / 3$ of dominant height) } \\
\hline Region & $7.73(2,228)$ & $<0.001$ & H: 0, K: $-0.014, S:-0.008$ \\
\hline Biomass & $161.01(1,228)$ & $<0.001$ & 0.71 \\
\hline Microtopography & $3.54(3,228)$ & 0.015 & north: 0.06 , east: 0.11 , slope: -0.03 \\
\hline$L A I_{e-l o w}$ & $6.07(1,228)$ & 0.015 & 0.1 \\
\hline
\end{tabular}

covariates with a positive influence on the AIC were considered in the models. Factor levels of the regions are abbreviated by the regions' first letters (Havešová, Kyjov, Stužica). Degrees of freedom are denoted by dfm (model) and dfe (error). $\mathrm{F}$ and $\mathrm{p}$ values and standardized regression coefficients (b) of the covariates are given. Significant relationships are displayed in bold.

significant $(\mathrm{p}<0.001)$.

The $L A I_{e}$ of the upper canopy layer had no influence on $A N P P_{\text {wood }}$ according to the extended model. Instead, the spatial heterogeneity of $L A I_{e}$ in the upper canopy (expressed by $\operatorname{IQR}\left(L A I_{e-u p}\right)$ ) exerted a significant positive effect on stand-level wood production; including this variable increased the model $\mathrm{r}^{2}$ from 0.56 to 0.65 (effect significant at $\mathrm{p}=0.02$; Table 3.2: centre). The model assigned an increase in $A N P P_{\text {wood }}$ of approximately $1 \mathrm{Mg} \mathrm{ha}^{-1} \mathrm{yr}^{-1}$ to the effect of a high spatial canopy heterogeneity (large IQR $\left(L A I_{e-u p}\right)$-value; Figure $\left.3.3 \mathrm{C}\right)$. In relation to the size of overall $A N P P$, this effect stands for an increase of approximately $10 \%$. 
Table 3.2: Influence of stand density (stem density, basal area), region, the three transformed microtopography parameters north, east and slope (see methods section), and canopy structure as reflected in $L A I_{e}$ and $L A I_{e}$-variability $\left(\mathrm{IQR}\left(L A I_{e}\right)\right)$ at plot-Level $A N P P_{\text {wood }}$ as derived from linear models.

\begin{tabular}{|c|c|c|c|c|c|}
\hline \multicolumn{2}{|c|}{ Model fit } & \multicolumn{4}{|l|}{ Model covariates } \\
\hline & & & $\mathrm{F}(\mathrm{dfm} / \mathrm{dfe})$ & $\mathrm{p}$ & $\beta$ \\
\hline \multicolumn{6}{|c|}{ Base model } \\
\hline$r^{2}$ & 0.56 & Basal area & $16.04(1,28)$ & $<0.001$ & 1.05 \\
\hline \multirow[t]{3}{*}{ AIC } & 141.64 & Stem density & $2.42(1,28)$ & 0.131 & \multirow{3}{*}{$\begin{array}{l}0.41 \\
\text { H: } 0, \mathrm{~K}: \mathbf{- 2 . 1 0}, \mathrm{S}: \mathbf{- 1 . 1 5} \\
\text { north: } \mathbf{- 0 . 0 6} \text {; east: } \mathbf{1 . 0 0} \\
\quad \text { slope: }-\mathbf{0 . 0 4}\end{array}$} \\
\hline & & Region & $3.89(2,28)$ & 0.032 & \\
\hline & & Microtopography & $3.57(3,28)$ & 0.026 & \\
\hline \multicolumn{6}{|c|}{ Upper canopy model } \\
\hline $\mathrm{r}^{2}$ & 0.65 & Basal area & $23.15(1,27)$ & $<0.001$ & 1.18 \\
\hline \multirow[t]{4}{*}{ AIC } & 136.13 & Stem density & $4.91(1,27)$ & 0.035 & 0.55 \\
\hline & & Region & $4.22(2,27)$ & 0.025 & \multirow{3}{*}{$\begin{array}{l}\mathrm{H}: 0, \mathrm{~K}:-2.19, \mathrm{~S}:-0.78 \\
\text { north: } 0.09 \text {; east: } 0.94 \text {; } \\
\text { slope: }-0.18 \\
0.64\end{array}$} \\
\hline & & Microtopography & $4.17(3,27)$ & 0.015 & \\
\hline & & $\operatorname{IQR}\left(L A I_{e}\right)$ & $6.26(1,27)$ & 0.019 & \\
\hline \multicolumn{6}{|c|}{ Lower canopy model } \\
\hline$r^{2}$ & 0.73 & Basal area & $27.50(1,27)$ & $<0.001$ & 1.11 \\
\hline \multirow{4}{*}{ AIC } & 127.05 & Stem density & $7.91(1,27)$ & 0.009 & 0.62 \\
\hline & & Region & $7.46(2,27)$ & 0.003 & \multirow{3}{*}{$\begin{array}{l}\mathrm{H}: 0, \mathrm{~K}:-2.46, \mathrm{~S}:-1.16 \\
\text { north: } 0.28 \text {; east: } 0.93 \text {; } \\
\text { slope: }-0.3 \\
0.9\end{array}$} \\
\hline & & Microtopography & $6.04(3,27)$ & 0.003 & \\
\hline & & $L A I_{e-l o w}$ & $15.81(1,27)$ & $<0.001$ & \\
\hline
\end{tabular}

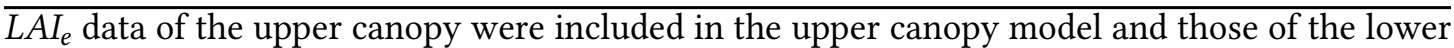
canopy in the lower canopy model. Only covariates with a positive influence on the AIC were considered in the models. Factor levels of the regions are abbreviated by the regions' first letters (Havešová, Kyjov, Stužica). Degrees of freedom are denoted by dfm (model) and dfe (error). The raw data of the used variables are presented with histograms and scatter plots in supplemental Figure 3.A1. F and p values and standardized regression coefficients (b) of the covariates are given. Significant relationships are displayed in bold. 
The effect of canopy structure on productivity became more apparent, when parameters characterizing the structure of the lower canopy were added to the base model. Here, the effect of spatial $L A I$ variation $\left(\mathrm{IQR}\left(L A I_{e-l_{0 w}}\right)\right)$ was not significant, but $L A I_{e-\text { low }}$ itself influenced stand productivity strongly in a positive way $(\beta=0.9, \mathrm{p}<0.001$; Table 3.2 : bottom). The inclusion of this structural parameter improved the base model considerably $\left(\mathrm{r}^{2}=0.73\right)$. The predicted increase in $A N P P_{\text {wood }}$ due to a higher $L A I_{e}$ of the lower canopy layer was similar to the productivity-promoting effect of upper canopy heterogeneity (IQR $\left.\left(L A I_{e-u p}\right)\right)$ (Figure 3.3D).

Due to the key role played by leaf area for light interception, canopy carbon gain and productivity, we chose optical $L A I_{e}$ measurements to characterize forest structural diversity. To analyse model sensitivity towards the selection of different indices characterizing canopy structural diversity, we additionally used the standard deviation and the Gini-Simpson coefficient of tree height $\left(h_{s d}\right.$ and $h_{g s}$ ), which are often used to describe the vertical layering of the canopy at the plot level. Since both parameters were negatively related to stem density $(p=0.03$ and $\mathrm{p}<0.001$, respectively), multicollinearity was avoided by dropping stem density from the models describing relationships between stand structure, $h_{s d}, h_{g s}$ and productivity. $h_{s d}$ showed a negative correlation with $A N P P_{\text {wood }}(\mathrm{b}=-0.78, \mathrm{p}=0.048)$, whereas the relationship between $h_{g s}$ and $A N P P_{\text {wood }}$ was positive (0.40) but not significant $(\mathrm{p}=0.16)$.

\subsection{Discussion}

\subsubsection{Biomass stocks of primeval and production forests}

Live aboveground biomass was high in the primeval forests Havešová and Stužica in comparison with Kyjov and also in relation to the primeval beech forest Uholka-Shyrokyi Luh in the Ukrainian Carpathians. Havešová and Stužica held 14 and $12 \%$ larger live wood volumes than Uholka; the average live wood volume of the three Slovakian forests was still $6 \%$ greater than that of the Ukrainian primeval forest (616 vs. $582 \mathrm{~m}^{3} \mathrm{ha}^{-1}$ ) (Hobi et al., 2015). However, the range of recorded live wood volumes was similar in the Slovakian and Ukrainian forest plots, and the maximum values on the individual plots were even higher in Uholka than in Slovakia (Hobi, personal communication). In contrast, wood volume estimates for primeval beech forests 
in Albania were ca. $15 \%$ higher than for Havešová and Stužica (Tabaku, 2000). The Slovakian mean values for aboveground live biomass (ca. $390 \mathrm{Mg} \mathrm{ha}^{-1}$ ), deadwood mass (ca. $85 \mathrm{Mg} \mathrm{ha}^{-1}$ ) and total biomass (ca. $470 \mathrm{Mg} \mathrm{ha}^{-1}$ ) may thus represent fairly good estimates for primeval beech forests in Eastern-central and South-eastern Europe. The relatively low biomass values in Kyjov are probably a consequence of the northern aspect of the reserve and perhaps the less fertile soil (Dystric Cambisol with high allophane content) where P fixation could play a role. There is no information on contrasting forest histories of the three Slovakian sites, which could explain the difference.

With approximately $320 \mathrm{Mg} \mathrm{ha}^{-1}$, the Slovakian production forests held on average about $83 \%$ of the aboveground live biomass of the nearby primeval forests. The difference was less than $10 \%$ (and not significant) in Stužica and Kyjov, but large in Havešová (60 \% larger biomass in the primeval forest). The biomass stocks of the Stužica and Kyjov production forests ranged between the biomasses of the growth and the optimal or terminal stages of the corresponding primeval forests, while the Havešová production forest contained less biomass than the growth stage of the primeval forest. For mature Central European beech production forests, aboveground biomasses in the range of $215-419 \mathrm{Mg} \mathrm{ha}^{-1}$ were reported (Röhrig, 1991).

When comparing primeval and production forests, it must be taken into account that the production forests are closed even-aged stands shortly before harvest with ages of 90-100 years in Stužica and Kyjov and ca. 70 years in Havešová. Stem densities (stand means 629 vs. 334 ha -1) were on average higher in the production forests than in the primeval forests Additionally, natural gap formation, which reduces live biomass on the gap area, takes place in the primeval forests (average percentage area of canopy gaps between 8 and $16 \%$, Feldmann et al., 2018; Drößler and von Lüpke, 2005), but not in the production forests, which are managed in Slovakia as cohorts with relatively short rotation period ( $¡ 100$ years) and no thinning during most of the production cycle. These structural characteristics explain why the production forests were able to accumulate about $85 \%$ of the aboveground live biomass of the primeval forests within less than 100 years.

In other studies in temperate forests, the biomass difference between managed and unmanaged forests was larger than found in Slovakia. For example, 'partially cut' F. sylvatica production 
forests in northwestern Spain held almost $100 \mathrm{Mg} \mathrm{ha}^{-1}$ smaller C stocks in the aboveground tree biomass than unmanaged forests (Merino et al., 2007). This can probably be explained by the fact that the unmanaged beech forests in Spain had been affected by moderate human disturbances in the past, which synchronized the forest development cycle in these stands and eventually resulted in a cohort with many big trees. In the Slovakian primeval forests, such a synchronization did not occur and the relative abundance of the development stages was more balanced. Very big trees were less abundant, and the biomass difference to the production forests was thus smaller.

Unexpected is the result that the wood biomass in the primeval forests was not different between the optimal and terminal stages, even though gap formation was in progress in the terminal stage plots. We explain this apparent steady state in biomass stocks by the fact that most gaps in natural beech forests are small, typically formed by only one or two fallen trees. This leads to an only moderate reduction in the biomass total of a plot. In addition, young trees are establishing rapidly in the gaps and partly compensate for the biomass loss. A marked biomass reduction by approximately $30-40$ percent was only observed with the transition from the terminal to the growth stage of forest development, when most of the dominant old trees had died.

The difference between production and primeval forest is much larger for the amount of deadwood; the latter exceeded the former by a factor of approximately 4.5 ( $85 \mathrm{vs} .19 \mathrm{Mg} \mathrm{ha}^{-1}$ on average). In the primeval forests, we found high deadwood amounts of 50 to greater than $100 \mathrm{Mgha}^{-1}$ not only in the terminal and subsequent growth stage, but also in the optimal stage. The data from Slovakia contrast with the reports of several authors who found reduced deadwood amounts in the optimal stage compared to the growth or terminal stages (Král et al., 2010; Tabaku, 2000). Our finding of continuously high deadwood amounts across the whole forest developmental cycle may be explained by four factors: (1) The amount of deadwood in a given plot is in part dependent on the presence of fallen trees originating outside the plot borders, where often a different development stage is present due to the small-scale mosaic structure of primeval beech forests. A clearer picture would emerge if the deadwood analysis would account for the origin of fallen logs. (2) In a primeval forest, trees are dying in all stages 
of the development cycle, through fierce competition in the thinning phase of young growth, in the optimal stage through damage by falling neighbour trees and in the terminal stage through senescence and pathogen attack. (3) In the Slovakian primeval beech forests, most patches assignable to a single development stage are small, resulting in a horizontal and vertical overlap of different stages at the plot level. Deadwood production due to tree senescence is therefore not only occurring in plots assigned to the terminal stage, but in plots with dominance of the growth and optimal stages as well. (4) Finally, in this relatively cool and moist climate, fallen beech logs may take up to 50 years to be fully decomposed (Př́větivý et al., 2016). This leads to a deadwood legacy, which can bridge one development stage.

\subsubsection{Aboveground productivity}

Productivity measurements in even-aged forest plantations have shown that ANPP typically peaks in the first decades, followed by a subsequent growth decline (Assmann and Davis, 1970; Genet et al., 2010; Utschig and Küsters, 2003; He et al., 2012; Ryan et al., 1997). This seems to suggest that primeval forests with abundance of old trees and a larger gap fraction should be less productive than even-aged production forests of less than 100 years. However, we found no difference in ANPP between primeval and production forests (means 10.0 vs. $9.9 \mathrm{Mg} \mathrm{ha}^{-1} \mathrm{yr}^{-1}$ ). Our figures are close to the mean ANPP value, which was calculated for Central European beech production forests from a literature survey of plot-level production data $\left(10.5 \mathrm{Mg} \mathrm{ha}^{-1} \mathrm{yr}^{-1}\right.$; Leuschner and Ellenberg, 2017).

Our stand-level production data indicate that the concept of an age-related NPP decline is not simply transferable from tree cohort studies to old-growth forests, because demography and canopy structure are largely different between the two forest types. In fact, $A N P P_{\text {wood }}$ remained high across all three forest development stages, in contrast to the declining trend suggested by the cohort data. In a previous study on the same plots, we showed with optical leaf area determination that the effective leaf area index remains constantly high from the growth to the terminal stage, while the spatial heterogeneity of the canopy in terms of leaf area distribution increases towards the terminal stage (Glatthorn et al., 2017). Thus, a large assimilating leaf surface is also present in the terminal stage of primeval beech forests, despite the process of 
gap formation. This can be explained by the small size of gaps in most beech old-growth forests and the ability of $F$. sylvatica for rapid lateral canopy expansion. A similar pattern was found in North-American temperate deciduous forests, where moderate disturbances below a certain threshold intensity did not lead to a decline in $A N P P_{\text {wood }}$ because the undisturbed forest patches were able to compensate the productivity loss caused by the dead trees (Stuart-Haëntjens et al., 2015). Hence, the invariance of $A N P P_{\text {wood }}$ from the growth to the terminal stage is not surprising. Although primeval beech forests seem to maintain high biomass stocks and also a high $A N P P_{\text {wood }}$ till the terminal stage of forest development, when major disturbances are absent, this pattern may be different in tree species with less vigorous lateral canopy expansion, as in conifers (Schulze et al., 2009) or oak species.

An important result is our finding that the ANPP of even-aged production forests does not necessarily exceed the productivity level of unmanaged primeval forests of the same species. This is valid at least for the Slovakian stands with an age of 70-100 years, which are characterized by rare thinning cycles and high stem densities. Younger production forests may well reach a higher productivity. The productivity of beech cohort stands has been reported to culminate at an age of 40 years, if no thinning is conducted (Utschig and Küsters, 2003), that of Pinus sylvestris plantations already at an age of 15 years (Mencuccini and Grace, 1996). How thinning influences productivity depends on thinning intensity and also on tree age (Pretzsch, 2005; Utschig and Küsters, 2003; Oliver and Larson, 1996). This suggests that younger beech stands and stands managed with other silvicultural systems than practiced in Slovakia might differ in their productivity relation to primeval forests. Replacement of $F$. sylvatica on sites where other species potentially have a higher productivity than beech might as well lead to different results. This could be the case in submontane areas where Picea abies was found to be more productive than F. sylvatica (Pretzsch, 2005). More data are needed to answer the question of how productivity of managed stands compares to that of the natural forest vegetation. This topic is of particular relevance when assessing the carbon sequestration potential of managed and old-growth forests.

Although ANPP was similar in primeval and production forests, net ecosystem production $(N E P)$ likely will be higher in the production forests due to their younger age and lower standing 
biomass. Moreover, the decay of the large deadwood amounts in the primeval forests likely is associated with elevated heterotrophic respiration rates, which lower NEP.

\subsubsection{Dependence of the growth of single trees on canopy structure}

Our model analysis shows that small trees ( $i 2 / 3$ of dominant height in the stand), which contributed $12 \%$ of $A N P P_{\text {wood }}$ in the stand, grew better, when the upper canopy was heterogeneous (high $L A I_{e-u p}$ variation), suggesting that they profited from patches with higher light levels in the understory. As expected, the radial growth of small understory trees responded negatively to a higher mean leaf area of the upper canopy. More surprising is the model result that the taller trees of the upper canopy had higher increments, when the $L A I_{e}$ of the lower canopy was larger. A possible explanation is that this canopy section includes also the lowermost shade crown layers of the upper canopy trees, which contribute with assimilates to the $\mathrm{C}$ balance of the trees. Thus, in a primeval forest with high heterogeneity of leaf area and radiation transmission, light conditions suitable for the establishment of a denser understory seem also to support the growth of the dominant trees with deep-reaching shade crowns.

\subsubsection{Dependence of ANPP wood $_{\text {on canopy structure }}$}

Main determinants of temperate forest productivity are temperature and growing season length, light availability, water and nutrient supply, and various stand structural characteristics such as stand density and leaf area index (Bartsch and Röhrig, 2016). By comparing even-aged production forests with primeval forests, we attempted to clarify the influence of canopy structure on $A N P P$, which is not well understood. In accordance with previous studies (Liang et al., 2016; Pretzsch et al., 2015), our models identified basal area as the most important structural property influencing $A N P P_{\text {wood }}$ in the 36 plots. Plot aspect was also influential with a lower $A N P P_{\text {wood }}$ on southern slopes, which may point to temporal water shortage in this exposition (van der Maaten, 2012).

However, we did not find a positive relationship between wood production and a darker and denser canopy, which contrasts with previous studies (Hardiman et al., 2011; Pretzsch et al., 2015). Hardiman et al. (2011) postulated the existence of an optimal LAI for productivity, which 
is already reached early in stand development, and that a further increase of productivity is only achievable through a diversification of canopy structure. We explain the missing positive effect of upper canopy $L A I$ on $A N P P_{\text {wood }}$ by the principally high beech $L A I$ s at our sites, leaving not much room for an $L A I$ effect on productivity. Even though leaf area is reduced by fallen senescent trees, neighbouring trees respond with vigorous lateral growth of branches and gaps are rapidly occupied by dense layers of beech offspring (Feldmann et al., 2018). The characteristic structure of the primeval forests and the principally favourable growing conditions lead to a rapid replacement of the leaf production capacity of dying old trees in the overstory, and the effect of gap formation on stand-level productivity is thus relatively small.

In support of our hypothesis (iii), we found a positive effect of spatial $L A I_{e}$ variation in the upper canopy $\left(\operatorname{IQR}\left(L A I_{e-u p}\right)\right)$ and of the density of the lower canopy $\left(L A I_{e-l o w}\right)$ on $A N P P_{\text {wood }}$. Large variation of LAIe-up and a high lower-canopy $L A I$ are expressions of a heterogeneous horizontal and vertical canopy structure, caused by the small-scale mosaic of co-occurring forest development stages in the primeval forests. Both measures for structural diversity are related to each other, so their effects on $A N P P_{\text {wood }}$ are not cumulative.

Our model results suggest that structural complexity of the canopy enhances $A N P P_{\text {wood }}$ in the primeval forests, independent of the effects of stand density and basal area on productivity. The model calculated an approximate increase in $A N P P_{\text {wood }}$ by $1 \mathrm{Mg} \mathrm{ha}^{-1} \mathrm{yr}^{-1}$ from plots with low to plots with high structural diversity.

In contrast to the models using $L A I_{e}$ for quantifying canopy structure, alternative models using tree height distribution at the plot level $\left(\mathrm{hsd} h_{s d}\right.$ and $\left.h_{g s}\right)$ as parameters did not detect a positive relationship between structural diversity and $A N P P_{\text {wood }}$. This indicates that methods, which assess canopy structure only indirectly, might not be suitable to fully capture complementary resource use caused by a more diverse canopy. In fact, groups of similar-sized trees can contain canopy gaps and form branches in lower crown parts with large spatial heterogeneity, which would create high canopy structural diversity, even though tree height distribution is largely uniform.

Other studies also found a positive relationship between stand structural complexity in general (Gadow et al., 2016; Pretzsch et al., 2016), or the degree of canopy heterogeneity (Ishii et al., 2004; 
Hardiman et al., 2011) and forest productivity. One possible mechanism underlying this effect is greater light transmission to lower canopy strata in a more heterogeneous upper canopy, which would increase carbon assimilation in the shade crown and in the regeneration layer (Hardiman et al., 2011). The different leaf layers in the crown of a tree use the penetrating light between upper sun and lower shade crown in a complementary way due to specific adaptations in leaf anatomy and the photosynthetic apparatus to the local light and air humidity conditions. Another possible explanation for a positive structural diversity effect on productivity could be that greater spatial heterogeneity in the canopy may lead to a higher proportion of shade leaves in the foliage of a tree. Due to the higher resource use efficiency (higher $\mathrm{C}$ return upon $\mathrm{C}$ investment) of shade as compared to sun leaves, this could promote productivity.

According to this reasoning, a productivity-promoting effect of canopy structure can only exist in forests whose species composition facilitates the development of distinct shade and sun crowns. Thus, our results are not transferable to forest communities that lack the necessary functional diversity. In these cases, even negative correlations between structural or species diversity and productivity can be expected as were described, for example, by Bohn and Huth (2017) and Jacob et al. (2010).

Temporal variation of climatic and edaphic conditions has been identified as important factors influencing the diversity-productivity relationship (Forrester and Bauhus, 2016). As our analysis comprised only 1 year, we cannot address the possible importance of interannual variation in growth-controlling factors on the effect of canopy structural diversity. In dry years, for example, tree growth most likely will be limited by water scarcity even in the montane belt, and complementary light use arising from a diverse canopy structure might be a less relevant factor. The irregular mast fruiting patterns of $F$. sylvatica may also reduce the importance of canopy structural diversity on productivity, as half or more of canopy carbon gain is often consumed by fruit production (Müller-Haubold et al., 2013).

Complementary resource use and facilitation among functionally different species have been identified as key mechanisms driving a positive diversity-productivity relationship in various ecosystems (Scherer-Lorenzen et al., 2005; Liang et al., 2016). Our results from primeval beech forests show that complementary resource use and facilitation can have positive effects on 
productivity also in single-species stands, when the structural heterogeneity of the canopy is high. In this case, the effect of structural diversity seems to replace that of species diversity. In accordance, citeProdForrester.2016 argued that a single species may be able to fulfil different functions in the ecosystem, when different age classes or individuals in different demographic position are present. The case of old-growth F. sylvatica forests shows that a single, morphologically and functionally highly plastic tree species is capable of filling most of the niches that are created by the high structural heterogeneity in a primeval forest. Apical and lateral branches with leaves of high light demand are capable of rapidly occupying gaps and canopy space in the upper crown, whereas highly shade-tolerant leaves in the lower shade crown of the same tree individual are able to reduce light availability in the understory to very low levels and to endure long periods of deep shade (Leuschner and Ellenberg, 2017). Thus, functional diversity in a community is caused not only by the presence of different species, but it can also be generated by the heterogeneous population structure of a single species and even by high functional plasticity within a single tree individual. This is empirical evidence for a positive effect of structural diversity on productivity in forest ecosystems.

\subsection{Conclusions}

This study in three true primeval forests of European beech shows that these remnants of the natural forest vegetation store more biomass and contain by far higher amounts of deadwood than production forests near final harvest (age 70- 100 years), which adds to their outstanding, well-documented value as hotspots of biodiversity. Even though the difference between primeval and production forests was significant only at one site, the aboveground live biomass was on average ca. $20 \%$ larger in the former $(+5,8$ and $60 \%$ at the three sites), demonstrating that large old-growth forests are important carbon stores not only for deadwood but also for biomass. Aboveground plant mass (live and dead) was even approximately $39 \%$ greater in the primeval forests. This needs careful consideration in the recent debate on the $\mathrm{C}$ sequestration potential of forests, which currently focuses on the $\mathrm{CO}_{2}$ mitigation potential achievable by the substituting effect of timber harvested in production forests. 
Despite lower stem densities and higher mean tree age, primeval forests were as productive as cohort-like production forests of the same species, thereby shedding new light on the debate, as to whether the productivity of forests declines beyond a certain age. It appears that F. sylvatica forests can reach a high NPP even when most trees are fairly old, if the growing conditions and stand and canopy structure are favourable. Future research should examine whether the relationship in the NPP of pairs of primeval and production forests changes with tree species, site conditions and the silvicultural management regime.

By comparing three principal forest development stages, we could show that any cyclical or directional change in productivity is remarkably small in beech old-growth forests. The assumed productivity decline in the terminal stage is hardly recognizable in plots of $500 \mathrm{~m}^{2}$ size due to the rapid gap closure characteristic for beech forests. This is certainly different for the rate of biomass accumulation (NEP), which must approach zero after the optimal stage is reached, because more biomass is lost due to tree death than is produced by the NPP of the remaining tree population and heterotrophic respiration should increase with the increase in deadwood. Thus, primeval beech forests must be perceived as spatially heterogeneous in horizontal and vertical direction, but they are remarkably uniform in space and time when it comes to ecosystem functions such as carbon cycling. This picture changes only when rare large-scale disturbance events such as windthrow take place, which can destroy the forest over several hectares.

Our results highlight the importance of smallscale heterogeneity in canopy structure for the productivity at the stand level. Based on model results, we estimate that about $10 \%$ of primeval forest $A N P P$ is caused by effects related to the high structural heterogeneity of the canopy. More comparative studies on the functioning of primeval and production forests are needed for better understanding the value of old-growth forests and for assessing the impact of forest management on the productivity and carbon storage of temperate forests. 


\subsection{Acknowledgements}

This study was possible through a grant of the Stemmler Foundation, a member of the Stifterverband für die Deutsche Wissenschaft, to C. Leuschner and M. Hauck. This support is gratefully acknowledged. We are also grateful to the Poloniny National Park authority, the local forest administrations and the Ministry of Defence of the Slovak Republic for the permits to conduct the study and for technical support during the fieldwork. 


\section{Appendix}
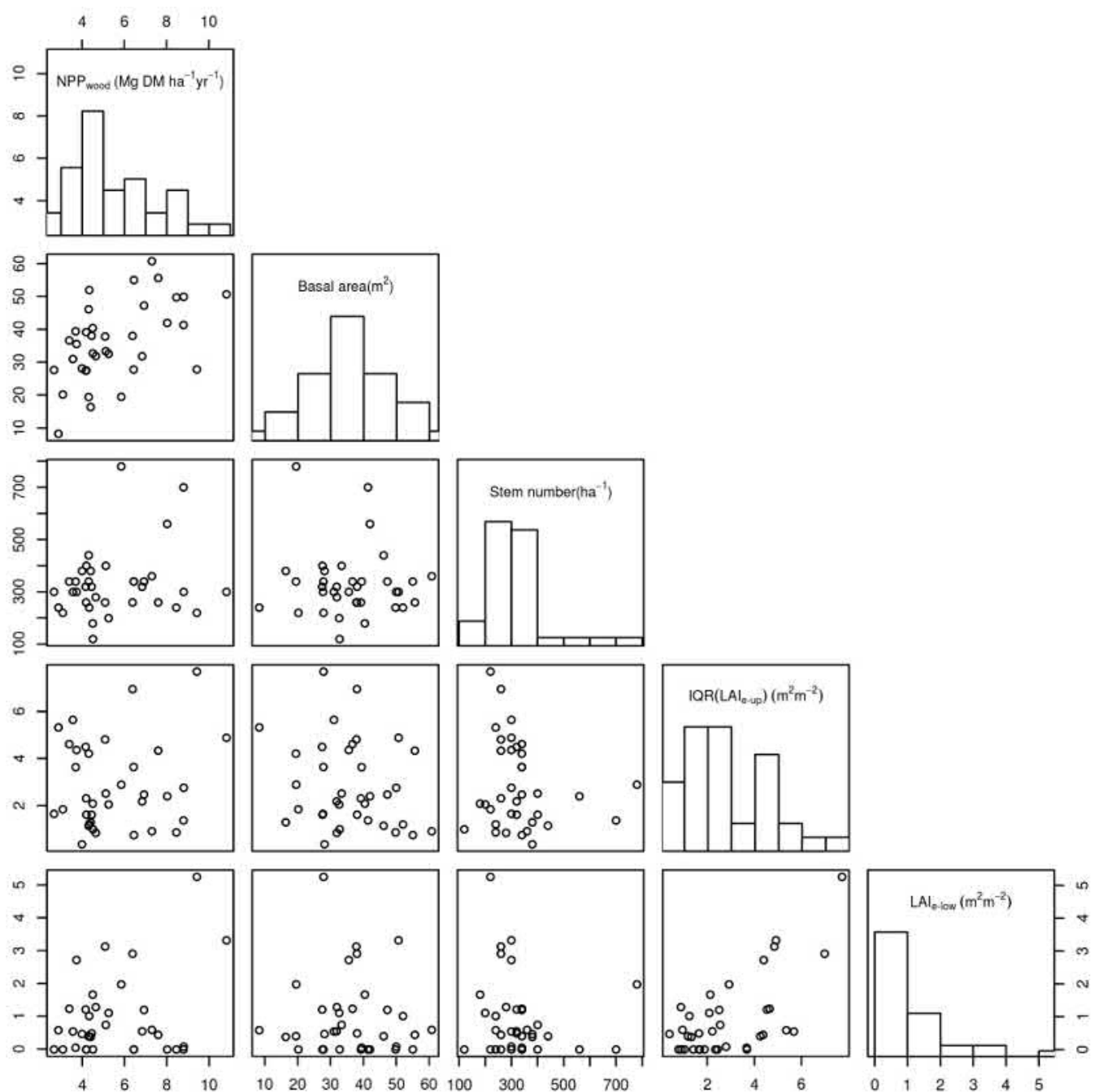

Figure 3.A1: Raw data of the major continuous variables which have been used for the linear models presented in Table 3.2 and Figure 3.2. Panels on the main diagonal do show histograms of the five variables. All other panels display scatterplots of the combinations of two variables. In each row of the panel-array the same variable is represented on the $\mathrm{x}$-axes (indicated by the histogram of the respective row) while in each column the same variables are represented on the panel y-axes (indicated by the histogram of the respective column). 


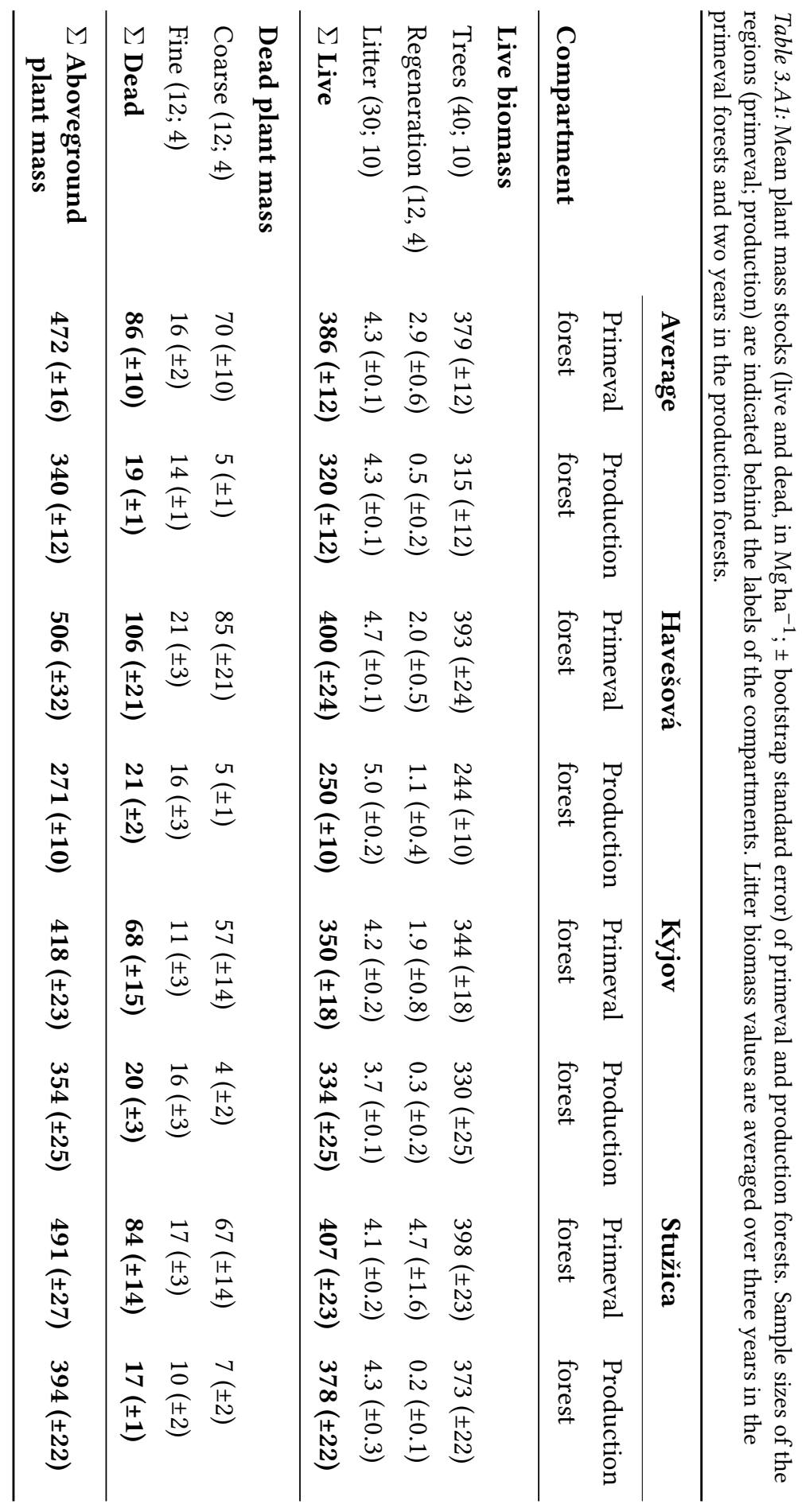


Table 3.A2: Mean plant mass stocks (live and dead, in $\mathrm{Mg} \mathrm{ha}^{-1} ; \pm$ bootstrap standard error) of the three primeval forest development stages. Sample sizes are indicated in paranthesis behind the labels of the compartments.

\begin{tabular}{|c|c|c|c|c|}
\hline & Average & Havešová & Kyjov & Stužica \\
\hline \multicolumn{5}{|l|}{ Growth stage } \\
\hline Live trees $(45,12,16,17)$ & $279( \pm 16)$ & $268( \pm 29)$ & $248( \pm 32)$ & $321( \pm 24)$ \\
\hline Regeneration $(36,12,12,12)$ & $0.8( \pm 0.2)$ & $0.6( \pm 0.2)$ & $0.9( \pm 0.3)$ & $1.1( \pm 0.4)$ \\
\hline$\Sigma$ Live & $280( \pm 16)$ & $268( \pm 29)$ & $249( \pm 32)$ & $322( \pm 24)$ \\
\hline Coarse deadwood $(36,12,12,12)$ & $68( \pm 14)$ & $78( \pm 15)$ & $72( \pm 23)$ & $53( \pm 31)$ \\
\hline Fine deadwood $(36,12,12,12)$ & $17( \pm 2)$ & $28( \pm 3)$ & $9( \pm 3)$ & $12( \pm 2)$ \\
\hline$\Sigma$ Dead & $84( \pm 15)$ & $107( \pm 17)$ & $81( \pm 25)$ & $98( \pm 14)$ \\
\hline$\Sigma$ Aboveground plant mass & $364( \pm 22)$ & $375( \pm 33)$ & $330( \pm 40)$ & $387( \pm 40)$ \\
\hline \multicolumn{5}{|l|}{ Optimal stage } \\
\hline Live trees $(34,12,12,10)$ & $440( \pm 25)$ & $435( \pm 47)$ & $425( \pm 35)$ & $461( \pm 49)$ \\
\hline Regeneration $(36,12,12,12)$ & $3.2( \pm 1.5)$ & $1.4( \pm 0.6)$ & $0.8( \pm 0.3)$ & $7.3( \pm 4.6)$ \\
\hline$\Sigma$ Live & $443( \pm 25)$ & $436( \pm 47)$ & $426( \pm 35)$ & $468( \pm 49)$ \\
\hline Coarse deadwood $(36,12,12,12)$ & $63( \pm 13)$ & $46( \pm 15)$ & $64( \pm 27)$ & $80( \pm 23)$ \\
\hline Fine deadwood $(36,12,12,12)$ & $19( \pm 3)$ & $25( \pm 7)$ & $17( \pm 7)$ & $14( \pm 4)$ \\
\hline$\Sigma$ Dead & $82( \pm 15)$ & $72( \pm 21)$ & $80( \pm 31)$ & $17( \pm 1)$ \\
\hline$\Sigma$ Aboveground plant mass & $525( \pm 30)$ & $508( \pm 51)$ & $506( \pm 48)$ & $562( \pm 55)$ \\
\hline \multicolumn{5}{|l|}{ Terminal stage } \\
\hline Live trees $(41,16,12,13)$ & $445( \pm 23)$ & $465( \pm 42)$ & $408( \pm 21)$ & $463( \pm 51)$ \\
\hline Regeneration $(36,12,12,12)$ & $4.8( \pm 1.3)$ & $3.4( \pm 1.2)$ & $4.4( \pm 2.8)$ & $6.6( \pm 2.4)$ \\
\hline$\sum$ Live & $450( \pm 23)$ & $468( \pm 42)$ & $412( \pm 21)$ & $469( \pm 52)$ \\
\hline Coarse deadwood $(36,12,12,12)$ & $76( \pm 18)$ & $124( \pm 51)$ & $31( \pm 16)$ & $73( \pm 10)$ \\
\hline Fine deadwood $(36,12,12,12)$ & $14( \pm 3)$ & $13( \pm 3)$ & $5( \pm 1)$ & $24( \pm 9)$ \\
\hline$\Sigma$ Dead & $91( \pm 18)$ & $137( \pm 49)$ & $37( \pm 16)$ & $84( \pm 14)$ \\
\hline$\Sigma$ Aboveground plant mass & $541( \pm 29)$ & $605( \pm 66)$ & $449( \pm 26)$ & $567( \pm 54)$ \\
\hline
\end{tabular}




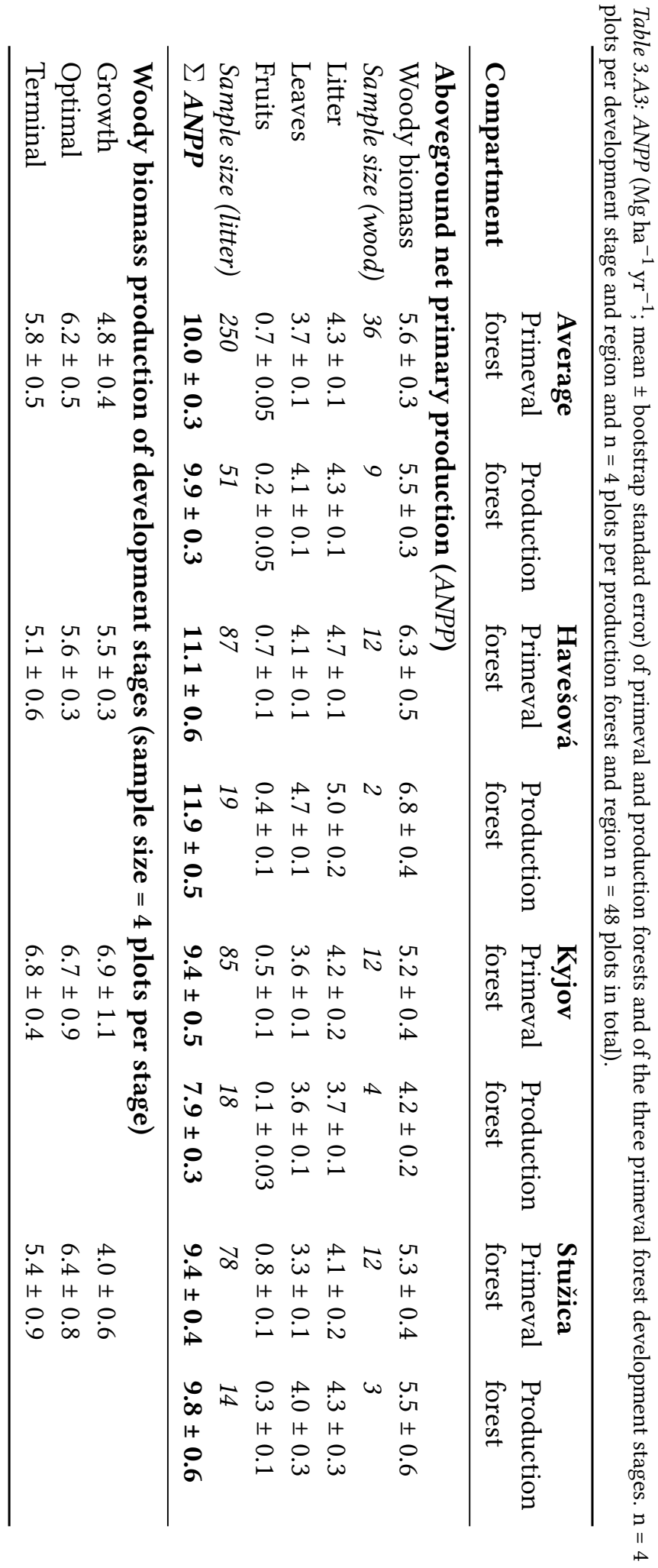


Table 3.A4: Influence of basal area, region, the three transformed microtopography parameters north, east and slope (see methods section), and canopy structural diversity as reflected in the standard deviation $\left(h_{s d}\right)$ and gini-simpson coefficient $\left(h_{g s}\right)$ of the tree heights at plot-level $A N P P_{\text {wood }}$ as derived from linear models. $\mathrm{F}$ and p-values and standardized regression coefficients $(\beta)$ of the covariates are given. Only covariates with a positive influence on the AIC were considered in the models. Factor levels of the regions are abbreviated by the regions' first letters (Havešová, Kyjov, Stužica). Degrees of freedom are denoted by dfm (model) and dfe (error). Significant relationships are displayed in bold.

\begin{tabular}{|c|c|c|c|c|c|}
\hline \multicolumn{2}{|c|}{ Model fit } & \multicolumn{4}{|l|}{ Model covariates } \\
\hline & & & $\mathrm{F}(\mathrm{dfm} / \mathrm{dfe})$ & $\mathrm{p}$ & $\beta$ \\
\hline \multicolumn{6}{|c|}{$\mathbf{h}_{\text {sd }}$ model } \\
\hline $\mathrm{r}^{2}$ & 0.59 & Basal area & $17.49(1,28)$ & $<0.001$ & 1.06 \\
\hline \multirow[t]{3}{*}{ AIC } & 139.50 & Region & $6.29(2,28)$ & 0.006 & \multirow{3}{*}{$\begin{array}{l}\text { H: } 0, \mathrm{~K}:-3.45, \mathrm{~S}:-1.04 \\
\text { north: } 0.1 \text {; east: } 0.83 \\
\quad \text { slope: }-0.25 \\
-0.78\end{array}$} \\
\hline & & Microtopography & $3.19(3,28)$ & 0.039 & \\
\hline & & $\mathbf{h}_{\text {sd }}$ & $4.29(1,28)$ & 0.048 & \\
\hline \multicolumn{6}{|c|}{$\mathbf{h}_{\mathrm{gs}}$ model } \\
\hline$r^{2}$ & 0.56 & Basal area & $15.2(1,28)$ & $<0.001$ & 1.02 \\
\hline \multirow[t]{5}{*}{ AIC } & 142.05 & Basal area & $15.2(1,28)$ & $<0.001$ & 1.02 \\
\hline & & Region & $4.63(2,28)$ & 0.018 & \multirow{2}{*}{$\begin{array}{l}\text { H: } 0, \mathrm{~K}:-2.37, \mathrm{~S}:-1.28 \\
\text { north: } 0.01 \text {; east: } 0.91 \text {; } \\
\quad \text { slope: }-0.11\end{array}$} \\
\hline & & Microtopography & $4.63(3,28)$ & 0.048 & \\
\hline & & & $4.29(1,28)$ & 0.048 & 0.64 \\
\hline & & $\mathrm{h}_{\mathrm{gs}}$ & $2.08(1,28)$ & 0.160 & 0.4 \\
\hline
\end{tabular}




\section{References}

Albrecht, L., 1991. Die Bedeutung des toten Holzes im Wald. Forstwissenschaftliches Centralblatt vereinigt mit Tharandter Forstliches Jahrbuch 110 (1), 106-113.

Annighöfer, P., Ameztegui, A., Ammer, C., Balandier, P., Bartsch, N., Bolte, A., Coll, L., Collet, C., Ewald, J., Frischbier, N., Gebereyesus, T., Haase, J., Hamm, T., Hirschfelder, B., Huth, F., Kändler, G., Kahl, A., Kawaletz, H., Kuehne, C., Lacointe, A., Lin, N., Löf, M., Malagoli, P., Marquier, A., Müller, S., Promberger, S., Provendier, D., Röhle, H., Sathornkich, J., Schall, P., Scherer-Lorenzen, M., Schröder, J., Seele, C., Weidig, J., Wirth, C., Wolf, H., Wollmerstädt, J., Mund, M., 2016. Species-specific and generic biomass equations for seedlings and saplings of European tree species. European Journal of Forest Research 135 (2), 313-329.

Assmann, E., Davis, P.W., 1970. The Principles of Forest Yield Study: Studies in the Organic Production, Structure, Increment and Yield of Forest Stands. Elsevier Science, Burlington.

Bartsch, N., Röhrig, E., 2016. Waldökologie: Einführung für Mitteleuropa. Springer Spektrum, Berlin and Heidelberg.

Bohn, F.J., Huth, A., 2017. The importance of forest structure to biodiversity-productivity relationships. Royal Society open science 4 (1), 160521.

Bohn, U., Neuhäusl, R., Gollub, R., Hettwer, C., Neuhäuslova, Z., Schlüter, H., Weber, H., 2003. Karte der natürlichen Vegetation Europas. Teil 1: Erläuterungstext. Landwirtschaftsverlag, Münster.

Bourdier, T., Cordonnier, T., Kunstler, G., Piedallu, C., Lagarrigues, G., Courbaud, B., 2016. Tree Size Inequality Reduces Forest Productivity: An Analysis Combining Inventory Data for Ten European Species and a Light Competition Model. PloS one 11 (3), e0151852.

Canty, A., Ripley, B., 2016. boot: Bootstrap R (S-Plus) Functions. R package version 1.3-18 .

Chave, J., Coomes, D., Jansen, S., Lewis, S.L., Swenson, N.G., Zanne, A.E., 2009. Towards a worldwide wood economics spectrum. Ecology Letters 12 (4), 351-366.

Chen, J.M., Black, T.A., Adams, R.S., 1991. Evaluation of hemispherical photography for determining plant area index and geometry of a forest stand. Agricultural and Forest Meteorology 56 (1-2), 129-143.

Commarmot, B., Bachofen, H., Bundziak, Y., Bürgi, A., Ramp, B., Shparyk, Y., Sukhariuk, D., Viter, R., Zingg, A., 2005. Structures of virgin and managed beech forests in Uholka (Ukraine) and Sihlwald (Switzerland): a comparative study. For. Snow Landsc. Res. 79 (1/2), 45-56.

Danescu, A., Albrecht, A.T., Bauhus, J., 2016. Structural diversity promotes productivity of mixed, uneven-aged forests in southwestern Germany. Oecologia 182 (2), 319-333.

Davison, A.C., Hinkley, D.V., 2009. Bootstrap methods and their application. Cambridge series on statistical and probabilistic mathematics. Cambridge Univ. Press, Cambridge, NY, 11. print edition.

Drößler, L., von Lüpke, B., 2005. Canopy gaps in two virgin beech forest reserves in Slovakia. Journal of Forest Science 10 (51), 446-457.

Ehbrecht, M., Schall, P., Juchheim, J., Ammer, C., Seidel, D., 2016. Effective number of layers: A new measure for quantifying three-dimensional stand structure based on sampling with terrestrial LiDAR. Forest Ecology and Management 380, 212-223.

Fahey, R.T., Fotis, A.T., Woods, K.D., 2015. Quantifying canopy complexity and effects on productivity and resilience in late-successional hemlock-hardwood forests. Ecological Applications 25 (3), 834-847.

Feldmann, E., Glatthorn, J., Hauck, M., Leuschner, C., 2018. A novel empirical approach for determining the extension of forest development stages in temperate old-growth forests. European Journal of Forest Research , 1-15.

Forrester, D.I., Bauhus, J., 2016. A Review of Processes Behind Diversity-Productivity Relationships in Forests. Current Forestry Reports 2 (1), 45-61.

von Gadow, K., Chun, Y.Z., Wehenkel, C., Arne Pommerening, Javier Corral-Rivas, Mykola Korol, Stepan Myklush, Gang Ying Hui, Andres Kiviste, Xiu Hai Zhao, 2012. Forest Structure and Diversity. In: T. Pukkala, K. von Gadow, 
eds., Continuous Cover Forestry, Managing Forest Ecosystems. Springer Netherlands, Dordrecht, pp. 29-83.

Gadow, K.v., Zhang, G., Durrheim, G., Drew, D., Seydack, A., 2016. Diversity and production in an Afromontane Forest. Forest Ecosystems 3 (1), 137.

Genet, H., Breda, N., Dufrene, E., 2010. Age-related variation in carbon allocation at tree and stand scales in beech (Fagus sylvatica L.) and sessile oak (Quercus petraea (MATt.) Liebl.) using a chronosequence approach. Tree Physiology 30 (2), 177-192.

Glatthorn, J., Pichler, V., Hauck, M., Leuschner, C., 2017. Effects of forest management on stand leaf area: Comparing beech production and primeval forests in Slovakia. Forest Ecology and Management 389, 76-85.

Gough, C.M., Curtis, P.S., Hardiman, B.S., Scheuermann, C.M., Bond-Lamberty, B., 2016. Disturbance, complexity, and succession of net ecosystem production in North America's temperate deciduous forests. Ecosphere 7 (6), e01375.

Green Report, 2009. Report on the status of forestry in the Slovak Republic of 2009. Ministry of Agriculture of the Slovak Republic, Bratislava.

Hardiman, B.S., Bohrer, G., Gough, C.M., Vogel, C.S., Curtis, P.S., 2011. The role of canopy structural complexity in wood net primary production of a maturing northern deciduous forest. Ecology 92 (9), 1818-1827.

Hardiman, B.S., Gough, C.M., Halperin, A., Hofmeister, K.L., Nave, L.E., Bohrer, G., Curtis, P.S., 2013. Maintaining high rates of carbon storage in old forests: A mechanism linking canopy structure to forest function. Forest Ecology and Management 298, 111-119.

He, L., Chen, J.M., Pan, Y., Birdsey, R., Kattge, J., 2012. Relationships between net primary productivity and forest stand age in U.S. forests. Global Biogeochemical Cycles 26 (3).

Hobi, M.L., Commarmot, B., Bugmann, H., 2015. Pattern and process in the largest primeval beech forest of Europe (Ukrainian Carpathians). Journal of Vegetation Science 26 (2), 323-336.

Ishii, H.T., Tanabe, S., Hiura, T., 2004. Exploring the relationships among canopy structure, stand productivity, and biodiversity of temperature forest ecosystems. Forest Science 50 (3), 342-355.

Jacob, M., Leuschner, C., Thomas, F.M., 2010. Productivity of temperate broad-leaved forest stands differing in tree species diversity. Annals of Forest Science 67 (5), 503.

Jonckheere, I., Fleck, S., Nackaerts, K., Muys, B., Coppin, P., Weiss, M., Baret, F., 2004. Review of methods for in situ leaf area index determination. Agricultural and Forest Meteorology 121 (1-2), 19-35.

Korpeĺ, Š., 1995. Die Urwälder der Westkarpaten. Gustav Fischer Verlag, Stuttgart.

Král, K., Vrška, T., Hort, L., Adam, D., Šamonil, P., 2010. Developmental phases in a temperate natural spruce-firbeech forest: Determination by a supervised classification method. European Journal of Forest Research 129 (3), 339-351.

Larsen, J.B., Hahn, K., Emborg, J., 2010. Forest reserve studies as inspiration for sustainable forest management Lessons learned from Suserup Skov in Denmark. Forstarchiv 2 (81), 28-33.

Lei, X., Wang, W., Peng, C., 2009. Relationships between stand growth and structural diversity in spruce-dominated forests in New Brunswick, Canada. Canadian Journal of Forest Research 39 (10), 1835-1847.

Leuschner, C., Ellenberg, H., 2017. Ecology of Central European Forests - Vegetation Ecology of Central Europe, Vol. I. Springer, Dordrecht.

Liang, J., Crowther, T.W., Picard, N., Wiser, S., Zhou, M., Alberti, G., Schulze, E.D., McGuire, A.D., Bozzato, F., Pretzsch, H., de Miguel, S., Paquette, A., Herault, B., Scherer-Lorenzen, M., Barrett, C.B., Glick, H.B., Hengeveld, G.M., Nabuurs, G.J., Pfautsch, S., Viana, H., Vibrans, A.C., Ammer, C., Schall, P., Verbyla, D., Tchebakova, N., Fischer, M., Watson, J.V., Chen, H.Y.H., Lei, X., Schelhaas, M.J., Lu, H., Gianelle, D., Parfenova, E.I., Salas, C., Lee, E., Lee, B., Kim, H.S., Bruelheide, H., Coomes, D.A., Piotto, D., Sunderland, T., Schmid, B., Gourlet-Fleury, S., Sonke, B., Tavani, R., Zhu, J., Brandl, S., Vayreda, J., Kitahara, F., Searle, E.B., Neldner, V.J., Ngugi, M.R., Baraloto, C., Frizzera, L., Balazy, R., Oleksyn, J., Zawila-Niedzwiecki, T., Bouriaud, O., Bussotti, F., Finer, L., Jaroszewicz, B., Jucker, T., Valladares, F., Jagodzinski, A.M., Peri, P.L., Gonmadje, C., Marthy, W., O’Brien, T., Martin, E.H., 
Marshall, A.R., Rovero, F., Bitariho, R., Niklaus, P.A., Alvarez-Loayza, P., Chamuya, N., Valencia, R., Mortier, F., Wortel, V., Engone-Obiang, N.L., Ferreira, L.V., Odeke, D.E., Vasquez, R.M., Lewis, S.L., Reich, P.B., 2016. Positive biodiversity-productivity relationship predominant in global forests. Science 354 (6309), 196.

Lichstein, J.W., Wirth, C., Horn, H.S., Pacala, S.W., 2009. Biomass chronosequences of United States forests: implications for carbon storage and forest management. In: C. Wirth, G. Gleixner, M. Heimann, eds., Old-Growth Forests: Function, Fate and Value. Springer Berlin Heidelberg, pp. 301-341.

Lindenmayer, D.B., Franklin, J.F., Fischer, J., 2006. General management principles and a checklist of strategies to guide forest biodiversity conservation. Biological Conservation 131 (3), 433-445.

Long, J.N., Shaw, J.D., 2010. The influence of compositional and structural diversity on forest productivity. Forestry 83 (2), 121-128.

Luyssaert, S., Schulze, E.D., Borner, A., Knohl, A., Hessenmoller, D., Law, B.E., Ciais, P., Grace, J., 2008. Old-growth forests as global carbon sinks. Nature 455 (7210), 213-215.

Marušák, R., 2007. Alternative harvest scheduling for final cut with respect to silvicultural requirements. Lesnícky časopis-Forestry Journal 53, 117-127.

Mencuccini, M., Grace, J., 1996. Hydraulic conductance, light interception and needle nutrient concentration in Scots Hydraulic conductance, light interception and needle nutrient concentration in Scots pine stands (Thetford, UK) and their relations with net aboveground primary production.pine stands and their relations with net primary productivity. Tree Physiology 16 (5), 459-468.

Merino, A., Real, C., Álvarez-González, J.G., Rodríguez-Guitián, M.A., 2007. Forest structure and C stocks in natural Fagus sylvatica forest in southern Europe: The effects of past management. Forest Ecology and Management 250 (3), 206-214.

Miller, J.B., 1967. A formula for average foliage density. Australian Journal of Botany 15 (1), 141-\&.

Müller-Haubold, H., Hertel, D., Seidel, D., Knutzen, F., Leuschner, C., 2013. Climate responses of aboveground productivity and allocation in Fagus sylvatica: a transect study in mature forests. Ecosystems 16 (8), 1498-1516.

Mura, M., McRoberts, R.E., Chirici, G., Marchetti, M., 2015. Estimating and mapping forest structural diversity using airborne laser scanning data. Remote Sensing of Environment 170, 133-142.

National Forest Centre, 2009. Forests in Slovakia. Ministry of Agriculture of the Slovak Republic, Bratislava.

Odum, E.P., 1969. The strategy of ecosystem development. Science (164), 262-270.

Oliver, C.D., Larson, B.C., 1996. Forest Stand Dynamics. Wiley, New York.

Parviainen, J., 2005. Virgin and natural forests in the temperate zone of Europe. For. Snow Landsc. Res. 79, 9-18.

Pretzsch, H., 2005. Diversity and productivity in forests: evidence from long-term experimental Plots. In: M. SchererLorenzen, C. Körner, E.D. Schulze, eds., Forest Diversity and Function: Temperate and Boreal Systems. Springer Berlin Heidelberg, Berlin, Heidelberg, pp. 41-64.

Pretzsch, H., del Río, M., Ammer, C., Avdagic, A., Barbeito, I., Bielak, K., Brazaitis, G., Coll, L., Dirnberger, G., Drössler, L., Fabrika, M., Forrester, D.I., Godvod, K., Heym, M., Hurt, V., Kurylyak, V., Löf, M., Lombardi, F., Matović, B., Mohren, F., Motta, R., den Ouden, J., Pach, M., Ponette, Q., Schütze, G., Schweig, J., Skrzyszewski, J., Sramek, V., Sterba, H., Stojanović, D., Svoboda, M., Vanhellemont, M., Verheyen, K., Wellhausen, K., Zlatanov, T., Bravo-Oviedo, A., 2015. Growth and yield of mixed versus pure stands of Scots pine (Pinus sylvestris L.) and European beech (Fagus sylvatica L.) analysed along a productivity gradient through Europe. European Journal of Forest Research 134 (5), 927-947.

Pretzsch, H., del Río, M., Schütze, G., Ammer, C., Annighöfer, P., Avdagic, A., Barbeito, I., Bielak, K., Brazaitis, G., Coll, L., Drössler, L., Fabrika, M., Forrester, D.I., Kurylyak, V., Löf, M., Lombardi, F., Matović, B., Mohren, F., Motta, R., den Ouden, J., Pach, M., Ponette, Q., Skrzyszewski, J., Sramek, V., Sterba, H., Svoboda, M., Verheyen, K., Zlatanov, T., Bravo-Oviedo, A., 2016. Mixing of Scots pine (Pinus sylvestris L.) and European beech (Fagus sylvatica L.) enhances structural heterogeneity, and the effect increases with water availability. Forest Ecology and Management 373, 149-166. 
Př́ivětivý, T., Janík, D., Unar, P., Adam, D., Král, K., Vrška, T., 2016. How do environmental conditions affect the deadwood decomposition of European beech (Fagus sylvatica L.)? Forest Ecology and Management 381, 177-187.

R Core Team, 2017. R: a language and environment for statistical computing. R Foundation for Statistical Computing Vienna, Austria.

Röhrig, E., 1991. Biomass and productivity. In: E. Röhrig, B. Ulrich, eds., Ecosystems of the World (Temperate Deciduous Forests). Elsevier, Amsterdam.

Ruiz-Peinado, R., Del Rio, M., Montero, G., 2011. New models for estimating the carbon sink capacity of Spanish softwood species. Forest Syst. (Forest Systems) 20 (1), 176-188.

Ryan, M.G., Binkley, D., Fownes, J.H., 1997. Age-Related Decline in Forest Productivity: Pattern and Process. In: D.B. Nedwell, A.H. Fitter, eds., Advances in Ecological Research, Advances in Ecological Research, volume v.27. Elsevier Textbooks, s.l., pp. 213-262.

Scherer-Lorenzen, M., Körner, C., Schulze, E.D., 2005. The functional signficance of forest diversity: a synthesis. In: M. Scherer-Lorenzen, C. Körner, E.D. Schulze, eds., Forest Diversity and Function: Temperate and Boreal Systems. Springer Berlin Heidelberg, Berlin, Heidelberg.

Schulze, E.D., Hassenmoeller, D., Knohl, A., Luyssaert, S., Boerner, A., Grace, J., 2009. Temperate and boreal oldgrowth forests: how do their growth dynamics and biodiversity differ from young stands and managed forests? In: C. Wirth, G. Gleixner, M. Heimann, eds., Old-Growth Forests: Function, Fate and Value, Ecological Studies, Analysis and Synthesis, volume 207. Springer-Verlag Berlin Heidelberg, Berlin, Heidelberg, pp. 343-366.

Schulze, E.D., Wirth, C., Mollicone, D., Ziegler, W., 2005. Succession after stand replacing disturbances by fire, wind throw, and insects in the dark Taiga of Central Siberia. Oecologia 146 (1), 77-88.

Soares, A.A., Leite, H.G., Souza, A.L., Silva, S.R., Lourenço, H.M., Forrester, D.I., 2016. Increasing stand structural heterogeneity reduces productivity in Brazilian Eucalyptus monoclonal stands. Forest Ecology and Management $373,26-32$.

Stage, A.R., 1976. An expression for the effect of aspect, slope, and habitat type on tree growth 22 (4), 457-460.

Stuart-Haëntjens, E.J., Curtis, P.S., Fahey, R.T., Vogel, C.S., Gough, C.M., 2015. Net primary production of a temperate deciduous forest exhibits a threshold response to increasing disturbance severity. Ecology 96 (9), 2478-2487.

Tabaku, V., 2000. Struktur von Buchen-Urwäldern in Albanien im Vergleich mit deutschen BuchenNaturwaldreservaten und-Wirtschaftswäldern. Dissertation. Cuvillier Verlag, Göttingen.

Utschig, H., Küsters, E., 2003. Wachstumsreaktionen der Buche (Fagus sylvatica (L.)) auf Durchforstungen? 130jährige Beobachtung des Durchforstungsversuches Elmstein 20. Forstwissenschaftliches Centralblatt 122 (6), 389-409.

van der Maaten, E., 2012. Climate sensitivity of radial growth in European beech (Fagus sylvatica L.) at different aspects in southwestern Germany. Trees 26 (3), 777-788.

Wutzler, T., Wirth, C., Schumacher, J., 2008. Generic biomass functions for Common beech (Fagus sylvatica) in Central Europe: Predictions and components of uncertainty. Canadian Journal of Forest Research 38 (6), 1661-1675.

Zuur, A.F., Ieno, E.N., Elphick, C.S., 2010. A protocol for data exploration to avoid common statistical problems: Data exploration. Methods in Ecology and Evolution 1 (1), 3-14. 



\title{
Classifying development stages of primeval European beech forests: is clustering a useful tool?
}

\author{
- Jonas Glatthorn - Eike Feldmann - Vath Tabaku - \\ - Christoph Leuschner - Peter Meyer - \\ Submitted manuscript
}

\begin{abstract}
Background: Old-growth and primeval forests are passing through a natural development cycle with recurring stages of forest development. Development stages are frequently used as a surrogate for 'stand age', which is often not precisely known in primeval forests. Several methods for assigning patches of different structure and size to forest development stages or phases do exist. All currently existing classification methods have in common that a priori assumptions about the characteristics of certain stand structural attributes such as deadwood amount are made.

We tested the hypothesis that multivariate datasets of primeval beech forest stand structure do possess an inherent, aggregated configuration of data points with individual clusters representing forest development stages. From two completely mapped primeval beech forests in Albania, seven ecologically important stand structural attributes are derived at 8216 and 9666 virtual sampling points (moving window, focal filtering). K-means clustering is used to detect clusters in the datasets (number of clusters (k) between 2 and 5). The quality of the single clustering solutions is analyzed with average silhouette width as a measure for clustering quality. In a sensitivity analysis, clustering is done with datasets of four different spatial scales of observation ( $200 \mathrm{~m}^{2}$ to $2000 \mathrm{~m}^{2}$, circular virtual plot area around sampling points) and with two different kernels (equal weighting of all objects within a plot vs. weighting by distance to the virtual plot center).
\end{abstract}


Results: The clustering solutions succeeded in detecting and mapping areas with homogeneous stand structure. The areas had extensions of more than $200 \mathrm{~m}^{2}$, but differences between clusters were very small with average silhouette widths of less than 0.28 . The obtained datasets had a homogeneous configuration with only very weak trends for clustering.

Conclusions: This implies for primeval beech forests that any discrimination between development stages means splitting continuous datasets at more or less arbitrarily selected thresholds. We thus present empirical evidence which may justify the conventional forest development stage classification schemes.

Keywords: Fagus sylvatica, Forest dynamics, Spatial observational scale, Moving window, Primeval forests, Forest development cycle.

\subsection{Background}

In primeval and old-growth European beech forests (Fagus sylvatica, stand replacement is mostly not caused by large disturbances like fire, severe windthrow or insect calamities. Instead, natural regeneration often takes place on a small scale initiated by the age-related dieback of single old trees leading to the formation of small gaps of ca. $100-250 \mathrm{~m}^{2}$. Subsequently, groups of saplings and young trees start to develop (Hobi et al., 2015). Advance regeneration beneath the canopy of old trees is also frequently observed (Hobi et al., 2015; Korpel, 1995). Without human influence, it is thought that European beech forests would represent multi-cohort forests on a small scale. It is, however, a matter of debate to which extent also large infrequent disturbances are driving stand dynamics and which area typically is covered by single-cohort patches with more or less homogeneous structure.

Usually there is no information on the true age of trees in primeval beech forests. As a consequence of their multiple-cohort structure and the resulting complex individual growth patterns (Hobi et al., 2015), 'stand age' (i. e., the time since the last larger disturbance event) is not an appropriate attribute to characterize the development status of a certain patch of primeval beech forests. Instead, classification into development stages and further subdivision into development phases of the forest development cycle (Watt, 1947) has been introduced by 
Leibundgut (1959) for European primeval forests and is widely accepted as a surrogate for stand age. Based on this categorization, different models have been developed to describe natural forest dynamics over time (e. g., Zenner et al., 2016; Korpeí, 1995). (Oliver and Larson, 1996) distinguish four different development stages for single- or multiple cohort stands: (1) the stand initiation stage occurs when a disturbance event causes partial or complete breakdown of the overstorey; (2) during the stem exclusion stage, competition is the main cause for mortality and stem number continuously decreases while living biomass is accumulating; (3) in the understorey re-initiation stage, more light may reach the ground when suppressed trees die and tree saplings and small trees establish; and (4) during the old-growth stage, large and senescent trees die and small to medium sized gaps form which are rapidly filled again by lateral branch growth of neighboring trees or by understorey trees. In multiple cohort stands like primeval beech forests, cohorts in all of these stages may occur simultaneously and horizontally layered.

In forest ecosystem research, the concept of forest development stages is used among others for describing habitat quality for different organism groups (Begehold et al., 2015; Dittrich et al., 2013; Larrieu et al., 2014; Winter and Brambach, 2011) or for characterizing the development of important stand properties such as leaf area index or structural diversity (Glatthorn et al., 2017).

While it is convenient to describe and classify growth phases of single trees (e.g., through age or diameter classes) and to distinguish development stages of single-cohort stands, classification of multiple-cohort stands is much more difficult. In the past, distinction between development stages was mostly done with dichotomous keys which use thresholds of specific stand structural attributes at the plot level (SSA, for example basal area, height or amount of deadwood) (Drößler and Meyer, 2006; Tabaku, 2000; Winter and Brambach, 2011; Zenner et al., 2016). Recently, with the aid of computer algorithms, more sophisticated classification methods for development stages and phases were developed (Huber, 2011; Král et al., 2010; Feldmann et al., 2018).

All these methods have in common that a priori assumptions about development stages and their characteristic compositions with respect to the used SSAs are made. For example, the occurrence of a certain amount of deadwood is usually one of the criteria for a forest patch to be assigned to the terminal development stage (senescence, breakdown stage Král et al., 2010; Korpel, 1995). These approaches with arbitrary parameter delimitation neglect the possible 
existence of biologically-determined thresholds in the structural data of old-growth forests, which could mark the transition from one development stage to another. Such breakpoints might occur if SSAs do not change gradually over time but when the stand structure adapts more rapidly after certain SSA thresholds are reached and/or discrete disturbance events change the intrinsic development. For example, the diameter distribution of some primeval European beech forests peaks at mid-range breast height diameters (DBH) (Westphal et al., 2006). This may indicate pulses of tree establishment caused by past disturbances. Another explanation is that trees reach the upper canopy at these DBH-classes which reduces competition with larger individuals and mortality rates drop immediately at such a site-specific diameter threshold (Westphal et al., 2006). We assume that similar effects can be observed and are more pronounced when multivariate data of the stand structure of primeval forests are analyzed. Our hypothesis is that point clouds of structural data from primeval forests are not homogeneously distributed, but that spatially separable clusters do exist which are corresponding to the development stages of the natural forest development cycle.

To test this hypothesis, we use stand structural data from two completely mapped primeval beech stands in Albania: Mirdita and Rajca. A moving window (focal filter) approach is used to aggregate the SSA-data in virtual plots over the entire area of two forests. Two parameters of the moving window (virtual plot size and kernel) were varied in a sensitivity analysis to ensure that potentially existing effects are not missed because of an inappropriate study design.

Our results may help to better understand the fundamentals on which the classification of forest development stages and phases is based on and to answer the question: Is a homogeneous, continuous distribution of SSA-data points split by the classification at arbitrarily selected breakpoints or is there a clustered configuration within the multivariate data sets detectable? The latter would hint towards the existence of site-specific thresholds which mark the transition from one development stage to another. 


\subsection{Methods}

\subsubsection{Study areas}

The study site Mirdita (5 ha) lies in the Munella mountain range in northern Albania $\left(41^{\circ} 55^{\prime}-\right.$ $\left.42^{\circ} 7 \mathrm{~N} ; 20^{\circ} 3^{\prime}-20^{\circ} 15^{\prime} \mathrm{E}\right)$. The terrain is sloping $\left(25^{\circ}-30^{\circ}\right)$ and has a southeastern exposition. The soils are Cambisols with relatively high nutrient supply. There is a Mediterranean mountain climate with an annual mean temperature of ca. $6{ }^{\circ} \mathrm{C}$, annual precipitation of ca. $2600 \mathrm{~mm}$ and high winter precipitation (values extrapolated from the closest weather station Domgjon at $5 \mathrm{~km}$ distance). Abies alba MiLl. and Acer pseudoplatanus L. The forest community can be assigned to the Fagetum asperuletosum association.

The study site Rajca (6 ha) is located in the Shebenik-Jabllanica mountain ranges in the east of central Albania $\left(41^{\circ} 14^{\prime} \mathrm{N}, 21^{\circ} 7^{\prime} \mathrm{E}, 1400-1450 \mathrm{~m}\right.$ a.s.l.). There is no climate station close by to extrapolate annual temperature and precipitation, but climatic conditions should be similar to Mirdita. The soil type is similar to Mirdita and the forest association is also the Fagetum asperuletosum with minor shares of A. alba and A. pseudoplatanus.

\subsubsection{Forest inventory}

The forest inventory was carried out in September 1998. In both study sites, standing live and dead trees with a $D B H \geq 7 \mathrm{~cm}$ cm were inventoried. $D B H$, decay class of the dead trees (Albrecht, 1990), and the coordinates of each tree were recorded. The tree height of a subset (100 to 150 trees per study site) of all inventoried trees was measured; the height of the remaining trees was estimated from empirically derived relationships between $D B H$ and stand height (stand height curves). Species identity, the coordinates of the log's end points and the decay class of lying deadwood pieces were recorded and the log diameters measured at the middle of the log. The extension of regeneration patches (areas covered by trees with a $D B H<7 \mathrm{~cm}$ ) was approximated by polygons and the coordinates of all corner points within the study sites were recorded. For a detailed description of the inventory's general results see Tabaku (2000). 

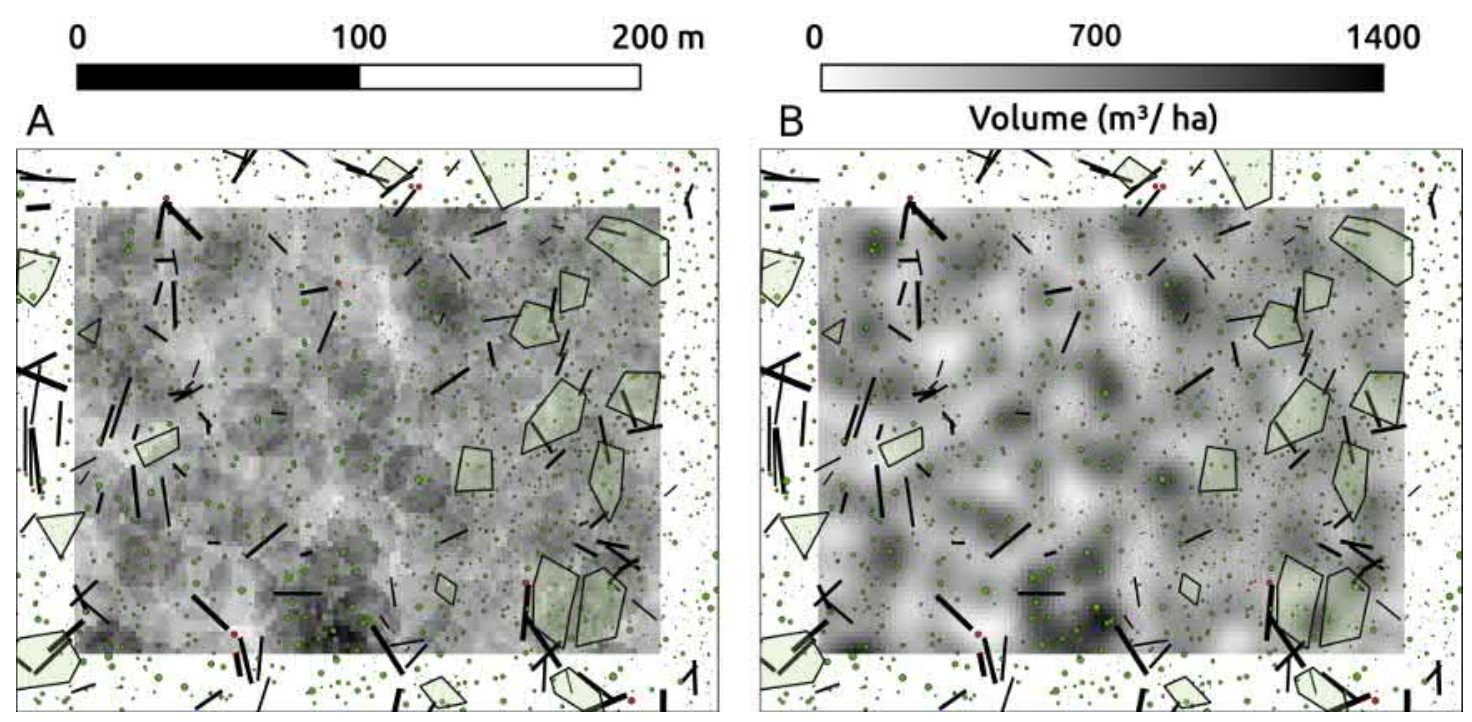

Figure 4.1: Stand maps of the primeval forest of Mirdita. Circles mark coordinates of trees, lines represent logs and green shaded areas outline regeneration patches (areas with a dense cover of trees with a diameter at breast height $<7 \mathrm{~cm}$ ). The background raster images show results of a moving window (living tree volume) for an observational scale (window area) of $500 \mathrm{~m}^{2}$. Panel A shows results of a uniform kernel (equal weighting of all objects within the window) while for panel B a bivariate normal kernel was applied (weighting of objects by their distance to the window center).

\subsubsection{Calculation of stand structural attributes}

We used a moving window (focal filter) approach which resulted in detailed maps of the distribution of the SSAs across the study areas (Fig. 4.1).

A geographic information system was used to place a regular grid of $2 \mathrm{~m}$ spacing over each of the study sites and virtual sampling points were established at each of the grid nodes. Seven SSAs were calculated for circular virtual plots centered at each of the sampling points (Table 4.1). To ensure that the boundaries of all virtual plots were located within the study areas, only sample points outside a $22 \mathrm{~m}$ wide buffer zone were used. In this way, matrices of structural data with the dimension $8216 \times 7$ (Mirdita) and $9666 \times 7$ (Rajca) were generated.

Lying trees often crossed the borders of the virtual plots. To account for only partial coverage of lying trees by a virtual plot, logs were segmented into $50 \mathrm{~cm}$ long pieces and each segment was referred to by its center coordinates. The volume of each deadwood segment was approximated by a frustum of a cone and a correction factor depending on its decay stage was applied (1, $0.95,0.8$ and 0.5 for decay classes 1 to 4$)$. The diameters at the segment's beginning and end 
Table 4.1: Descriptions and abbreviations of plot-level stand structural attributes (SSA).

\begin{tabular}{ll}
\hline Abbreviation & Description \\
\hline$N$ & Number of trees per hectare \\
$D B H_{\text {med }}$ & Median of diameter at breast height \\
$D B H_{i q r}$ & Interquartile range of the diameter at breast height \\
$H_{\text {max }}$ & Maximum tree height \\
$V_{\text {live }}$ & Volume of living trees per hectare \\
$V_{\text {dead }}$ & Deadwood volume per hectare \\
Reg & Proportion of the area covered by regeneration \\
\hline
\end{tabular}

were estimated from the middle diameter of the respective log and an assumed tapering of $10 \mathrm{~mm} \mathrm{~m}^{-1}$.

Likewise, regeneration patches were rasterized into $1 \mathrm{~m}^{2}$ elements to calculate the proportion of the virtual plot area covered by regeneration.

The spatial variability of SSAs changes depending on the spatial observational scale (virtual plot area around sampling points; Král et al., 2014). Thus, to account for the effects of variable observation scales, the analysis was conducted at four scales ranging from $200-2000 \mathrm{~m}^{2}$.

The usual procedure of assessing the stand structure of forests is via research plots of different sizes and equal weighting of all objects within the boundaries of the plots (e.g., Kramer and Akça, 2008). We hypothesized that equal weighting of all objects (uniform kernel) is not optimal because more distant objects are influencing the stand structure at a specific point less than close objects. To test this hypothesis, we additionally used a bivariate normal kernel for data aggregation (Venables and Ripley, 2007) and compared the results of both kernels in a sensitivity analysis. The normal kernel weighted more distant objects less than closer ones, which resulted in smoother maps of the spatial distributions of the SSA (Fig. 4.1 B). The bandwidths of the normal kernels were chosen to correspond best to the dimensions of the uniform kernels: the integrated kernel density of a normal kernel equaled 0.95 within the boundaries of the respective uniform kernel. 


\subsubsection{Graphical display and clustering of the structural data}

For the graphical display of the structural data, principal component analysis (PCA) was used and the first four principal components were plotted against each other (Fig. 4.2).

Prior to analysis, all SSAs were standardized to have zero mean and unit variance. To find potentially existing clusters in the data structure, k-means clustering with two to five clusters was applied (Everitt, 2011). The quality of the clustering solutions was assessed with the average silhouette width (Kaufman and Rousseeuw, 2009). The silhouette coefficient ranges between one and minus one. Values close to one indicate good representation of an object by its cluster. All calculations of clusters and silhouette coefficients were done in R (R Core Team, 2016) using the package 'flexclust' (Leisch, 2006). To analyze which SSAs were most relevant for the separation of the clusters of a specific cluster solution, the between-groups (clusters) variance of the SSAs known from classical discriminant analysis of the standardized SSA was used (Var between; Venables and Ripley, 2007).

\subsection{Results}

\subsubsection{Emergence of clusters at different observation scales}

In Fig. 4.2 the first principal component (PC) of the aggregated SSA data-matrices is plotted against the second to fourth principal component and results of k-means clustering $(\mathrm{k}=3)$ are depicted. In the Mirdita site small observation scales (virtual plot sizes of $200 \mathrm{~m}^{2}$ and $500 \mathrm{~m}^{2}$ ) lead to a uniform and homogeneous point distribution of the SSAs (panels A1 to B3). No obvious groups are visible, and k-means clustering leads to an arbitrary division of the point clouds. With an observation scale of $1000 \mathrm{~m}^{2}$, a vague structure is emerging. At least two bigger clusters are visible when PC2 or PC3 is plotted against PC1 (panels C1 and C3). When looking at PC3 and PC1 (panel C2) several smaller subclusters are apparent as well. All clusters are not clearly distinguished from one another but blurring at their borders. At the $2000 \mathrm{~m}^{2}$-scale the image is similar as at the $1000 \mathrm{~m}^{2}$-scale with two main clusters and several smaller and blurring subclusters. 


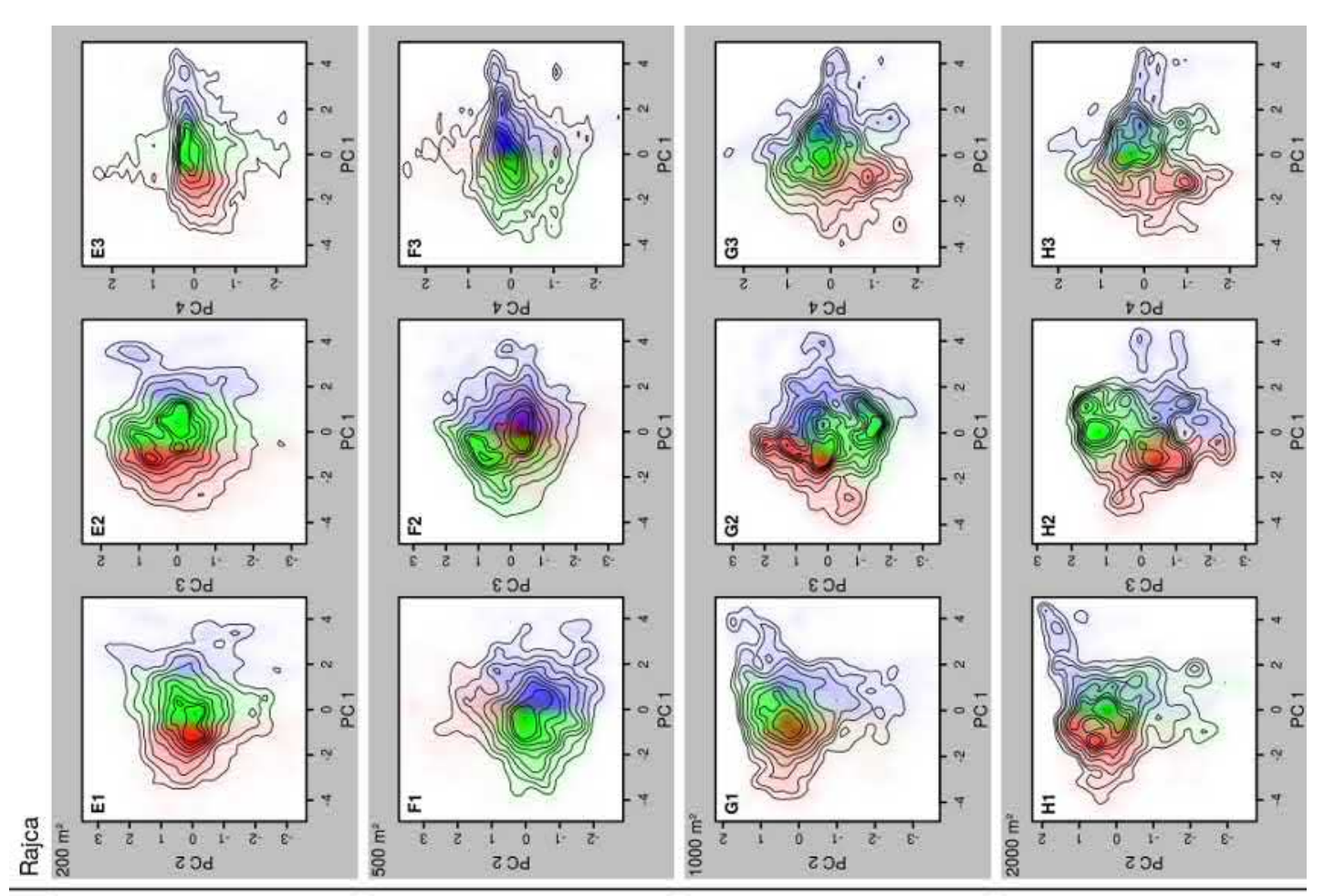

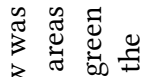

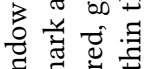

$3 \infty \infty$

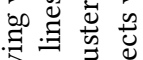

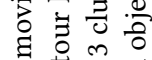

य节要击

割 00

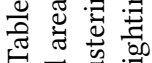

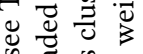

की

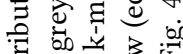

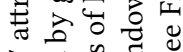

$\therefore$ 总节言

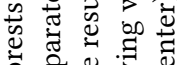

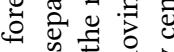

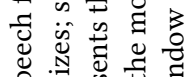

तै

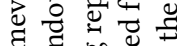

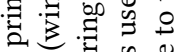

3.

पू

䒕
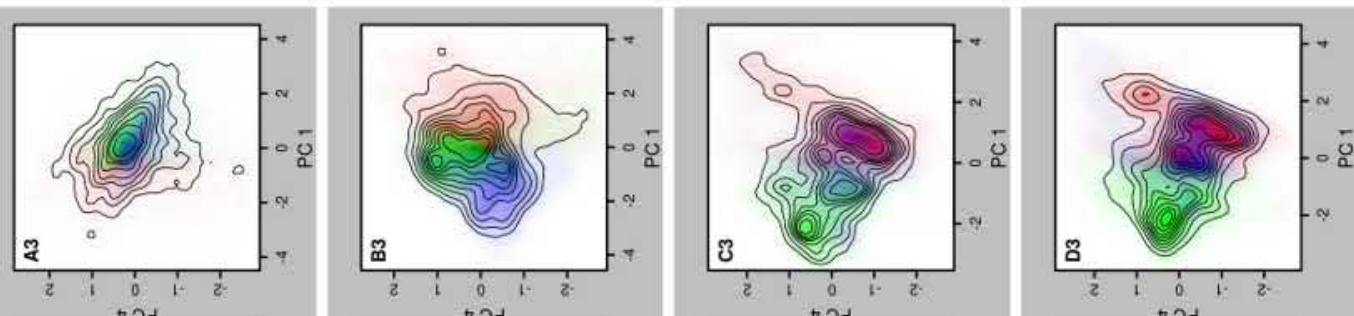

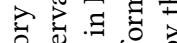

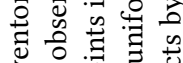

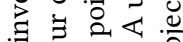

岁

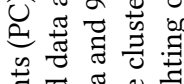

氙渮

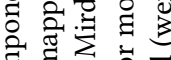

छี छ

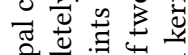

월 द्वे है

द्ञี

㐘

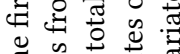

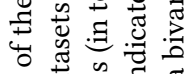

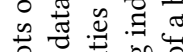

을

言焉荠

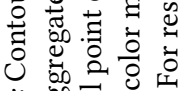

भंष

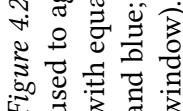


In the Rajca site the trend of a somewhat better separability with increasing plot size is visible as well but clusters do only emerge at the largest scale of $2000 \mathrm{~m}^{2}$ (panels $\mathrm{H} 1$ to $\mathrm{H} 3$ ). At smaller scales (panels E1 to G3) some peaks are visible (e.g., panels F1 to G2), but possible clusters are not very well distinguished.

The bivariate normal kernel provides a very similar picture as the uniform kernel Fig. 4.A1).. The overall appearance of the normal kernel is a bit smoother, but clusters are not better distinguishable from each other.

\subsubsection{Quality of the clustering}

Average silhouette widths obtained for the clustering of the SSAs by this study were mostly below 0.25 (Table 4.2). Silhouette coefficients smaller than 0.25 are indicative for 'no substantial structure' according to Kaufman and Rousseeuw (2009). There was a slightly better separability of the datasets at the greater observation scales in Mirdita with a maximum value of 0.27 of the 5-cluster solution at the $2000 \mathrm{~m}^{2}$. Except for that, the cluster solutions did have an equally low quality for all observation scales, both kernels and study areas.

\subsubsection{Between-cluster differences of stand structural attributes}

The relevance of each SSA for the specific clustering solution was analyzed with the betweencluster variances of the standardized ( $\operatorname{Var}_{\text {between }}$, Fig. 4.3). In Mirdita, $N$ and $D B H_{\text {med }}$ were of higher relevance for most of the cluster solutions, whereas the other attributes $\left(V_{\text {live }}, D B H_{\text {iqr }}\right.$, $\left.H_{\text {max }}, V_{\text {dead }}, R e g\right)$ were less important. In Rajca, the most relevant attribute changed a lot between observation scales and cluster number. Even though there was no single attribute and no set of combined attributes which was most important for the determination of the clusters, differences between $V_{\text {dead }}$ of the clusters were almost always only minor. This attribute seemed to have no relevance for the clustering.

\subsubsection{Spatial representation of clusters}

Maps of areas with similar stand structure differed greatly between the observation scales (Figs. 4.4 and 4.A3). 
Table 4.2: Average silhouette widths of the clustering solutions of stand structural data of two primeval beech forests. A moving window approach with a uniform and a bivariate normal kernel and of several observation scales (rows) was used. K-means clustering $(\mathrm{k}=2-5$, columns) was applied to obtain different clustering solutions.

\begin{tabular}{lllllllllll}
\hline & \multicolumn{3}{c}{ Uniform kernel } & \multicolumn{8}{c}{ Bivariate normal kernel } \\
& \multicolumn{9}{c}{ Number of clusters } & \multicolumn{5}{c}{ Number of clusters } \\
& 2 & 3 & 4 & 5 & 2 & 3 & 4 & 5 \\
\hline \multirow{4}{*}{ Mirdita } & Observational scale & & & & & & & \\
& $200 \mathrm{~m}^{2}$ & 0.18 & 0.16 & 0.18 & 0.22 & 0.17 & 0.17 & 0.21 & 0.22 \\
& $500 \mathrm{~m}^{2}$ & 0.18 & 0.19 & 0.21 & 0.22 & 0.18 & 0.18 & 0.21 & 0.17 \\
& $1000 \mathrm{~m}^{2}$ & 0.20 & 0.22 & 0.24 & 0.24 & 0.19 & 0.21 & 0.23 & 0.23 \\
& $2000 \mathrm{~m}^{2}$ & 0.20 & 0.26 & 0.26 & 0.27 & 0.20 & 0.24 & 0.23 & 0.25 \\
& & & & & & & & & \\
Rajca & $200 \mathrm{~m}^{2}$ & 0.22 & 0.19 & 0.22 & 0.23 & 0.21 & 0.21 & 0.23 & 0.22 \\
& $500 \mathrm{~m}^{2}$ & 0.21 & 0.23 & 0.20 & 0.20 & 0.21 & 0.23 & 0.18 & 0.20 \\
& $1000 \mathrm{~m}^{2}$ & 0.21 & 0.18 & 0.20 & 0.20 & 0.21 & 0.18 & 0.21 & 0.21 \\
& $2000 \mathrm{~m}^{2}$ & 0.21 & 0.22 & 0.24 & 0.21 & 0.21 & 0.19 & 0.23 & 0.23 \\
\hline
\end{tabular}
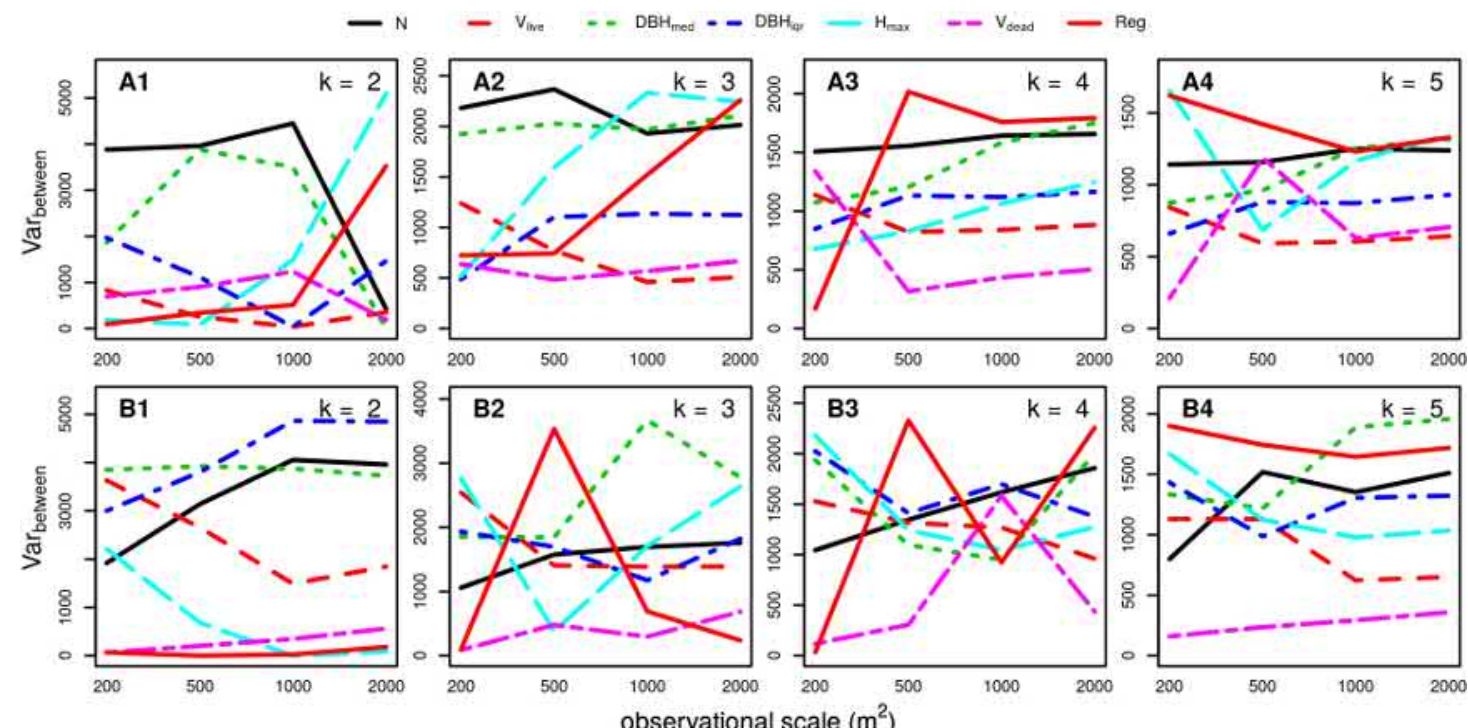

Figure 4.3: Between-clusters variance of stand structural data (7 attributes, abbreviations see Table 4.1) of the primeval beech forests Mirdita (A1-A4) and Rajca (B1-B4). K-means clustering was used to detect clusters (2 to 5 clusters, panels 1 to 4). A moving window approach with a uniform kernel (equal weighting of all objects within the window) of several observation scales was used to aggregate the datasets (x-axis). For the results of a bivariate normal kernel see Fig. 4.A2 (weighting of objects by their distance to the window center). 
4.3Classifying development stages of primeval European beech forests: is clustering a useful tool?

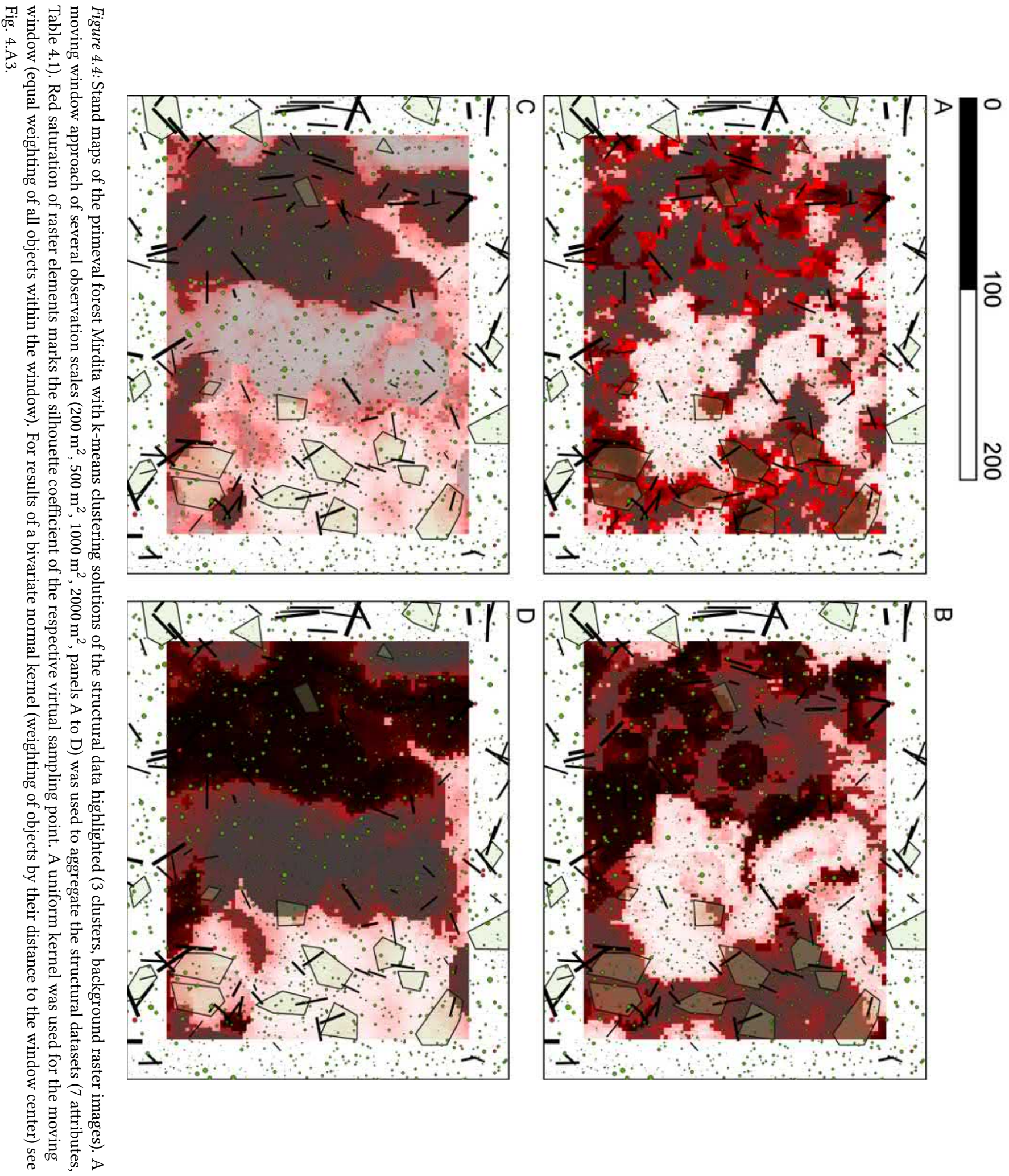


At low observation scales $\left(200 \mathrm{~m}^{2}\right.$ and $500 \mathrm{~m}^{2}$, panels $\mathrm{A}$ and B) the mosaic-like structure of patches with a homogeneous stand structure belonging to different clusters was more finegrained with patch sizes often below $100 \mathrm{~m}^{2}$. Single, dominant features within the borders of a virtual plot often decided about the clustering outcome. But even at such small scales, large patch sizes stretching over 1 ha and more occurred. Many of the patches touched the outer limits of the study area, so their absolute size is unknown. To accurately estimate patch-size distributions, the study area size would have to be several times larger.

At greater observation scales $\left(1000 \mathrm{~m}^{2}\right.$ and $2000 \mathrm{~m}^{2}$, panels $\mathrm{C}$ and $\left.\mathrm{D}\right)$, the overall appearance of the patch distribution was a lot smoother. Patch sizes were bigger and often stretched over $200 \mathrm{~m}^{2}$ and more. Single features did not dominate the clustering process anymore.

Maps of the same observation scale but with differing numbers of clusters produced similar results (Figs. 4.5 and 4.A4). When the number of clusters was increased, usually one cluster was split instead of creating a completely new classification of the points. The maps in Fig. 4.5 depict areas with homogeneous stand structures at a specific observation scale.

At all observation scales, the silhouette coefficient (red shade of pixels) was biggest in the areas close to patch borders. These horizontal transition zones between homogeneous forest patches were particularly hard to classify for the clustering algorithm. In the center of patches, areas with low silhouette coefficients were less frequent but did occur as well.

\subsection{Discussion}

The visualization of potentially existing clusters in the stand structural data with the first principal components did not reveal substantial aggregation of data points. In the contrary, only at greater observation scales of $1000 \mathrm{~m}^{2}$ and $2000 \mathrm{~m}^{2}$ there were only slight peaks visible in the contour plots (Figs. 4.2 and 4.A1). However, the low averages of the silhouette coefficients of all cluster solutions irrespective of observation scale indicate that these peaks are no evidence for the presence of real clusters in the data. The slight peaks appearing at greater observation scales might well be just an artifact of the size of the study areas and the high similarity of points which are located close to one another. Additionally, even though both completely mapped 
4.4Classifying development stages of primeval European beech forests: is clustering a useful tool?

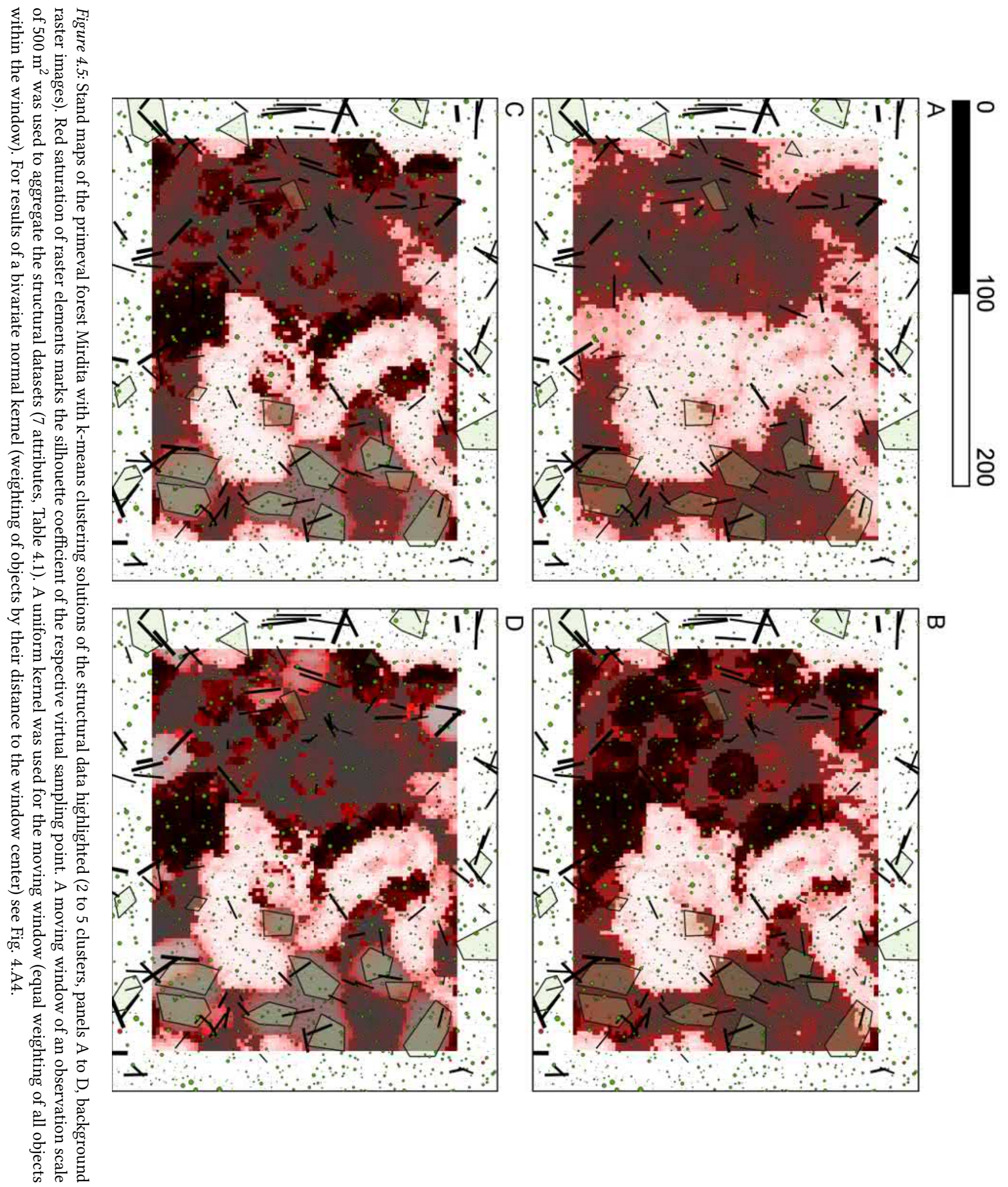


areas were large ( 5 ha and 6 ha), it is likely that some common combinations of SSAs did just not occur within the boundaries of the study sites and are underrepresented in the datasets.

The low separability of the data into clusters may also be caused by the multi-cohort stand structure of beech primeval forests. Such a structure results in the overlap of characteristics of multiple development stages in the same forest patch. In forests, where major disturbances lead to single-cohort structures, potentially existing clusters might have higher average silhouette coefficients and less blurring clusters than are observed in out forests.

The low quality of the clustering solutions suggest that, at least with respect to the studied variables, the natural forest development cycle does not lead to the emergence of clear thresholds between different development stages. This does not challenge the concept of classifying research plots into development stages in general, which has reliably and successfully been used to describe the forest development cycle in many previous studies. Instead, the results suggest that transitions between single stages are rather continuous. This means that the usually applied practice to arbitrarily select thresholds, which fit best to the respective ecosystems, study designs and questions, is confirmed.

Even though the selected attributes to describe the forest structure in this study were selected with care, more suitable variables to reflect the natural forest development cycle may exist. In compliance with current methods to describe development stages in the field, we used status variables like stand density, maximum tree height, regeneration abundance, and others (see Table 4.2). Ecosystem processes and functions like mortality or biomass accumulation and decay are not included neither in our selection of variables, nor in most other empirical studies addressing the classification of forest development stages. This is not because the importance of processes for forest development is neglected (in fact many authors state their relevance, e.g. Meyer, 1999; Oliver and Larson, 1996; Korpel, 1995), but rather because such variables are much more difficult to monitor and suitable datasets for such analyses hardly exist. We cannot rule out the possibility that including other variables, especially variables describing ecosystem processes and functioning, might have resulted in clearer clustering solutions than observed here.

When using the uniform kernel (i.e. equal weighting of objects within a virtual plot) for the 
aggregation of the structural data of the forests, the resulting maps of the distribution of the SSA over the study area are grainy (Fig. $4.1 \mathrm{~A}$ ). Points lying directly next to each other (2 m distance) can be largely different depending on whether a single prominent structural feature falls into the boundaries of a virtual plot or not. Highest aggregated values of some SSAs (e.g., live wood volume; Fig. 4.3) do not occur in the direct vicinity of single objects with high attribute values, but right in the middle of multiple prominent objects. This is because the distribution of large trees is due to competition usually not random, but tends to be more regular at scales where competition between single trees dominates the spatial distribution of large trees (ca. $10 \mathrm{~m}$ and less; Janík et al., 2016). It is more likely to encounter multiple prominent objects within a virtual plot when its center is close to plot radius distance from such an object.

In contrast, due to the weighting of objects by distance from the sampling point, the distribution maps of the normal kernel are smoother with maximum aggregated values close to prominent objects (Fig. 4.1 B). For the analysis of the relationship between structural features and other ecosystem attributes which are influenced by their distance to strong competitors (like for example regeneration or herb cover), the normal kernel could turn out to be superior.

In contrast to our hypothesis, the use of a bivariate normal kernel for data aggregation did not improve the performance of the clustering algorithm. Silhouette coefficients of the cluster solutions and visual appearance of the contour plots were equally poor. No otherwise hidden clusters or relationships between attributes do emerge when features more distant from a location in a primeval forest are downweighted for the assessment of its stand structure. All sort of different combinations of SSAs are equally likely and no clusters are present in the data structure. This does not discard the use of a bivariate normal kernel instead of a uniform kernel in general for the description of forest structure. For other applications, this approach still might be appropriate.

Even though in many clustering solutions $D B H_{\text {med }}$ and $N$ seemed to be important attributes for the separation of the clusters, the changing order of the most relevant SSAs depending on observation scale, number of clusters, and study site seemed to be coincidental and not driven by a unique underlying data structure. Differences between the two study areas are probably due to deviating site conditions and stand structure in Mirdita as compared to Rajca. 
The first site has a more shallow soil and seems to be on average closer to the 'stand initiation' or 'stem-exclusion' stage with high stem numbers and a low $D B H_{m e d}$.

The irrelevance of $V_{\text {dead }}$ for the clustering solutions is most likely because its spatial distribution across the study area is rather homogeneous and does not correspond well with the distribution pattern of other attributes. In contrast to earlier studies (e.g., Král et al., 2010; Tabaku, 2000), and in agreement with our results, Glatthorn et al. (unpublished) and Larrieu et al. (2014) found that the amount of deadwood within a plot is not necessarily a good indicator for its development stage. The idea of high amounts of deadwood in the terminal stage and carry-over effects to the growth stage bases on the assumption of a strictly cyclic succession of development stages (i.e, $\rightarrow$ growth $\rightarrow$ optimal $\rightarrow$ terminal $\rightarrow$ growth $\rightarrow$..; Korpel, 1995). But when tree cohorts of different ages are present at a forest patch and disturbance only causes a partial breakdown of the tree cover, transition from one development stage to any other may occur. In conjunction with a high residual time of deadwood logs and snags up to 50 years (Přivětivý et al., 2016), this may cause high deadwood amounts in any part of the development cycle. Deviating conclusions on deadwood persistence in the forest cycle by other studies may be caused by diverging classification methods. When the amount of deadwood is a key variable in a dichotomous key to assign development stages, conclusions about varying amounts of deadwood are circular reasoning.

At first glance, only moderate or missing relationships between the deadwood amount and forest development stage seems to be surprising because processes like mortality and decay doubtlessly play central roles in natural forest dynamics. However, the total amount of deadwood may not be a good proxy for such processes, as it just describes the status quo and not the underlying dynamics. A classification of deadwood objects into decay classes, which account for elapsed time since tree death, or direct measurement of deadwood dynamics through repeated measurements or recording of respiration rates may lead to results which are closer linked to forest development stages.

K-means clustering does not result in clearly separated clusters with distinct thresholds. But the algorithms still lead to the objective splitting of the study sites into zones with maximum homogeneity within the same zone and maximum difference to areas of other zones (Figs. 4.4, 
4.5, 4.A3, and 4.A4).. Areas of the same cluster in the maps were more likely subject to a similar development history. Large connected areas with a homogeneous stand structure (100 $\mathrm{m}$ to $200 \mathrm{~m}$ in length) give an impression, at which scale stand replacement takes place in primeval forests.

Patch sizes obtained by this method are, irespective of the observation scale, all bigger than patches identified for example by the classification into development stages with supervised algorithms done by Král et al. (2010). Besides the effect of different computational methods, different patch sizes may also be identified because of differing stand dynamics in stands with deviating tree species composition (e.g., spruce-silver fir-beech stands as compared to almost pure beech stands investigated here) or a differing set and weighting of specific SSAs used in the studies. Patch size may also depend on the number of development phases distinguished. For example, (Tabaku, 2000) identified eight development phases with the consequence that observed patch size was smaller than in our study with only three stages separated.

\subsection{Conclusions}

The moving window approach together with k-means clustering succeeded in detecting and precisely mapping areas with homogeneous stand structure, with the results depending on the observation scale. The evaluation of the clustering process revealed that the point clouds of the structural data are rather homogeneous without clearly separated clusters in the data of the two investigated primeval forests. This shows that any separation of development stages relying on stand structural data means to split a continuous point cloud at more or less arbitrarily selected thresholds. This is valid at least for primeval beech forests in Albania. These results help to better understand the procedure of forest development classification. Just as the classification of tree $D B H$ into arbitrary diameter-classes, which is a long-standing practice in forestry and forest ecology, the classification of development stages does separate a continuous multivariate point cloud of a set of SSAs of a natural forest into ecologically meaningful categories. As we couldn't detect clusters in the point clouds, which would have suggested the existence of naturally superimposed thresholds, the current practice of arbitrarily selecting such thresholds 
with expert knowledge or with algorithms is justified. From our results, the only advice to be given for the development of new and the improvement of old classification schemes for the natural forest development cycle is to reduce the current emphasis on the presence of deadwood. The amount of deadwood rather seems to vary randomly over time with only weak relationship to other stand attributes, at least in primeval European beech forests. 


\section{Appendix}

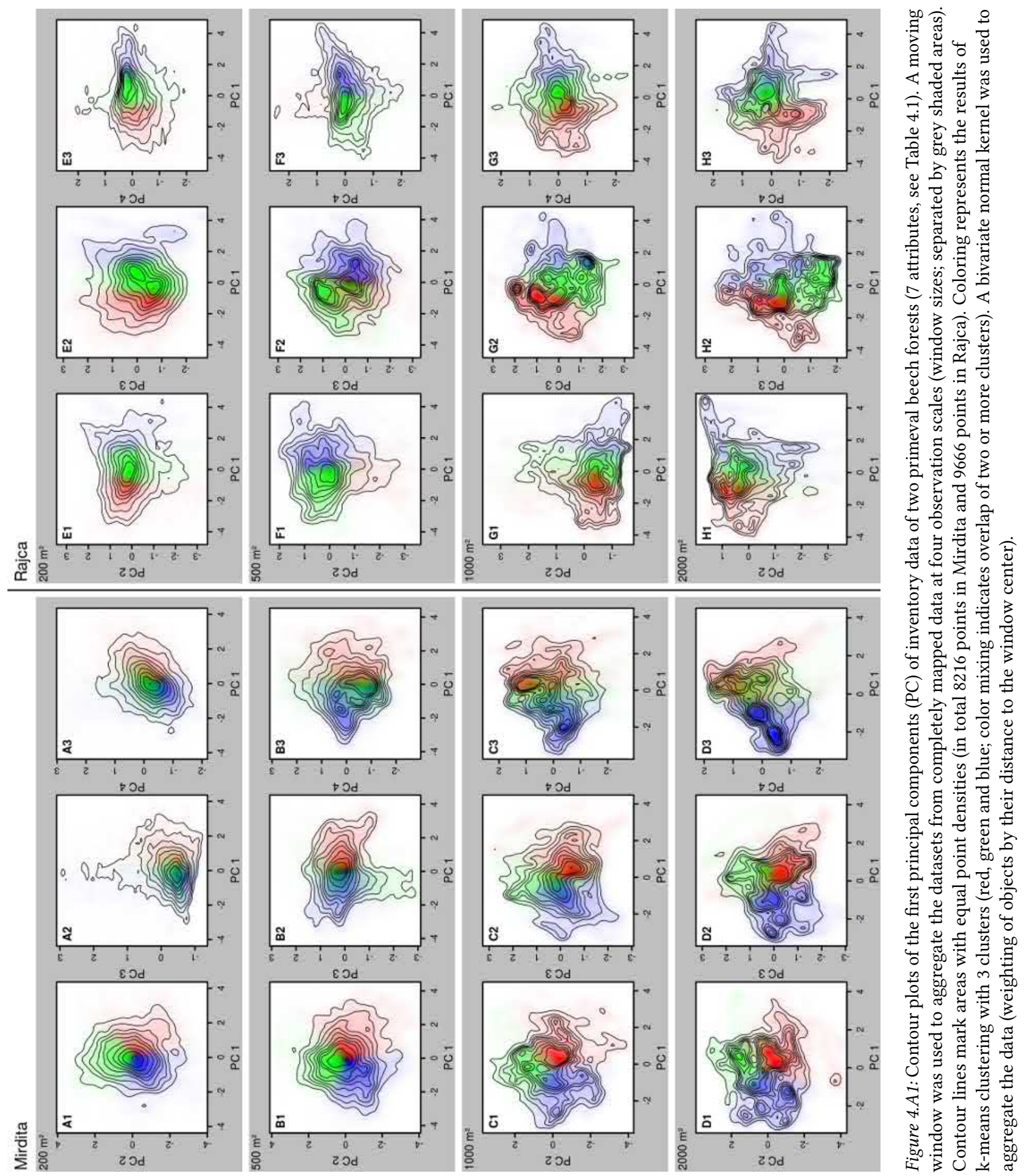



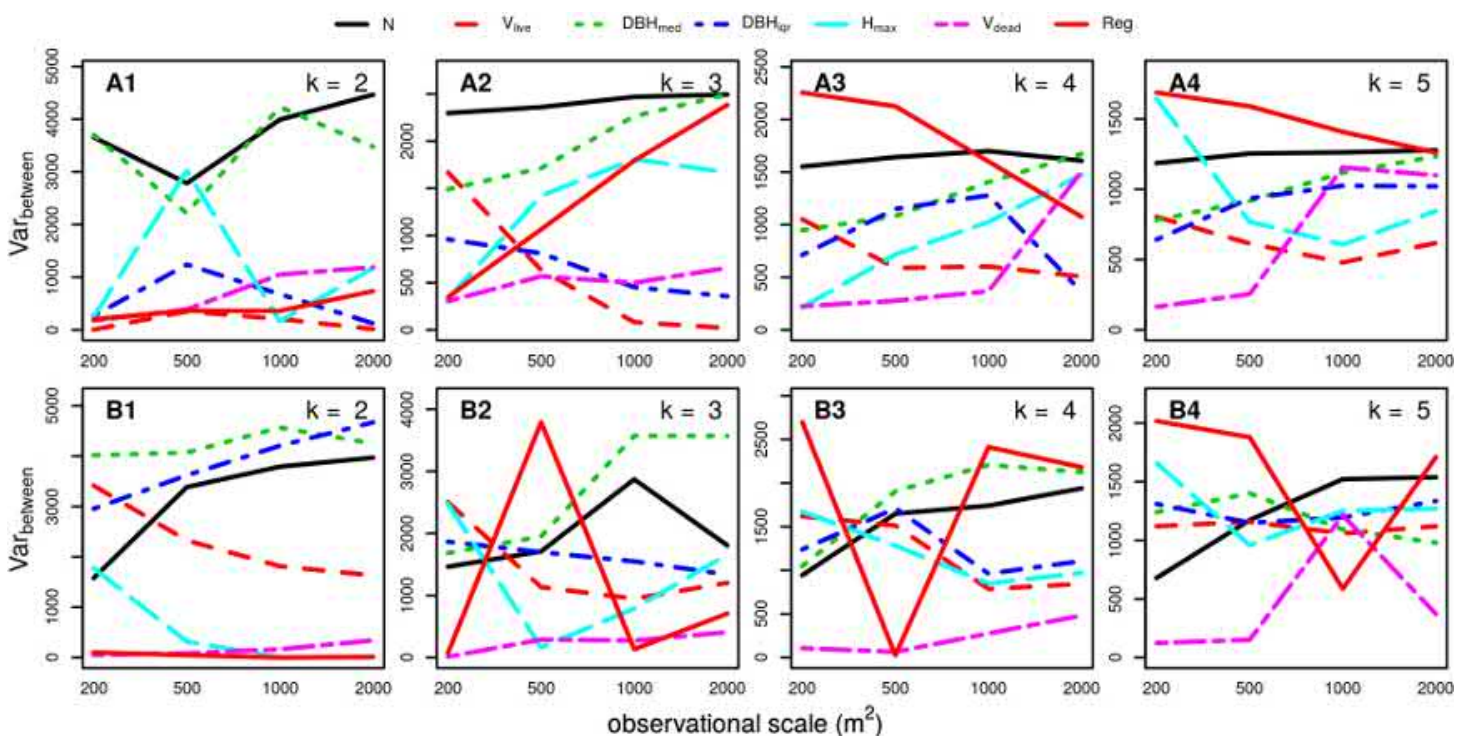

Figure 4.A2: Between-clusters variance of stand structural data (7 attributes, abbreviations see Table 4.1) of the primeval beech forests Mirdita (A1-A4) and Rajca (B1-B4). K-means clustering was used to detect clusters (2 to 5 clusters, panels 1 to 4). A moving window approach with a bivariate normal kernel was applied (weighting of objects by their distance to the window center). 
4.5Classifying development stages of primeval European beech forests: is clustering a useful tool?

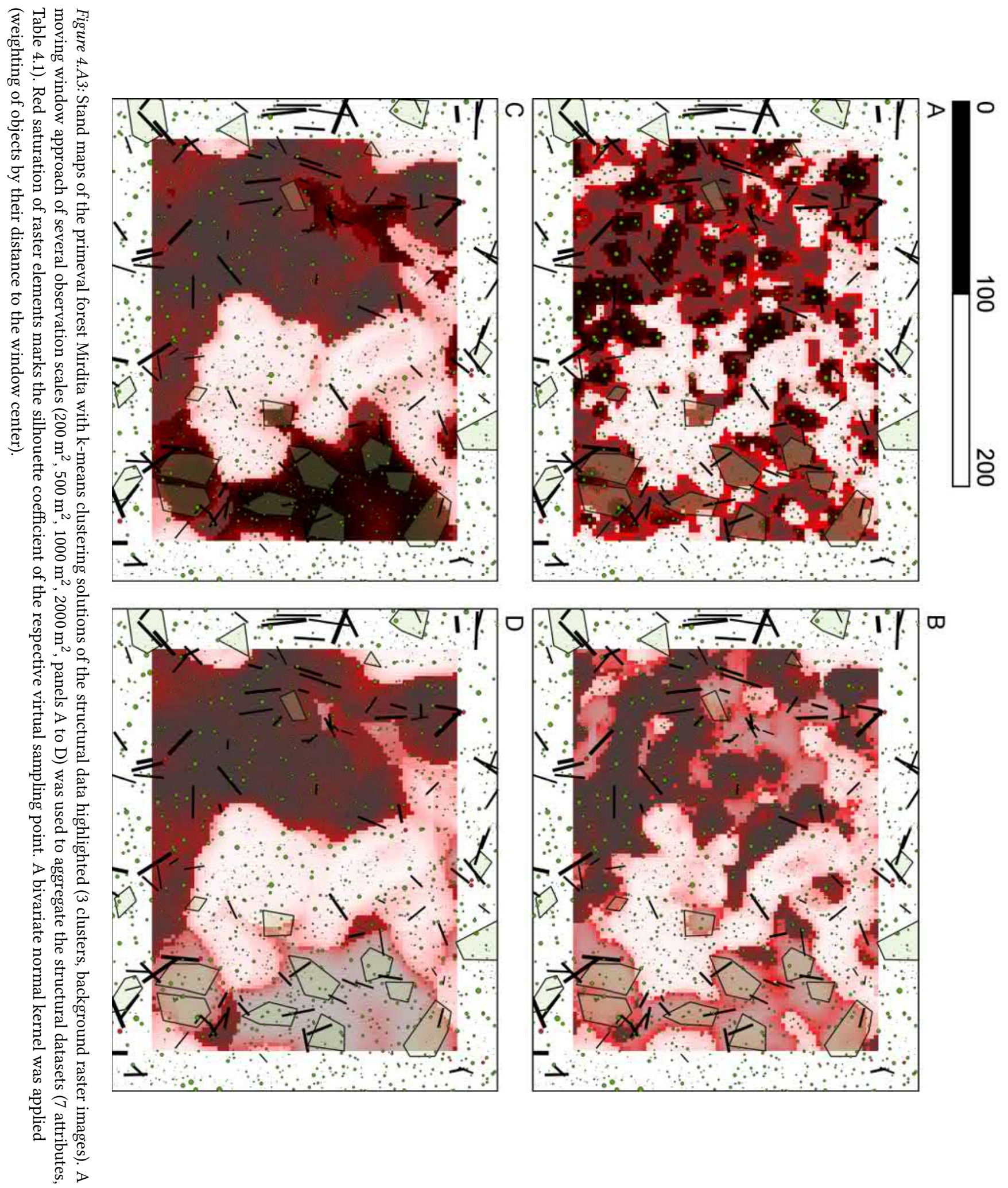



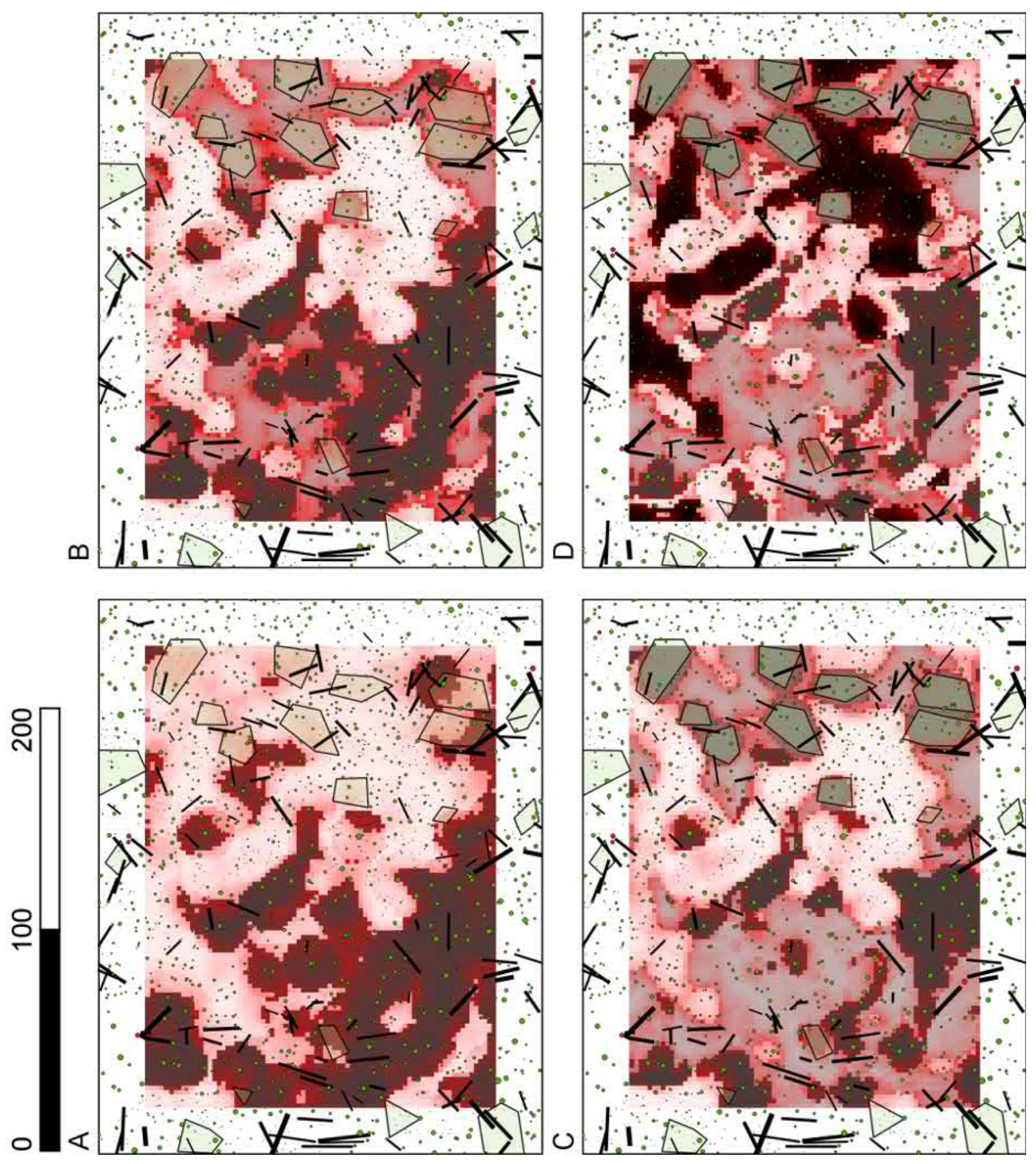


\section{References}

Albrecht, L., 1990. Grundlagen, Ziele und Methodik der waldökologischen Forschung in Naturwaldreservaten. Schriftenreihe Naturwaldreservate in Bayern, I .

Begehold, H., Rzanny, M., Flade, M., 2015. Forest development phases as an integrating tool to describe habitat preferences of breeding birds in lowland beech forests. Journal of Ornithology 156 (1), 19-29.

Dittrich, S., Hauck, M., Jacob, M., Rommerskirchen, A., Leuschner, C., Hermy, M., 2013. Response of ground vegetation and epiphyte diversity to natural age dynamics in a Central European mountain spruce forest. Journal of Vegetation Science 24 (4), 675-687.

Drößler, L., Meyer, P., 2006. Forest development stages in two virgin beech reserves in Slovakia. Forstarchiv 77, $155-161$.

Everitt, B.S., 2011. Cluster analysis. Wiley series in probability and statistics. Wiley, Chichester, 5. ed. edition.

Feldmann, E., Glatthorn, J., Hauck, M., Leuschner, C., 2018. A novel empirical approach for determining the extension of forest development stages in temperate old-growth forests. European Journal of Forest Research , 1-15.

Glatthorn, J., Feldmann, E., Pichler, V., Hauck, M., Leuschner, C., unpublished. Biomass stock and productivity of primeval and production beech forests: Greater canopy structural diversity promotes productivity .

Glatthorn, J., Pichler, V., Hauck, M., Leuschner, C., 2017. Effects of forest management on stand leaf area: Comparing beech production and primeval forests in Slovakia. Forest Ecology and Management 389, 76-85.

Hobi, M.L., Commarmot, B., Bugmann, H., 2015. Pattern and process in the largest primeval beech forest of Europe (Ukrainian Carpathians). Journal of Vegetation Science 26 (2), 323-336.

Huber, M.O., 2011. Statistical models to identify stand development stages by means of stand characteristics. Canadian Journal of Forest Research 41 (1), 111-123.

Janík, D., Král, K., Adam, D., Hort, L., Samonil, P., Unar, P., Vrska, T., McMahon, S., 2016. Tree spatial patterns of Fagus sylvatica expansion over 37 years. Forest Ecology and Management 375, 134-145.

Kaufman, L., Rousseeuw, P.J., 2009. Finding Groups in Data: An Introduction to Cluster Analysis, Wiley series in probability and statistics, volume v.344. John Wiley \& Sons Inc, Hoboken, 99th ed. edition.

Korpeĺ, Š., 1995. Die Urwälder der Westkarpaten. Gustav Fischer Verlag, Stuttgart.

Král, K., Janík, D., Vrška, T., Adam, D., Hort, L., Unar, P., Šamonil, P., 2010. Local variability of stand structural features in beech dominated natural forests of Central Europe: Implications for sampling. Forest Ecology and Management 260 (12), 2196-2203.

Král, K., Valtera, M., Janík, D., Šamonil, P., Vrška, T., 2014. Spatial variability of general stand characteristics in central European beech-dominated natural stands - Effects of scale. Forest Ecology and Management 328, 353-364.

Kramer, H., Akça, A., 2008. Leitfaden zur Waldmesslehre. Sauerländer, Frankfurt am Main, 5., überarb. aufl. edition.

Larrieu, L., Cabanettes, A., Gonin, P., Lachat, T., Paillet, Y., Winter, S., Bouget, C., Deconchat, M., 2014. Deadwood and tree microhabitat dynamics in unharvested temperate mountain mixed forests: A life-cycle approach to biodiversity monitoring. Forest Ecology and Management 334, 163-173.

Leibundgut, H., 1959. Über Zweck und Methodik der Struktur- und Zuwachsanalyse von Urwäldern. Schweizerische Zeitschrift für Forstwesen (110), 111-124.

Leisch, F., 2006. A toolbox for -centroids cluster analysis. Computational Statistics \& Data Analysis 51 (2), 526-544.

Meyer, P., 1999. Bestimmung der Waldentwicklungsphasen und der Texturdiversität in Naturwäldern. Allgemeine Forst und Jagd-Zeitung 10-11 (170), 203-211.

Oliver, C.D., Larson, B.C., 1996. Forest Stand Dynamics. Wiley, New York.

Přivětivý, T., Janík, D., Unar, P., Adam, D., Král, K., Vrška, T., 2016. How do environmental conditions affect the deadwood decomposition of European beech (Fagus sylvatica L.)? Forest Ecology and Management 381, 177-187. 
R Core Team, 2016. R: A Language and Environment for Statistical Computing. Vienna, Austria.

Tabaku, V., 2000. Struktur von Buchen-Urwäldern in Albanien im Vergleich mit deutschen BuchenNaturwaldreservaten und-Wirtschaftswäldern. Dissertation. Cuvillier Verlag, Göttingen.

Venables, W.N., Ripley, B.D., 2007. Modern applied statistics with S. Statistics and computing. Springer, New York, NY, 4. ed., corr. print edition.

Watt, A.S., 1947. Pattern and process in the plant community. Journal of Ecology 35 (1/2), 1-22.

Westphal, C., Tremer, N., Oheimb, G.v., Hansen, J., von Gadow, K., Härdtle, W., 2006. Is the reverse J-shaped diameter distribution universally applicable in European virgin beech forests? Forest Ecology and Management 223 (1-3), 75-83.

Winter, S., Brambach, F., 2011. Determination of a common forest life cycle assessment method for biodiversity evaluation. Forest Ecology and Management 262 (12), 2120-2132.

Zenner, E.K., Peck, J.E., Hobi, M.L., Commarmot, B., Ewald, J., 2016. Validation of a classification protocol: Meeting the prospect requirement and ensuring distinctiveness when assigning forest development phases. Applied Vegetation Science 19 (3), 541-552. 



\section{ChAPTER \\ Synopsis}

Structure and functioning of forests are closely linked to each other and every alteration of the stand structure will have an immediate impact on ecosystem functioning (von Gadow et al., 2012). Knowledge about the mechanisms behind these relationships will enable us to better evaluate the consequences of forest management on ecosystem services and will assist us with their sustainable maintenance. The studies presented in the previous chapters focus on some key aspects of links between forest stand structure and ecosystem functioning and how they are affected by forest management. This will support the advancement of silvicultural-systems for the sustainable management of forest ecosystems.

\subsection{Effects of forest management}

Management for production in the studied Slovakian forests results in a great alteration of biomass stocks, stand-, and canopy structure compared to the untouched primeval forests. Canopy density $\left(L A I_{e}\right)$ of the primeval forests is greater by ca. $1.6 \mathrm{~m}^{2} \mathrm{~m}^{-2}$, canopy structural diversity $\left(\operatorname{IQR}\left(L A I_{e}\right)\right)$ is ca. 2.5 times higher (increase of $\left.1.0 \mathrm{~m}^{2} \mathrm{~m}^{-2}\right)$. Live-, dead- and total aboveground biomass stocks are greater by ca. $20 \%$ (insignificant at two sites), $340 \%$, and $39 \%$ respectively. Aboveground productivity rates $(A N P P)$ are approximately equal in both systems (ca. $10 \mathrm{mg} \mathrm{ha}^{-1} \mathrm{yr}^{-1}$ ).

The presented studies only quantified the aboveground parts of biomass stocks and productivity rates. Especially in old-growth and primeval forests big parts of the total carbon stocks are located belowground (Dean et al., 2017). Even-aged management of forests usually results in a decrease of the belowground live biomass and especially of the soil organic matter (Dean et al., 2017; Merino et al., 2007). The difference between total (sum of above- and belowground) biomass stocks of both analyzed systems are likely to be even higher than the $39 \%$ greater stocks in the primeval forests described in chapter 3. A precise description of the differences in belowground biomass and carbon stocks of production and primeval forests is an important 
task for future research.

The selection of study sites in the production forests focused on stands which had already reached their maximum age in the production cycle and were about to be harvested in the coming years. This study design is motivated from an ecological perspective in depicting the point where stand development is disrupted in production forestry and in describing which structures are going to be absent because stands with older trees are missing compared to the fully developed primeval forests. For a comparison of stand and ecosystem averages throughout the full development cycles (the natural development cycle and the production cycle), younger production stands have to be sampled as well through selection of, for example, additional plots in at least two more production forests of younger ages. How such a complete survey could complement the results of this work is, without additional data, speculative, but some hypothesis can be formulated on the base of current knowledge. Biomass stocks are in young stands closely related to stand age (Liu et al., 2014), so a complete survey of the production cycle would lead to even more pronounced differences in live and dead biomass stocks to primeval forests. Canopy heterogeneity can as well be expected to be lower in younger production stands because structural diversity usually needs time to develop (Brassard et al., 2008; Hardiman et al., 2011). Leaf area and ANPP on the other hand is probably a bit lower in older production forests because of the age-related productivity decline and the close relationship between leaf area and productivity in younger stands (He et al., 2012; Ryan et al., 1997). At the same time, production forests experience a time of low productivity directly after stand establishment until a fully developed canopy with high leaf areas can be generated. But for F. sylvatica this time period is very short (Konôpka et al., 2016) and probably will not have a big impact on average annual $N P P$, especially when advanced regeneration after removal of the last trees at the end of the preceding production cycle is already present. This is the case in most even-aged silvicultural systems for beech (Röhrig et al., 2006).

Even-aged forest management is the worldwide most common silvicultural-system (Puettmann et al., 2015) and European beech forests are, according to the potential natural vegetation (Bohn et al., 2003), one of the most important forest types in central Europe. So the results about the impact of Slovakian age-class production forestry on stand structure and ecosystem functioning 
are representative for a large part of central European forests. But great efforts have been undertaken to establish alternative silvicultural systems in many regions of the world (Puettmann et al., 2015) and 'even-aged'-forestry may take on different forms as well, depending on rotation age or duration of the regeneration period, which are rather short in the Slovakian production forests. For example, live biomass of primeval and production forests are probably less different with longer rotation periods. While the trend towards lower biomass stocks and structural diversity in production forests shown by this work and other studies (e.g., Merino et al., 2007) will be hard to overcome totally by even-aged forestry, future research should focus as well on the magnitude of the effect of different silvicultural-systems with varying management intensities (e.g., Gossner et al., 2014; Kahl and Bauhus, 2014).

The result of equal ANPP of production and primeval forests remarkably demonstrates the high growth potentials of stands consisting of old and young trees alike. These findings have to be considered in debates about impacts of management for timber on the ANPP.

The present work provides evidence about the uniqueness of the structure and dynamics of primeval European beech forests and highlight their outstanding value and necessity to effectively preserve their last remnants. The documented stand averages can serve as benchmarks to indicate the naturalness of alternative silvicultural systems which aim for higher carbon stocks and diversity and to monitor the transformation process of former production forests which were declared nature reserves towards old-growth structures.

\subsection{Differences of stand structure and ecosystem functioning during natural forest development}

Development of stand characteristics in primeval beech forests seems to be substantially different from the one in even-aged stands.

Stand leaf area is high during all development stages and is even increasing under the presence of large trees. This is in contrast to the development in even-aged stands, where leaf area is rapidly increasing during the first years of stand development and then declines constantly with increasing stand age (e.g., He et al., 2012; Ryan et al., 1997). In primeval forests, emerging 
gaps from dying trees are rapidly filled by (1) lateral branch growth of neighboring trees and (2) canopy expansion of small trees and advanced regeneration which are already present at the time of gap occurrence. Complementary usage of the available light resources in the different vertical canopy strata leads to very dense canopies with high leaf areas throughout the development cycle. This is also effecting ANPP and the small-scale heterogeneity of the canopy.

Canopy structural diversity is as well equally high during all natural development stages in primeval forests with a weak trend towards greater vertical stratification within the terminal development stage. Even on plots with maximum dominance of the growth stage with a lot of young and small trees, sufficient presence of larger trees guarantees a high heterogeneity of the canopy.

During the growth stage, aboveground live biomass is lowest. It increases by on average ca. $60 \%$ in the optimal stage and remains at this high level until the terminal stage is reached. This pattern of live biomass accumulation during early forest development is in agreement with the current model of the development cycle (Korpel, 1995). Amounts of deadwood were found to be equally distributed throughout the development cycle by the present work. This is in contrast to the current model, which assumes high amounts of deadwood during the terminal stage and carry-over effects to the growth stage.

Several reasons can be the origin for this phenomenon (see as well chapter 3.4). Feldmann et al. (2018) detected substantial relative shares of two or even all three development stages in many of the same plots used as well by this work. This has implications for our current model of natural forest development and especially for our idea of origin and decay of dead biomass, which assumes a continuous passing through a cycle with only one possible direction of movement. When all possibly occurring combinations of stand structures, relative shares of several development stages, and disturbance events are considered, transition between all stages and residence in the same stage for a longer time period are also possible (Feldmann et al., 2018). For example, in terminal-plots with additional high shares of trees representing the optimal stage, senescence of the oldest trees may result in a transition of a forest patch from the terminal to the optimal, not to the growth stage. Deadwood which originates when transition from one stage to another is induced by tree mortality may be carried over to any development 
stage. This explains equally distributed deadwood shares throughout the development cycle.

Unfortunately, it was not possible to relate litter production to stand structure or forest development due to the unknown extent of the 'footprint' of the litter traps (Chapter 1.6.3). In terms of aboveground woody biomass production $\left(A N P P_{\text {wood }}\right)$, no significant differences between development stages were detected between development stages, but there was an insignificant trend towards a lower $A N P P_{\text {wood }}$ in the growth stage even though younger stands are assumed to have the bigger growth potential compared to old stands (Ryan et al., 1997) This disagreement can be explained by the stand structure in the primeval forests. Competition for light with bigger trees growing outside of the plots potentially constrains $A N P P_{\text {wood }}$ of growth-plots which are dominated by young and small trees. Another likely explanation are beneficial complementary effects on plots of the optimal and terminal stage due to a diverse stand structure and a resulting higher productivity (see the following section).

Almost all analyzed structural parameters $\left(L A I_{e}, \operatorname{IQR}\left(L A I_{e}\right), A N P P_{\text {wood }}\right)$ showed a different pattern during natural forest development than would have been expected from previous research in even-aged forest stands. Some of these characteristics, like constantly high leaf areas and productivity, are desirable features for production forests as well. This can be reached through the emulation of stand structures and prevailing disturbance regimes of primeval forests. The results highlight as well tipping stones in the generalization of results from age-class to natural forest stands. Future research should focus on changing patterns of stand structural attributes, ecosystem properties and functions in the course of natural forest development to make allowance for the distinctiveness of old-growth and primeval forests.

\subsection{Canopy structure and productivity of forests}

Previous research about the relationship between canopy structure and productivity of forests was mostly limited to the $L A I$ or light interception of the canopy. Both of them were mostly found to be positively related to the NPP (e.g, Hardiman et al., 2011; Pretzsch et al., 2015). The data presented in chapter 3 did not follow this pattern. This can be explained by a generally high average $L A I_{e}$ on all plots of the present study. A steeper $L A I_{e}$-gradient and the presence of plots 
with low leaf areas as well would have been necessary to statistically detect such a relationship. On the other hand there was a strong and significant positive link between two measures for canopy structural diversity and $A N P P_{\text {wood }}$ : (1) the heterogeneity of the $L A I_{e}$ in the upper canopy and (2) a dense forest understorey below $4.5 \mathrm{~m}$ (high $L A I_{e}$ of the lower canopy). Both parameters are related to each other $(\mathrm{r}=0.66, \mathrm{p}<0.001)$, which suggests that the effect is not cumulative and that the combination of both types of canopy structural diversity is responsible for the promoting effect on $A N P P_{\text {wood }}$.

A positive influence of biodiversity (including structural diversity) on ecosystem functioning is usually attributed to the presence of beneficial complementary effects on resource use efficiency (Naeem et al., 1994). In mixed stands complementarity often originates from tree species diversity (Liang et al., 2016). In the case of pure F. sylvatica forests, trees of different age classes are functionally different (shade-tolerant saplings and young trees vs. light demanding overstorey trees), so complementarity can arise from a high adaption to different light regimes within the upper and lower canopy. One possible interpretation of the results is that an increased structural diversity is only a side effect of a greater tree functional diversity, which actually is the underlying cause for the promotion of $A N P P_{\text {wood }}$. On the other hand, functional diversity is probably unable to unfold its full potential in forests where stand development led to a low structural diversity. So the underlying cause in a productivity promoting effect probably lies with both factors: the combination of functional and structural diversity.

One obvious reason for the productivity promoting effect of structural diversity is the higher light transmittance to lower canopy strata, where the presence of a dense understory adapted to low light levels enables an efficient use of most of the remaining light (Hardiman et al., 2013). If microclimatic differences between upper and lower canopy like a reduced vapor pressure deficit (VPD) and lower wind speeds (Larcher, 2001) are considered as well, additional complementary effects are thinkable. The more favorable within-canopy climatic conditions might cause leaves of the lower canopy to suffer less from drought stress and to maintain photosynthesis under conditions when leaves of the upper canopy are already forced to close their stomata. An increasing $\delta 13 \mathrm{C}$-content of leaves of tall beech trees along a vertical gradient between $20-40 \mathrm{~m}$ in Havešová is supporting this hypothesis in indicating greater stomatal 
limitation of gas exchange at greater canopy heights (Gottschall et al., unpublished). More research about the microclimate within beech forest canopies, its dependence on the stand structure in general, and canopy structural diversity in particular and implications for stomatal closure and photosynthetic activity of leaves is needed to validate this hypothesis.

The present study was carried out in a montane environment between 550-990 $\mathrm{m}$ a.s.l. At this elevation, growth of beech forests is limited by temperature constrains, whereas in lower elevations water is the main limiting factor (Dulamsuren et al., 2016). As long as the physiological background of the productivity promoting effect of canopy structural diversity remains unclear, it is difficult to make predictions about the generalizability of the detected productivity promoting effect of canopy structural diversity. The effect of stand and canopy structure on the light regime will probably not be as relevant for tree growth when water availability is the most important growth limiting factor. Interactive influences between drought stress and structural diversity on productivity have to be analyzed by studies with a water availability gradient and for different stand structures simultaneously.

The relevance for forestry practice of a productivity promoting effect of canopy structural diversity has to be evaluated with care. The lack of knowledge concerning the generalizability of the findings to other sites and elevations has to be eliminated before implications can be stated clearly. Stand structure and composition in general is very different in primeval and production forests. It may well be that sole alteration of a single ecosystem attribute will not have the desired effect because preconditions are too different in both systems. Additionally, increased structural diversity (especially greater vertical layering) will most likely facilitate the development of more and thicker branches at the lower trunk and reduce timber quality which is not desirable if high quality wood is the silvicultural production target. But if other aims like production of energy wood and biodiversity conservation have priority, timber quality is less important. A positive effect of structural diversity of forests on the diversity of different taxonomic groups is frequently discussed, so an additional facilitative effect on the productivity may further encourage the increase of structural diversity of forests by silvicultural means. Future research should aim for an assessment of the effect of canopy structural diversity on ecosystem functioning within production forests of different silvicultural regimes including 
alternative systems which are avoiding mono-layered even-aged stands on a broad range of sites and elevations (see for example Pukkala and von Gadow, 2012 and literature cited).

\subsection{Development stage separation}

In chapter 4 , the potenital of unsupervised classfication (k-means clustering) to differentiate between stages of the natural development cycle was assessed. The results show that multivariate data matrices of stand structural attributes of primeval beech forests are rather homogeneously distributed and no clearly from one another separable clusters are present in the structural data of two primeval forests. The falsification of the hypotheses is relevant in confirming the present practice of making a priori assumptions about structural characteristics of development stages and selecting thresholds for their discrimination adapted to specific study designs and hypotheses with expert knowledge, which is potentially assisted by supervised classification algorithms.

For the calculation of plot-level stand characteristics, weighting of objects by distance to the plot-center was introduced (bivariate normal kernel). Even though this method did not improve the clusterability of the multivariate data matrices, its usefulness in other contexts still needs to be evaluated. Especially when the relationships between parameters which are referring to a specific point and do not have an areal reference (e.g., light transmission through the canopy, air or soil temperature, relative air humidity, and more) is the central objective of an analysis, this approach seems promising because it is able to account for a decreasing influence of objects with increasing distance to a specific point.

The observational scale (virtual plot sizes between $200-2000 \mathrm{~m}^{2}$ ) did have a big influence on the resultant structural data matrices and on the relationships between stand structural attributes. This emphasizes in agreement with other studies (Král et al., 2014; Zenner et al., 2015) the need to view the observational scale as an important characteristic of the stand structure and to include sensitivity analyses of its effect in studies concerning the stand structure of forests. 


\section{References}

Bohn, U., Neuhäusl, R., Gollub, R., Hettwer, C., Neuhäuslova, Z., Schlüter, H., Weber, H., 2003. Karte der natürlichen Vegetation Europas. Teil 1: Erläuterungstext. Landwirtschaftsverlag, Münster.

Brassard, B.W., Chen, H.Y., Wang, J.R., Duinker, P.N., 2008. Effects of time since stand-replacing fire and overstory composition on live-tree structural diversity in the boreal forest of central Canada. Canadian Journal of Forest Research 38 (1), 52-62.

Dean, C., Kirkpatrick, J.B., Friedland, A.J., 2017. Conventional intensive logging promotes loss of organic carbon from the mineral soil. Global Change Biology 23 (1), 1-11.

Dulamsuren, C., Hauck, M., Kopp, G., Ruff, M., Leuschner, C., 2016. European beech responds to climate change with growth decline at lower, and growth increase at higher elevations in the center of its distribution range (SW Germany). Trees 176, 60.

Feldmann, E., Glatthorn, J., Hauck, M., Leuschner, C., 2018. A novel empirical approach for determining the extension of forest development stages in temperate old-growth forests. European Journal of Forest Research , 1-15.

von Gadow, K., Chun, Y.Z., Wehenkel, C., Arne Pommerening, Javier Corral-Rivas, Mykola Korol, Stepan Myklush, Gang Ying Hui, Andres Kiviste, Xiu Hai Zhao, 2012. Forest Structure and Diversity. In: T. Pukkala, K. von Gadow, eds., Continuous Cover Forestry, Managing Forest Ecosystems. Springer Netherlands, Dordrecht, pp. 29-83.

Gossner, M.M., Schall, P., Ammer, C., Ammer, U., Engel, K., Schubert, H., Simon, U., Utschick, H., Weisser, W.W., 2014. Forest management intensity measures as alternative to stand properties for quantifying effects on biodiversity. Ecosphere 5 (9), art113.

Gottschall, F., Leuschner, C., Hauck, M., Pichler, V., Glatthorn, J., Schuldt, B., unpublished. The hydrostatic gradient drives vertical changes in leaf morphological and branch hydraulic properties in the crown of tall European beech trees of tall European beech trees .

Hardiman, B.S., Bohrer, G., Gough, C.M., Vogel, C.S., Curtis, P.S., 2011. The role of canopy structural complexity in wood net primary production of a maturing northern deciduous forest. Ecology 92 (9), 1818-1827.

Hardiman, B.S., Gough, C.M., Halperin, A., Hofmeister, K.L., Nave, L.E., Bohrer, G., Curtis, P.S., 2013. Maintaining high rates of carbon storage in old forests: A mechanism linking canopy structure to forest function. Forest Ecology and Management 298, 111-119.

He, L., Chen, J.M., Pan, Y., Birdsey, R., Kattge, J., 2012. Relationships between net primary productivity and forest stand age in U.S. forests. Global Biogeochemical Cycles 26 (3).

Kahl, T., Bauhus, J., 2014. An index of forest management intensity based on assessment of harvested tree volume, tree species composition and dead wood origin. Nature Conservation 7 (2), 15-27.

Korpeĺ, Š., 1995. Die Urwälder der Westkarpaten. Gustav Fischer Verlag, Stuttgart.

Král, K., Valtera, M., Janík, D., Šamonil, P., Vrška, T., 2014. Spatial variability of general stand characteristics in central European beech-dominated natural stands - Effects of scale. Forest Ecology and Management 328, 353-364.

Larcher, W., 2001. Ökophysiologie der Pflanzen: Leben, Leistung und Stressbewältigung der Pflanzen in ihrer Umwelt. UTB, Stuttgart.

Liang, J., Crowther, T.W., Picard, N., Wiser, S., Zhou, M., Alberti, G., Schulze, E.D., McGuire, A.D., Bozzato, F., Pretzsch, H., de Miguel, S., Paquette, A., Herault, B., Scherer-Lorenzen, M., Barrett, C.B., Glick, H.B., Hengeveld, G.M., Nabuurs, G.J., Pfautsch, S., Viana, H., Vibrans, A.C., Ammer, C., Schall, P., Verbyla, D., Tchebakova, N., Fischer, M., Watson, J.V., Chen, H.Y.H., Lei, X., Schelhaas, M.J., Lu, H., Gianelle, D., Parfenova, E.I., Salas, C., Lee, E., Lee, B., Kim, H.S., Bruelheide, H., Coomes, D.A., Piotto, D., Sunderland, T., Schmid, B., Gourlet-Fleury, S., Sonke, B., Tavani, R., Zhu, J., Brandl, S., Vayreda, J., Kitahara, F., Searle, E.B., Neldner, V.J., Ngugi, M.R., Baraloto, C., Frizzera, L., Balazy, R., Oleksyn, J., Zawila-Niedzwiecki, T., Bouriaud, O., Bussotti, F., Finer, L., Jaroszewicz, B., Jucker, T., Valladares, F., Jagodzinski, A.M., Peri, P.L., Gonmadje, C., Marthy, W., O’Brien, T., Martin, E.H., Marshall, A.R., Rovero, F., Bitariho, R., Niklaus, P.A., Alvarez-Loayza, P., Chamuya, N., Valencia, R., Mortier, F., Wortel, V., Engone-Obiang, N.L., Ferreira, L.V., Odeke, D.E., Vasquez, R.M., Lewis, S.L., Reich, P.B., 2016. Positive 
biodiversity-productivity relationship predominant in global forests. Science 354 (6309), 196.

Liu, Y., Yu, G., Wang, Q., Zhang, Y., 2014. How temperature, precipitation and stand age control the biomass carbon density of global mature forests. Global Ecology and Biogeography 23 (3), 323-333.

Merino, A., Real, C., Álvarez-González, J.G., Rodríguez-Guitián, M.A., 2007. Forest structure and C stocks in natural Fagus sylvatica forest in southern Europe: The effects of past management. Forest Ecology and Management 250 (3), 206-214.

Naeem, S., Thompson, L.J., Lawler, S.P., Lawton, J.H., Woodfin, R.M., 1994. Declining biodiversity can alter the performance of ecosystems. Nature 368, 734-737.

Pretzsch, H., del Río, M., Ammer, C., Avdagic, A., Barbeito, I., Bielak, K., Brazaitis, G., Coll, L., Dirnberger, G., Drössler, L., Fabrika, M., Forrester, D.I., Godvod, K., Heym, M., Hurt, V., Kurylyak, V., Löf, M., Lombardi, F., Matović, B., Mohren, F., Motta, R., den Ouden, J., Pach, M., Ponette, Q., Schütze, G., Schweig, J., Skrzyszewski, J., Sramek, V., Sterba, H., Stojanović, D., Svoboda, M., Vanhellemont, M., Verheyen, K., Wellhausen, K., Zlatanov, T., Bravo-Oviedo, A., 2015. Growth and yield of mixed versus pure stands of Scots pine (Pinus sylvestris L.) and European beech (Fagus sylvatica L.) analysed along a productivity gradient through Europe. European Journal of Forest Research 134 (5), 927-947.

Puettmann, K.J., Wilson, S.M., Baker, S.C., Donoso, P.J., Drössler, L., Amente, G., Harvey, B.D., Knoke, T., Lu, Y., Nocentini, S., Putz, F.E., Yoshida, T., Bauhus, J., 2015. Silvicultural alternatives to conventional even-aged forest management - what limits global adoption? Forest Ecosystems 2 (1), 611.

Pukkala, T., von Gadow, K., eds., 2012. Continuous Cover Forestry. Managing Forest Ecosystems. Springer Netherlands, Dordrecht.

Röhrig, E., Bartsch, N., Lüpke, B.v., Dengler, A., 2006. Waldbau auf ökologischer Grundlage: 91 Tabellen, UTB Forstund Agrarwissenschaften, Ökologie, Biologie, volume 8310. UTB, Stuttgart, 7., vollst. aktual. aufl. edition.

Ryan, M.G., Binkley, D., Fownes, J.H., 1997. Age-Related Decline in Forest Productivity: Pattern and Process. In: D.B. Nedwell, A.H. Fitter, eds., Advances in Ecological Research, Advances in Ecological Research, volume v.27. Elsevier Textbooks, s.l., pp. 213-262.

Zenner, E.K., Peck, J.E., Hobi, M.L., Commarmot, B., 2015. The dynamics of structure across scale in a primaeval European beech stand. Forestry 88 (2), 180-189. 